Universidad Nacional de La Plata

Facultad de Bellas Artes

Maestría en Estética y Teoría de las Artes

\title{
Los cuadros de las Cañas
}

Cuando Goya hizo pintura a martillazos

Felipe Montes Bernal

\author{
Director \\ Juan David Cárdenas \\ Codirectora \\ Natalia Matewecki \\ La Plata, Argentina, 2019
}




\section{Índice}

$\begin{array}{lr}\text { Introducción } & 3\end{array}$

$\begin{array}{lr}\text { Capítulo } 1 & 7\end{array}$

1.1 Los cuadros de Buenos Aires, la partida X-28

1.2 Los cuadros de capricho. Las primeras series de la obra personal

1.3 Las tablas de la Academia de San Fernando

1.4 Los cuadros de las cañas en el inventario de 1812

1.5 Los cuadros de base negra y otro cuadro en el Museo de Buenos Aires

1.6 Las últimas series de la obra de investigación

1.7 Elementos pictóricos de los cuadros de Buenos Aires
a. El fondo coloreado
b. El negro
c. La luz modulada como bruma
d. Los grupos de figuras

Capítulo 2

2.1 De la idea a lo pictórico

2.2 Cuerpo y figura desde la no-representación

2.3 Fuerzas, potencias e intensidades

2.4 El posicionamiento del pintor y las posibilidades de hechos

2.5 El hecho pictórico como producción de lo sensible

2.6 Hacer pintura a martillazos

A modo de conclusión:

Violencia pictórica. Celebración de la vida como juego estético

Apéndice: Ilustraciones

Bibliografía 


\section{Introducción}

La primera vez que visité el Museo Nacional de Bellas Artes de Buenos Aires un grupo de pinturas cautivó mi atención de manera particular. Se trataba de varios óleos de mediano formato firmados por Francisco de Goya. Lo primero que me sorprendió fue la intensa violencia y expresividad del tratamiento, que superaba mi propia expectativa en cuanto a las libertades que podía tomarse el pintor respecto de los cánones clásicos, a principios del silo XIX. Los temas eran variados: un baile popular, un incendio y unas escenas de bandoleros; pero compartían los mismos problemas pictóricos en cuanto a la disposición de los grupos de figuras, el tratamiento del espacio, la preponderancia del negro y la fuerza en la aplicación del impasto. Empecé a investigar un poco sobre estas obras en el catálogo de Goya y encontré que hacen parte de la obra personal, que el pintor realizó como investigación para sí mismo, al margen de su obra de encargo, que en el caso de Goya es la gran mayoría de su trabajo. A parte de esto, algo las hacía especialmente particulares: pertenecen a un grupo de cuadros en los que Goya usó, en adición a los pinceles, cañas cortadas a manera de una espátula irregular, para la aplicación y modelado del óleo.

Empezó, entonces, a tomar forma una inquietud respecto a qué razón había tras la decisión o la necesidad de tomar esas cañas para golpear y rayar el óleo con tanta violencia. ¿Por qué los pinceles no habían sido suficientes? Resulta obvio que Goya es uno de los pintores más analizados y comentados de la historia de la pintura occidental. Lo ha hecho especialmente relevante el hecho de ser considerado un punto de referencia del paso entre arte clásico y arte moderno, hallándose en la frontera entre dicho cambio histórico del arte. A partir de él, las condiciones de producción y la manera de trabajar de los pintores se transforman, desde el modelo de encargo para la iglesia o la monarquía, propia del arte clásico, al modelo de artista autogestionado, que acepta encargos, pero tiene libertad para desarrollar trabajos personales, que son experimentales, tanto en tema como en técnica, respondiendo solo a los intereses investigativos personales del artista. Esto lo pone en el inicio del modo de trabajo de un artista moderno, un modo de trabajo que en muchos sentidos se mantiene en la contemporaneidad.

De otro lado, es también obvio que muchas cosas han cambiado desde el tiempo de Goya en la forma en que se hace el arte y en la que circula; de hecho, en lo que se 
entiende por arte. En especial en lo que se refiere a la ampliación absoluta de las técnicas y los materiales de las artes plásticas, desde la pintura o la escultura hasta la pluralidad más radical posible. Se suma a ello la exigencia contemporánea de un contenido conceptual para las obras y de un posicionamiento ideológico, político y social claro de parte del artista. Incluso, se ha llegado a poner en cuestión vez tras vez, la validez de la pintura como técnica tradicional, y su pertinencia en el marco del arte contemporáneo. Teniendo todo esto en cuenta, me interesó plantearme qué tiene para decirnos la producción particular de este reducido grupo de cuadros, estudiados como un caso especial y relevante, sobre la naturaleza de los valores pictóricos que un artista como Goya podía perseguir. Esto permitiría luego pensar sobre la pertinencia de dichos valores frente a las exigencias teóricas del arte contemporáneo, en el sentido de que, posiblemente, valores conceptuales rescatados de la revisión cuidadosa de los cuadros de las cañas del Museo de Buenos Aires, suministren posturas relevantes al posicionamiento de la pintura en la escena actual.

Un motivo por el que los cuadros de las cañas, en particular, pueden servir para avanzar en esa dirección de análisis es porque pertenecen, justamente, a la obra que Goya hace para sí mismo, como investigación personal. Si bien los problemas esenciales de la pintura de Goya también aparecen en su obra de encargo, en ella tienen que mantenerse restringidos, respondiendo a las exigencias de los modelos clásicos que aun imperaban, en especial en las expectativas de sus contratantes. Pero en la obra de investigación personal, el artista tiene la libertad para indagar sobre las posibilidades últimas de los elementos que le interesan y, en concreto, en la serie de los cuadros de las cañas se van a desarrollar características claves para todo su trabajo posterior. Al estar realizados con una particularidad técnica que los separa del resto de la obra, ofrecen la posibilidad de hacer visibles elementos pictóricos muy específicos, así como de plantear conceptos precisos sobre el uso y el valor de estos elementos, valor que puede ser rescatado para una teoría estética de la pintura que alcance nuestros días.

Para desarrollar adecuadamente este análisis es necesario partir de una revisión directa del grupo específico de cuadros, pero puesta en contexto con las distintas etapas y series que marcaron la obra de investigación personal de Goya. Este es el centro del trabajo realizado en el capítulo uno de esta investigación, en el que se parte de la hipótesis de que la obra estaba orientada por unas preocupaciones muy específicas, que iban más allá del asunto de los temas, que, si bien tiene su importancia, no logra explicar del todo 
los resortes internos del trabajo personal del pintor. De modo que la investigación se propuso, en primer lugar, rastrear los problemas y valores pictóricos que orientan el trabajo de personal de Goya, para enunciarlos y luego estudiar cómo van evolucionando y se van consolidando a lo largo de las distintas series de cuadros. El primer elemento al que se puede hacer seguimiento es el problema del grupo de figuras sometido a fuertes movimientos de caída dentro de la acción en el espacio. Este problema básico se conecta con otros, como la potencia del negro como materia de oscuridad que domina la lectura de la mirada sobre el cuadro; la fuerza expresiva de la línea negra de dibujo, que, si bien suministra un punto de partida formal al grupo de figuras, se libera del apego a la forma clásica en la búsqueda de una expresividad independiente. Esta independencia es posible gracias a la separación de la relación de claroscuro, de modo que el blanco y el negro pueden actuar como valores independientes, desligados de la función de modelado de la forma, dejando al flujo de la materia de óleo como valor pictórico propiamente dicho, suministrar la base de la definición formal. De ahí se desprende la preponderancia del impasto y el modelado expresivo, que conduce a la necesidad del uso de las cañas. A lo largo de las distintas series y momentos estudiados, el pintor va poniendo el énfasis en uno $\mathrm{u}$ otro de estos elementos, profundizando en sus posibilidades expresivas y su influencia en el resultado total de cada cuadro. Este estudio del desarrollo de los elementos permite hacer una valoración más ajustada de lo que ocurre en los cuadros de Buenos Aires y su importancia dentro de todo el proceso de investigación de Goya.

Ahora bien, la obra de Goya ha sido estudiada en forma muy amplia, en especial en su perspectiva histórica, la pertinencia de su trabajo en el momento político y social en que se ubica y también a nivel técnico. En el inicio del capítulo dos, hago un repaso sucinto de algunos ejemplos paradigmáticos entre dichos estudios, sobre todo con el objetivo de subrayar el modo en que ponen el énfasis en los aspectos de la comunicación externa de las obras con el contexto de su producción. Como mi pregunta tiene que ver con los problemas pictóricos y su valoración posible dentro de una teoría de la pintura, me fue necesario acudir a un marco teórico distinto, que contrasta en buena medida con estos estudios principales. La idea es proponer una lectura complementaria, que enriquezca el estudio de estas obras específicas de Goya, partiendo desde su técnica y los valores pictóricos, entendidos dentro del dominio de una experiencia de la sensación, en contraste con el ámbito de la comunicación del discurso. Dicha concepción vitalista parte desde la definición nietzscheana del arte, como ha sido entendida y desarrollada 
por autores como Lyotard, Deleuze, Cacciari, Sontag, Guattari, Rosset, entre otros. Se trata de una concepción que puede compaginarse, además, con las declaraciones teóricas de algunos pintores como Cezanne y Bacon, sobre su propio trabajo y sobre una teoría general de la pintura. Desde esta perspectiva, cada obra de arte funciona como un acontecimiento que pone en juego una serie de fuerzas, potencias e intensidades, caracterizándose por un sostenimiento interno que mantiene el movimiento de la experiencia de sensación. El arte celebra la vida como puro juego estético, al tiempo que valora él mismo la experiencia, constituyéndose en un proceso que resulta a la vez creativo y crítico en el sentido neitzscheano.

A partir de esa perspectiva, resulta factible construir unos valores conceptuales que se correspondan a la forma que la experiencia de la sensación adopta específicamente en los cuadros de las cañas, para lo cual es necesario hacer uso de las herramientas teóricas que los autores mencionados proveen, posibilitando el armado y caracterización de dichos conceptos y resaltando este grupo de cuadros como caso significativo y particular dentro del conjunto de la obra de Goya; logrando además, sumar elementos a la valoración estética de la pintura desde la perspectiva vitalista del arte. Más allá de las apreciaciones teóricas de los autores, que sirven para ubicar los elementos básicos y la orientación del modo de valoración, el capítulo apunta a hacer aparecer los valores expresivos que ponen en juego los cuadros de las cañas, con el propósito de dejar hablar conceptualmente a la experiencia de sensación que ocurre allí. En síntesis, en esta tesis se apunta a llamar la atención sobre un grupo pequeño y bien definido de cuadros, que no han sido estudiados como caso particular, a fin de obtener unas proposiciones valorativas concretas, que pueden contribuir al desarrollo teórico de una visión estética de los problemas pictóricos frente al marco del arte contemporáneo. 


\section{Capítulo 1}

\section{Los cuadros de Buenos Aires, la partida X-28}

El círculo negro rodea al grupo de figuras y parece atraparlo y arrastrarlo en un movimiento de caída: un derrumbamiento. La calidad pastosa del óleo amarra los cuerpos en el movimiento frenético de cada escena. Aunque se trate de un episodio de guerra, un incendio, una tormenta o una fiesta popular lo que aparece en cada uno de estos cuatro cuadros, es un grupo que se unifica cuando la catástrofe aglutina las figuras y las atraviesa con el fluir y la variación de intensidades de su propia materia. Un paraje desolado en el campo o un rincón vacío de la ciudad completan el aire de cada escena, como dejando espacio abierto para que se expanda el ruidoso soplo de la violencia. Se trata del grupo de cuadros identificados como la partida X-28 en el inventario de los bienes de Goya de 1812, en el que la colección de pinturas fue adjudicada a su hijo Xavier, razón por la cual son marcados con la mencionada sigla. A principios de siglo $\mathrm{XX}$ fueron adquiridos por coleccionistas argentinos y tres de ellos se encuentra hoy en el Museo Nacional de Bellas Artes de Buenos Aires. Estos son: Escena de guerra (Fig. 1 y 2), Baile Popular (Fig. 3 y 4) e Incendio de un Hospital (Fig. 5 y 6); todos de 72 x $100 \mathrm{~cm}$. El cuarto cuadro de este grupo, Huracán (Núm. 583, Gudiol, 1980, pág.117), se destruyó fatalmente en el incendio del Jockey Club de esta ciudad en 1953². Se trata, en efecto, de un grupo muy particular, cuya importancia dentro de la obra del artista y dentro de la historia de la pintura merece ser estudiada y revalorada por varias razones.

Son singulares, en primer lugar, por pertenecer a ese grupo especial de pinturas que Goya trabajó con espátulas de caña para aplicar el óleo sobre el soporte, reemplazando o complementando el uso de pinceles. A su vez, estos cuadros de las cañas marcan un punto de inflexión dentro del proceso que el artista desarrolla en sus obras de investigación personal, iniciado en la convalecencia que vivió en 1793. Pero lo más relevante es que algunos de los elementos que aparecen en estos cuadros, tales como: la libertad del color en relación con el dibujo; la separación de la luz y la sombra de las labores de definición de la forma; la equivalencia directa de la intensidad material con la

\footnotetext{
${ }^{1}$ Los números entre paréntesis que siguen a cada cuadro citado corresponden a la numeración de las ilustraciones en el Apéndice (Pág. 74). Cuando estos siguen la numeración del catálogo de Gudiol, se ha citado el año de edición referido y la página correspondiente.
} 
producción del motivo, por mencionar algunos, son verdaderos hitos que representan una completa revolución de los cánones clásicos y, de hecho, habrá que esperar más de un siglo para ver trabajos de características comparables. Para hacer una valoración de estos cuadros tan particulares desde una perspectiva pictoricista y vitalista, es necesario considerar qué ocurre en ellos con los elementos pictóricos, enmarcando este acontecimiento dentro del desarrollo de los problemas generales que Goya trabaja en su obra personal, y acá se encuentran, por ejemplo, las razones que lo llevaron al uso de las cañas. Es necesario entender por qué Goya se vio conducido a separar sus intereses íntimos respecto a la pintura, del trabajo que hacía por encargo. Desde este enfoque es posible situar el lugar destacado que ocupan estos cuadros en el desarrollo de la pintura occidental.

Al plantear una perspectiva pictoricista, me estoy refiriendo a la intención que tengo en esta investigación de centrar el foco de atención en el trabajo pictórico propiamente dicho, en su evolución y particularidades, y en lo que nos revela sobre la pintura como un juego estético en el que se implican valores de afirmación de la sensación y la experiencia, dejando en un segundo plano los problemas del significado y el sentido, que en el caso de Goya han sido ampliamente estudiados. El primer paso es revisar las condiciones en las que se empiezan a generar los elementos que caracterizan a los cuadros de Buenos Aires y para eso es necesario partir de las primeras series de la obra personal de Goya, donde es posible rastrear las condiciones de su gestación y desarrollo.

\section{Los cuadros de capricho. Las primeras series de la obra personal}

El trabajo de investigación personal propiamente dicho se inicia alrededor de 1793, coincidiendo con la convalecencia de la grave enfermedad que dejó a Goya definitivamente sordo. Tras varios años trabajando principalmente como pintor de la corona, primero en los bocetos para los tapices de la casa real y luego en el cargo de pintor de cámara - lo que sin duda representó consolidarse en el lugar de un artista de fama y reconocimiento- y tras alcanzar también una notoriedad para la iglesia por sus trabajos de temas religiosos, Goya empieza a trabajar paralelamente en su propio taller, mientras sigue realizando por encargo de la corona retratos de toda la familia real y es requerido por las altas esferas del clero y por miembros de la burguesía y la nobleza, que pagan muy bien el prestigio de ser retratados por el maestro. Pero al margen de todos estos encargos, el artista va a dedicar tiempo para trabajar en cuadros que 
responden únicamente a sus propios intereses y en los cuales desarrolla los elementos pictóricos que en verdad le han interesado siempre, y que aparecen restringidos en obra de compromiso. Goya se formó en la tradición clásica de la pintura y manejaba con maestría, tanto la perfección dibujística del Neoclásico, como el claroscuro y la expresividad formal del Rococó, que en España aun mostraba más las características del Barroco tardío. Pero durante el tiempo en que Goya vive se da justamente la transición hacia el Romanticismo, que trajo consigo una serie de exigencias desde el punto de vista del sentido y el mensaje que se pretende trasmita una pintura, lo que derivó en un tipo pintura menos pendiente de los elementos plásticos. Si bien su trabajo tiene algunas características asociadas al Romanticismo y ha sido ampliamente estudiado desde una óptica sociopolítica que pone énfasis en el sentido libertario y revolucionario, con el que Goya parece fijarse en los problemas de la sociedad en que vivió, un análisis detallado de su obra de investigación, puede revelar otra faceta de los intereses del artista, que se acerca más la preocupación por los problemas estéticos y la valoración de estos como expresión de la vitalidad humana.

En carta de enero de 1794 a su amigo Bernardo Iriarte, Goya le comenta sobre esta primera serie de cuadros que realiza para sí mismo, en su convalecencia:

para ocupar la imaginación mortificada en la consideración de mis males y para resarcir, en parte los grandes dispendios que me han ocasionado, me dediqué a pintar un juego de cuadros de gabinete (...) he logrado hacer observaciones a las que regularmente no dan lugar las obras encargadas, en las que el capricho y la invención no tienen ensanche (Gudiol, 1980, pág. 40).

Se hace evidente que durante algún tiempo el artista venía presintiendo un cierto tipo de intereses pictóricos que no tenían cabida en las obras de encargo, un material y elementos que ahora tiene la necesidad de desarrollar. Este hecho parte en dos en forma inevitable el catálogo de Goya. Si bien en las obras encargadas, que son la gran mayoría, se puede percibir hasta cierto grado los elementos técnicos y expresivos que va a estudiar y desarrollar en su obra personal, los encargos responden a unas imposiciones de compromiso, de lo que se esperaba de la apariencia de la pintura; restricciones de las que poco a poco se libera y que al final son abandonadas por completo en la obra de investigación. Para situar este caso dentro de la historia de la pintura, se debe pensar en que hasta ese momento los pintores habían trabajado insertados en una función que tenía que ver con el poder, los grupos que lo detentaban y las distintas maneras como este poder se manifestaba y representaba visualmente en relación con el resto de la sociedad, ya sea que se piense en la iglesia y la práctica religiosa que incluía el uso la 
imagen, o en el estado absolutista, la nobleza y la aristocracia. En el otro extremo del espectro tenemos al artista moderno, del que se supone que solo pinta lo que quiere y lo que le interesa, en el marco de una postura autorreferencial, centrada en la expresión y en problemas estéticos muy específicos, que defiende la independencia del arte por sí mismo. Pienso, por ejemplo, en Bacon. Preguntado sobre de dónde sale una pintura, responde así: "The main problem is how to create with one's instinct something that one sees. (...) The main problem is managing to create something instinctively" (Archimbaud, 1993, pág. 73).

Por supuesto, no se trata de que los artistas anteriores a Goya no hayan sentido estos instintos o no los hayan seguido. El asunto es que tal vez supieron infiltrar y desarrollar esos instintos al interior de las exigencias del poder que los financiaba y les daba espacio de visibilidad. Miguel Ángel y el Greco, por ejemplo, llevan al extremo sus investigaciones sobre la figura, usando a su favor las necesidades expresivas del cristianismo de su época. Velásquez introduce todo un repertorio expresionista y subversivo en la pintura, sin salirse de los cánones de la pintura clásica, que le exigía su trabajo en la corte española. Pero Goya siente que no puede hacer lo mismo. Siente que hay cosas que él quiere pintar y no caben en la pintura de encargo que ha hecho hasta el momento. Es posible considerar como un antecedente de esta manera de trabajo, a los autorretratos del final de la vida de Rembrandt, cuando se encuentra ya despreocupado de las consideraciones del gusto de la época.

Siguiendo lo que Goya explica sobre estos primeros trabajos, menciona su intención de legar los cuadros a la Real Academia de San Fernando y describe uno de los cuadros de la serie como "un corral de locos y dos que están luchando desnudos, con el que los cuida, cascándoles y otros con los sacos (es asunto que he presenciado en Zaragoza)" (Gudiol, 1980, pág. 40). Este comentario empieza a revelar detalles de la manera de trabajar que va a usar en sus obras personales. Pinta acontecimientos que ha presenciado, escenas en las que algo ha llamado su atención, ha visto algo, se puede decir para conectarlo con las palabras de Bacon, "create with one's instinct something that one sees". Por su puesto Goya es primero un extraordinario dibujante y grabador, todo el tiempo está haciendo dibujos y bocetos de lo que ve y le interesa, y los va agrupando por series. En 1799 publica una primera tirada de su célebre colección de grabados con el nombre de Los Caprichos, palabra que había usado también en la carta a Iriarte en referencia a los temas estas primeras obras de investigación. Al respecto, en 
los comentarios del anuncio de prensa que acompañó la publicación de la serie de grabados, Goya afirma que

ha escogido como asuntos proporcionados para su obra, entre la magnitud de extravagancias y desaciertos que son comunes en toda la sociedad civil, y entre las preocupaciones y embustes vulgares, autorizados por la costumbre, la ignorancia ó el interés, aquellos que ha creído más aptos á suministrar materia para el ridículo, y exercitar al mismo tiempo la fantasía del artífice (Dell’Acqua, 1976, pág. 84).

Es obvio que hay una conexión entre la libertad temática y expresiva de los grabados, ampliamente estudiados por la crítica, y la de sus cuadros personales. La experimentación del dibujo y el grabado es llevada a la pintura, pues debe continuarse también por medios pictóricos.

Al revisar los datos del catálogo se encuentra que esta primera serie de cuadros personales legada a la Academia -que Goya ha descrito como "juego de cuadros de gabinete" refiriéndose a su informalidad y a su, más bien, reducido tamaño- se compone en total de 14 obras al óleo sobre hojalata (Núm. 300 a 313, Gudiol, 1980, pág.106), que tienen entre 42 y $52 \mathrm{~cm}$ de lado x 31 o $32 \mathrm{~cm}$ de largo. Es importante tener en cuenta el soporte y los tamaños, porque Goya va a desarrollar su obra de investigación a través de series más o menos cortas; así como "tuvo siempre la tendencia formar series con sus dibujos, esta tendencia a unir obras en colecciones aparece incluso en su pintura" (Gudiol, 1980, pág.57) Estas pequeñas series de cuadros, que se agrupan fácilmente por el soporte elegido y tamaños iguales o muy cercanos, las va realizando cada vez que le queda un tiempo libre del trabajo de los encargos, y en cada una se pueden ver que aborda de manera especial elementos específicos de su investigación, que se van desarrollando de una serie a otra. En esta primera serie van a quedar definidos algunos de los temas que veremos aparecer en toda su obra personal: 8 cuadros de tema taurino, 2 escenas de diversión popular, un naufragio, un incendio, bandidos en un asalto, el interior de una prisión y el descrito corral de locos. De modo que se interesa por lo vulgar, lo despreciado, por las costumbres y formas de entretenimiento de las clases populares $\mathrm{y}$, de modo especial, por los desastres de todo tipo y las diversas manifestaciones de violencia, como las escenas de guerra y los asaltos armados. Se podría postular que, si Goya tiene una idea en mente, sería la de pintar justo todo lo contrario que aparece en su obra de encargo, es decir: pintar lo feo, lo popular, lo pobre, lo oscuro, el desastre, la caída, la violencia. 
Además, esta serie ya muestra con claridad algunos de los elementos y problemas pictóricos que Goya pretende desarrollar en sus cuadros de capricho, que están íntimamente ligados a la temática que elige, aquellos problemas pictóricos que, él sentía, no tenían cabida en las obras por encargo. En la explicación de esta serie que acompaña al catálogo razonado, Gudiol propone que

constituye el punto de partida de la admirable ruta pictórica final del gran artista, la que llevará a la cumbre de la quinta del sordo. Es obra ejecutada con una delicadeza extraña, animada con una especie de inquietud que alcanzará en ciertas pinturas posteriores una intensidad alucinante. (...) Sorprende en ellas la extrema sensibilidad de la pincelada, la destreza con que esta sugiere calidades y formas, es decir, dibuja con el color (1980, pág. 41).

Estos comentarios proporcionan buenas pistas para comprender los elementos, porque su aproximación a las obras es principalmente pictoricista, dado que, como catalogador de la obra, Gudiol se fija primero en sus características técnicas y estilísticas, antes que en el posible sentido. Primero habla de una delicadeza extraña, lo que implica un cuidado de cierto detalle y un trabajo minucioso pero extraño, porque no conduce a una representación más precisa de la realidad, sino a la instauración de una inquietud (Gudiol, 1980, pág. 41). Es una palabra sorpresiva para referirse a los motivos de un pintor, y Gudiol la usará repetidamente en su análisis de la obra personal de Goya, relacionándola con el aumento gradual de la intensidad expresiva y un interés cada vez más evidente por pintar la destrucción, la ruptura, la caída, en palabras de Gudiol, "su abierta plasmación de la violencia y de los más bestiales instintos de la humanidad" (Gudiol, 1980, pág. 46). Se trata de desbaratar la predilección clásica por la apariencia de belleza y armonía y reemplazarla con la pintura de la violencia y la oscuridad. Sobre este abandono de los modelos representativos tradicionales, a favor de una expresividad personal y particular, Goya afirma en el mismo anuncio de prensa de los grabados de Los Caprichos, que, si bien la representación de los modelos de la naturaleza "es tan difícil, como admirable cuando se logra, no dejará de merecer alguna estimación el que apartándose enteramente de ella, ha querido exponer a los ojos formas y actitudes que solo han existido hasta ahora en la mente humana" (Dell'Acqua, 1976, pág. 84).

Ahora bien, si se compara esta primera serie de cuadros de capricho con los cuadros de Buenos Aires, de la partida X-28, es evidente la distancia que Goya tuvo que recorrer para liberar los elementos pictóricos que le interesaban, desarrollar cada elemento en su complejidad y enfrentarse a intensidades cada vez mayores de violencia pictórica, sin destruir la unidad del cuadro. Es posible rastrear, comparando las obras, algunos 
desarrollos del proceso de experimentación. El uso del valor del negro como línea de dibujo, que se hace visible y se va liberando poco a poco de la función de definir la forma, para volverse independiente y expresivo; la forma se sustenta, cada vez más, solo en la aparición fluida de la materia y ya no en el modelado clásico de luz y sombra. Además, la materia del óleo se vuelve cada vez más densa, hasta derivar en impastos pesados y texturas que resaltan con fuerza, sobre la superficie de los cuadros. Esto permite masas independientes, tanto de luz como de oscuridad, que no tienen ya funciones de delimitar los planos, ni establecer una jerarquía de fondo y figura; es decir, ya no son interdependientes, como ocurre en el claroscuro, sino que cada una manifiesta y sostiene libremente sus propias cualidades expresivas. También el color se libera doblemente: primero de su relación con la forma, en lo que se conoce como color local, $y$, segundo de la variación tonal de colores que estaba subordinada al claroscuro en el modelado de la representación clásica. Tal vez es en la libertad del uso del color en donde mayor distancia se percibe entre estos primeros cuadros y los de Buenos Aires. Las primeras series de la obra personal presentan paletas más bien restringidas, y la investigación pasa primero por el problema del claroscuro y la relación entre trazo y forma. En estos primeros caprichos, lo que parece concentrar la atención de Goya es la articulación del grupo de figuras en la violencia del movimiento de caída, que marca el inicio de una evolución en la que las figuras terminarán perdiendo por completo su individualidad.

El asunto es que al marcar estos distintos elementos y compararlos en su desarrollo, dentro de las distintas series que componen la obra personal de Goya, se entiende más fácilmente el proceso que tuvo que ocurrir y la distancia que había que transitar para llegar a los extremos de intensidad de los cuadros de la partida X-28. En este proceso es útil fijarse en algunas series específicas, anteriores al uso de las cañas, para luego poder resaltar lo que ocurre en los cuadros en que estas son empleadas y, puntualmente, en los cuadros de Buenos Aires. Entre 1794 y 1795 se ha fechado la siguiente serie de trabajos personales: un grupo de 8 cuadros en óleo sobre lienzo de idéntico tamaño, 41 x $32 \mathrm{~cm}$, que se conservan en la colección de los Marqueses de la Romana (Núm. 329 a 336, Gudiol, 1980, pág.107). De nuevo aparecen escenas de carácter violento y oscuro, como asaltos o fusilamientos por grupos de bandidos o el interior de un hospital. Otro tema recurrente en los dibujos y grabados, que a partir de esta serie va a ser muy importante también en la pintura de investigación, es el de los actos religiosos populares y los tribunales de la inquisición -asunto, de nuevo, bastante oscuro-. A medida que avanza 
el proceso de concreción de los nuevos elementos con el paso de las distintas series, el uso del claroscuro se hace cada vez más expresivo y los trazos más libres y enérgicos. De hecho, Goya va a terminar superando el problema del claroscuro, pero en estos cuadros en particular, se interesa en las posibilidades que aparecen al usar directamente la masa de luz como intensidad expresiva, cuando esta toma la forma de una pincelada violenta, que construye y emborrona, al mismo tiempo, tanto las figuras como el espacio. En todo caso, la interdependencia de luz y sombra, aunque puesta en extrema tensión, se sigue manteniendo; y, además, la relación de estos dos elementos con la constitución de las figuras. Lo que diferencia a los cuadros de Buenos Aires es la independencia expresiva que van a alcanzar en ellos los distintos elementos, cuando Goya supere por completo el problema del claroscuro.

El siguiente grupo corresponde a otro tema clave en los intereses de Goya, se trata de cinco pequeños lienzos de asuntos fantásticos y brujería (Núm. 349, 351 a 354, Gudiol, 1980, pág.108), que en 1798 adquiere la Duquesa de Osuna y que Goya debió pintar, en algún momento libre entre los encargos de 1796 hasta ese año. De nuevo, todos los cuadros de la serie tienen el mismo tamaño, 43 x $30 \mathrm{~cm}$. Ahora Goya presenta macabras escenas en que participantes, extasiados o aterrados, de cultos malignos, son testigos de las acciones de los brujos o de la aparición directa de los demonios invocados. Lo curioso es que, si bien su tema es, de cierta manera, más oscuro que el de las series anteriores, el tratamiento parece retroceder a una mayor definición de las figuras, que reduce la expresividad formal y conserva la individualidad de los personajes. Este aparente retroceso en el desarrollo de los elementos permite caracterizar mejor las condiciones de la investigación pictórica personal de Goya. Ya que debe dar prioridad a los encargos, el trabajo entre cada una de estas series se encuentra espaciado en el tiempo. No hay una evolución lineal. Lo que hace es trabajar un aspecto específico de los problemas pictóricos que le interesan y hacer avanzar ese aspecto que le está preocupando, para, cada vez más, profundizar en sus posibilidades en cada serie. Específicamente en esta serie de cuadros de brujería, si bien presenta una apariencia menos violenta en su tratamiento, se ve cómo la atmosfera de oscuridad del negro se independiza de la relación con el fondo y de la definición de la forma y el espacio. Si se compara el uso del negro en estos cuadros y los del grupo de Los Marqueses de la Romana, se puede notar que el negro pasa de ser el fondo contrastante que permite a la luz construir las figuras, a aparecer más bien, como elemento constituyente de una materia distinta a la de las figuras, que de hecho las rodea, las asedia, persigue y 
domina. Es decir que, a partir de esta serie, el negro alcanza un nuevo estatuto en relación con la figura, pues ya no tiene que ver con su construcción desde el fondo del cuadro: más bien se trata de que la oscuridad acecha a la figura desde su propio espacio y la atrae o la arrastra hacia una situación de caída. Un hito de esta nueva libertad formal y del valor de independencia de la oscuridad en el cuadro, se puede encontrar en la extraordinariamente dinámica composición del cuadro Brujos en el aire.

Hasta aquí es posible ya enumerar los caracteres básicos que configuran el asunto o problema pictórico, que Goya siente la necesidad de trabajar en sus cuadros de investigación personal. También se ha contrastado la manera como, en los distintos grupos de cuadros o pequeñas series, el pintor va abordando estos caracteres desde distintos matices y poniendo el énfasis en uno $\mathrm{u}$ otro elemento. Este rastreo es importante porque permite estudiar el desarrollo de cada elemento y las dinámicas que los relacionan a la luz de la experiencia de sensación en cada serie y en cada cuadro. Uno de los hitos en el proceso de investigación personal de Goya es la serie de tablas de la Academia de San Fernando. Dada su relevancia, merece un estudio detenido para poder establecer una comparación que ayude a situar mejor la importancia del manejo de elementos alcanzado en los cuadros de la partida X-28.

\section{Las tablas de la Academia de San Fernando}

En algún momento entre 1806 y 1815, Goya va a pintar la serie de su obra personal que tal vez ha alcanzado más notoriedad, exceptuando los famosos murales de la Quinta del Sordo. Se trata de las cinco tablas que fueron legadas más tarde a la Academia de San Fernando por Manuel García de la Prada (Núm. 498 a 502, Gudiol, 1980, pág.114). Cuatro tienen el mismo tamaño, 45 x $72 \mathrm{~cm}$, Tribunal de la inquisición, Disciplinantes, Casa de locos y Corrida de toros; y uno 83 x 62 cm, El entierro de la Sardina. En estos cuadros se perfilan ya con total claridad los mismos elementos desarrollados en los cuadros de Buenos Aires, a excepción del uso de las cañas. Las figuras aparecen bocetadas de manera muy libre, usando el color y la materia en un flujo vigoroso, que define los personajes, pero insertos en la dinámica de su propio movimiento. El trazo negro del dibujo se hace más perceptible y dominante, pero no en relación con la construcción de la forma, ni tampoco sosteniendo la estructura de planos desde el fondo. Este trazo de dibujo queda libre para establecer una dinámica particular del negro, que manifiesta sus propias intensiones: da la impresión de ir tendiendo una red que 
mantuviera las figuras atrapadas en la violencia de la acción. Gudiol describe el proceso técnico empleado:

Sobre la imprimación de matiz rosa claro se pintó un esbozo preparatorio, manchando con color muy fluido la masa de todos los elementos esenciales. Después de plasmar cada una con su tono, se dio precisión a las figuras con pinceladas lineales de negro, como si se realizara un dibujo sobre las manchas de color. (1980, pág. 57).

Entonces Goya está usando el tono cálido del fondo y las diferencias tonales entre los colores vivos y fluidos para armar el espacio, sin depender del claroscuro. Así el trazo negro queda liberado para remarcar la velocidad del ritmo general del cuadro, y conformar la dinámica de cada escena.

La composición de estos cuadros está sustentada en el despliegue de grandes grupos de personas. Hay un desarrollo gradual desde la masa anónima, que sirve para marcar la dinámica del movimiento interno de cada cuadro, hasta la definición de las figuras principales. Esto constituye una diferencia con los cuadros del grupo X-28, en los que Goya usa un grupo, si bien numeroso, más compacto y que no alcanza la sensación de una multitud en movimiento, lo que sí pasa en las tablas de Academia. Por ejemplo, en Los disciplinantes se aprecia cómo se ha pintado de forma muy directa sobre la base cálida la multitud que observa a los que se flagelan, solo esbozando muy rápidamente las figuras con marrón oscuro, dejando ver el color de la base. Luego, a medida que aparecen las figuras centrales de la escena van siendo definidas mediante la aplicación de oleo más denso, hasta llegar al impasto, con texturas muy marcadas y vigorosas, que suministran a los cuerpos una materia real, expuesta a la acción violenta del pintor sobre ella (Ver ilustración 499, detalle, en el Apéndice). También se puede notar en estos cuadros que las formas particulares son definidas a partir de la aplicación vigorosa y suelta del manchado de color, como por ejemplo en Corrida de toros, al fijarse en el picador y su caballo, se ve cómo se ha usado el gris bastante líquido para definir el caballo dejando ver la pincelada, de la misma forma que el ocre en el pantalón del picador o el azul de la tela que sostiene el personaje que está detrás del caballo. En cambio, ya en la chaqueta del picador y el traje de su compañero se aprecia que el óleo es llevado al impasto de materia gruesa, para resaltar la textura con blancos y amarillos. Detrás de ellos se puede ver la multitud que observa, apenas definida sobre la base cálida, y poco a poco algunos personajes dentro de la masa van siendo definidos, mediante la aplicación de algún color que da forma a un vestido o a algún otro detalle (Ver ilustración 501, detalle, en el Apéndice). De modo que cada zona presenta una 
elaboración detallada, pero no en el sentido de una descripción realista de la figura, sino una elaboración casi abstracta, referida a la intensidad del ritmo interno de cada cuadro, evidenciando una violencia que ocurre realmente sobre la materia del óleo, en la brusquedad con que se aplica el impasto, en el trazo vigoroso y en la mancha más líquida de color que deja ver la acción de la pincelada. Esa manera de elaboración detallada alcanza una máxima intensidad en el grupo del Entierro de la Sardina, tal vez porque todos los personajes están mucho más juntos, lo que genera una mayor densidad en los elementos que van apareciendo para proporcionar cuerpo y presencia material a las figuras (Ver ilustración 502, detalle, en el Apéndice). De hecho, el ritmo interno de los grupos de figuras aglutinadas, que se observaba ya desde la serie de 1793, alcanza en este punto el rompimiento completo de la individualidad, en favor de la vibración constructiva que arrastra a las figuras en un ritmo vertiginoso, una intensidad que se manifiesta generando su propia estructura de movimiento sobre el grupo indiferenciado, construyendo la dinámica de cada cuadro sobre la relación de fuerzas que se da entre las distintas masas de figuras. Es esta necesidad creciente de hacer vibrar la materia pictórica, la que anuncia el uso de las espátulas de caña.

\section{Los cuadros de las cañas en el inventario de 1812}

En el año de 1812 muere la esposa de Goya, Josefa Bayeu. Se realiza un inventario de todos sus bienes, con el propósito de adjudicar la mitad de estos a su hijo Xavier, como herencia materna. En dicho inventario se incluye la colección de pinturas en poder de Goya para ese momento, entre la que se encuentran algunos bocetos de otros artistas y las obras de investigación personal producidas a partir de 1807, etapa en que aparecen los cuadros de las cañas. Gudiol explica que el valor total de los bienes que incluían inmuebles, muebles, cuadros libros, joyas, ropas y dinero líquido fue de 357.728 reales. De estos, la biblioteca fue tazada en 1.500 y los cuadros en 11.239 reales. Aclara también que

Adjudicando a su hijo la colección de pintura, sin valor real en aquel momento, fácilmente podía retenerla en su casa, como así sucedió. En efecto los cuadros quedaron colgados en domicilio del pintor, pero no por ello Xavier dejó de asegurar su propiedad marcando cada una de las obras con una sigla formada por un gran X, inicial de Xavier, seguida de un número de inventario (...) Gracias a esta sigla ha sido posible la identificación de un buen número de los cuadros que formaban parte de la colección de Goya en 1812 (Gudiol, 1980, pág. 60). 
El hecho de que Goya tuviera estos cuadros en su poder y de que Gudiol afirme que no tenían valor real, muestra hasta qué punto las obras de investigación personal, diferían por completo de los encargos. Por supuesto, Goya vivía de hacer encargos y les daba prioridad. Solo pintaba sus series personales cuando tenía tiempo libre, pero teniendo claro que era muy difícil que sus clientes se interesaran por cuadros de esas características, con un tratamiento tan extraño para ellos; así que los hacía para sí mismo y los mantenía colgados en su casa.

La partida número 15 del inventario aparece reseñado como "unas ylanderas", avaluado en 100 reales (Gudiol, 1980, pág. 60). Corresponde al óleo de 95 x 107 cm, núm. 561 del catálogo (Gudiol, 1980, pág. 117). El tratamiento y la disposición de los elementos es acorde con la línea de las tablas de la Academia, solo que en este cuadro la dinámica de la composición que logra la oscuridad sostenida en la relación entre los arcos, el grupo de figuras del segundo plano y la luz que se trasluce desde el fondo de color alcanza mucha más contundencia; como si Goya tuviera cada vez más claro su interés primordial de atrapar grupos de figuras en redes dinámicas de oscuridad, cada vez más poderosas. Si bien se trata de un grupo numeroso, ya no aparece la multitud, que era un elemento importante en las tablas, sino que todos los personajes están abarcados y conectados entre sí por el movimiento único de la acción, la misma estructura que van a tener los cuadros de Buenos Aires. El movimiento fluye de una figura a otra: por ejemplo, desde el brazo extendido de la mujer del primer plano a la izquierda, agitando la rueda, pasa a la inclinación de las dos mujeres de la derecha, las obliga a replegarse hasta el piso y de allí rebota para replicarse en el grupo, más oscuro, del segundo plano y luego en los arcos detrás de este.

En este inventario de 1812 ya aparecen los primeros grupos de cuadros de las cañas. Es en esta etapa donde Goya empieza a usar las cañas como espátulas para aplicar el óleo. En el catálogo de Noguer-Rizzoli se introduce este grupo de cuadros citando dos testimonios relativos a la particular técnica empleada en su realización. Primero el comentario del padre Tomás López, quien, tras visitar la casa del hijo de Goya en 1887, afirma haber visto un grupo de "8 a 10 lienzos pintados sin pinceles, es decir, con unos cuchillitos de caña, de cuyo procedimiento Goya se declaraba inventor". De otro lado, recoge la declaración del nieto del artista Mariano Goya, quien afirma, al referirse al grupo de cuadros, que "la singular violencia de estas piezas es el resultado del empleo de canutos oportunamente cortados a un extremo, a que Goya recurrió, para trabajar los 
densos empastes de color" (Dell'Acqua, 1976, p.125). Como se mencionó antes respecto del tratamiento de las tablas de la Academia, se nota que la libertad expresiva, aunque supone apartarse tanto de la precisión del dibujo como del modelado del claroscuro, no conduce a Goya a la simplificación formal. Al contrario, la mancha y el trazo empiezan a requerir un tratamiento detallado que enfatice la fuerza expresiva de la aplicación de la materia, ya que es en esa aplicación que se sustenta la acción del cuadro. En realidad, no se trata de representar la violencia de la acción y el movimiento de un grupo de figuras, sino de que esa violencia ocurra físicamente en el lienzo sobre la materia del óleo. Goya tiene que expoliar y torturar su materia hasta el extremo, en el momento de la aplicación sobre el soporte, y para eso no le alcanzan los pinceles. Así que recurre a prepararse unas espátulas de caña, que lejos de aplanar los gruesos impastos, como sucede con la espátula de lámina metálica, lo que hacen es rayar y triturar el óleo, a medida que se va aplicando.

Volviendo al catálogo de Gudiol, encontramos que la primera partida del inventario de 1812 dice "quatro quadros iguales" que están avaluados en 1.800 reales, lo que supone la tasación más alta del inventario, 450 reales cada obra. Se han identificado gracias a la marca X-1 como los números 563 a 566 del inventario (Gudiol, 1980, pág. 117). Son los cuadros: La Cucaña, de 80 x 103 cm; Procesión, de 102 x $125 \mathrm{~cm}$; Carnaval, de 84 x $104 \mathrm{~cm}$ y Corrida de toros en plaza partida, de 98 x $126 \mathrm{~cm}$. Serían, al parecer, los primeros cuadros en los que Goya emplea las cañas, aunque solo las va a utilizar en algunos sectores como los fondos de cielo, el paisaje, las edificaciones y en algunas figuras distantes, mientras que continúa usando el pincel para trabajar las figuras de los primeros planos. Gudiol describe el trabajo de las cañas, al tiempo que resalta el proceso de experimentación que conduce a los cuadros de la partida X-28

Aquí la espátula actuó aplastando y extendiendo la masa de color y creando formas por simple frotamiento. Estas obras se unen, en su aspecto técnico con los 4 lienzos de Buenos Aires, que también figuran en el inventario de 1812 bajo el número 28, y en las cuales se advierte un mayor dominio de la espátula, y a la vez mayor cautela en su empleo (Gudiol, 1980, pág. 65).

El uso de las cañas, por supuesto, da un acabado muy intenso y expresivo a estos cuadros de la partida X-1, a lo que contribuye también el uso de la línea negra de dibujo para definir las figuras, como ya aparecía en las tablas de la Academia. Se aprecia, además, el tratamiento acentuado del impasto, que define los grupos a partir del flujo de la materia del óleo, aplicado incluso con una amplia variedad cromática. Pero, en general, estos cuadros parecen más contenidos, con una más rigurosa y convencional 
estructura del dibujo y mucho más sobrios, si se comparan con la violencia fluida que se percibe en las Hilanderas; careciendo, además, de la contundente atmosfera de oscuridad de este último, que es un anuncio al protagonismo del negro en los cuadros de Buenos Aires.

De la partida X-12, que se describe como "otros doce con horrores de la guerra", avaluados en total en 2.000 reales, así como de la X-9, "otros seis de varios asuntos", tazados en 800 reales, no se han logrado identificaciones ciertas. El catálogo incluye tentativamente algunos cuadros de pequeño formato con escenas que se asocian formalmente a la serie de grabados de la misma época Los desastres de la guerra. Algunos de estos tienen rasgos de haber sido intervenidos por las cañas, pero resulta muy difícil asegurar si son obra de Goya o de uno de sus varios seguidores, que copian en especial estas escenas de guerra y también adoptaron el uso de las cañas. Se puede tomar por caso la partida X-18 del inventario, "un gigante" que tradicionalmente se ha aceptado como El coloso (Núm. 580, Gudiol, 1980, Pág. 117). Muy recientemente ha sido protagonista de un intenso debate sobre su correcta atribución a Goya. El Museo del Prado, bajo el liderazgo de Manuela Mena, presentó una extensa investigación en la que se declara que no es obra de Goya, si bien un grupo de expertos liderados por Nigel Glendinning se opone de forma tajante a su descatalogación. Al margen de la controversia, la investigación de Mena disponible en el portal del Museo suministra información técnica e historiográfica muy relevante para el análisis de los cuadros de las cañas (Mena, 2011). Se pone énfasis en la técnica directa de Goya, que se aprecia tanto en su obra de encargo como en su obra personal. Esta consiste en definir muchos elementos directamente sobre la base, casi siempre de un rojo más bien vivo e iluminado, con trazos y efectos aplicados de forma segura y contundente. Tanto las Tablas de la Academia, como los cuadros de Buenos Aires corresponden a esta caracterización técnica. Respecto al tema de las fechas y el inventario de 1812, Mena explica que el inventario fue corregido en 1814 y que aun después de esta fecha es muy posible que, si Goya vendió alguna obra del inventario, Xavier la reemplazara con otra de similares características, a lo que habría dado lugar el hecho de que el inventario hace descripciones muy someras de los cuadros. De modo que la fecha de 1812 no sería una fecha límite para la realización de estas obras, por lo que se puede decir simplemente que los cuadros de las cañas -en particular los de la partida X-28 que son el centro de este análisis- son contemporáneos a las tablas de la Academia, sin que se pueda establecer claramente cuáles se pintaron primero. 
Otro reputado lienzo que ha corrido con una suerte similar a la de El coloso, es Ataque a una fortaleza (Núm. 645, Gudiol, 1980, pág. 120), en el que es perceptible el trabajo con las cañas y cuya autoría también ha resultado cuestionada. El análisis técnico de la investigación de Mena revela que mientras Goya suele definir sobre la base con mucha seguridad, dejando transparentar o incluso dejando ver el rojo vivo de la base, en $E l$ coloso se han aplicado capas de pintura oscura que impiden ver la base. Los detalles, incluidos los realizados con las cañas, lejos de ser seguros y directos, resultan dudosos $\mathrm{y}$, sobre todo, ejecutados con demasiados trazos, lo que les quita soltura. Incluso las figuras resultan más bien torpes y duras en el trabajo de la físionomía general, así como en los detalles. Lo mismo puede decirse Ataque a una fortaleza, que no parece alcanzar el nivel de maestría reflejado en los cuadros de Buenos Aires, ni en lo referente a la seguridad de la construcción de las figuras ni en la definición de las masas de color, como se puede observar al comparar el acabado más bien caótico de la montaña, con la contundencia de los espacios de los cuadros de Buenos Aires. Más allá de decantarse por una u otra postura de la controversia respecto a la autoría de estos cuadros, es muy relevante que la investigación destaque precisamente la maestría, expresividad y contundencia del tratamiento logrado por Goya en los grupos de figuras, por ejemplo, en las tablas de la Academia, que Mena utiliza como piedra de toque, en su análisis técnico. Sería muy importante incluir en esta discusión a los cuadros de Buenos Aires, ya que su rico tratamiento, definición y expresividad logradas resultan aún más impresionantes, teniendo en cuenta que se trabajaron con espátulas de caña y con empastes de óleo mucho más densos que las tablas de la Academia. Ni en El coloso ni en Ataque a una fortaleza las figuras muestran la misma calidad de tratamiento. A pesar de que Goya, según los testimonios que se citaron, había inventado el uso de las cañas, es claro que algunos de sus aprendices o colaboradores lo pueden haber aprendido, lo que dificulta la identificación de las obras autógrafas. Esto amerita un estudio técnico minucioso de todo el grupo de los cuadros de las cañas, en el que los cuadros de Buenos Aires podrían convertirse en un punto relevante de comparación, que permita establecer mejor las atribuciones y entender con más profundidad el uso que Goya hizo de esta técnica. 


\section{Los cuadros de base negra y otro cuadro en el Museo de Buenos Aires}

Otro grupo de cuadros trabajados con las espátulas de caña ha sido catalogado por Gudiol con fecha cercana a 1818 y, en todo caso, posterior a 1812. Uno de estos cuadros ha llegado también al Museo Nacional de Bellas Artes de Buenos Aires, si bien presenta varias características que lo hacen diferir de los tres cuadros que se conservan del grupo X-28. Se trata de Escena de disciplinantes (Fig. 7). Básicamente, Gudiol se basa en la fecha del inventario de las obras legadas a Xavier y clasifica como posteriores a 1812 los cuadros de investigación personal que no resulten identificables en las descripciones de dicho inventario, ya sea que muestren rastros de la acción de las cañas o sean ejecutados solo con pinceles. Como ya se señaló, las investigaciones más recientes han planteado que el inventario fue revisado posteriormente y que la obras pudieron ser reemplazadas unas por otras, de modo que es muy difícil fechar las obras personales de Goya, y lo correcto es establecer un periodo aproximado desde 1803 hasta 1818 inclusive, para fechar el grupo de cuadros de investigación que incluye las Tablas de la Academia y todos los cuadros de las cañas. Pero otro de los argumentos de la clasificación de Gudiol, resulta muy relevante porque tiene que ver con la técnica, ya que los cuadros que se suelen fechar más cercanamente a 1819 están pintados sobre base negra, lo que Gudiol define como "la norma casi constante del artista en el periodo crucial que precede a las pinturas de la Quinta del Sordo” (Gudiol, 1980, pág. 76). Como se mencionó, Mena explica en su trabajo sobre la descatalogación de El Coloso, que Goya solía usar bases rojizas claras y definir los elementos con una técnica directa, dejando ver la base cálida, lo que permite mayor intensidad cromática a todos los elementos. Siendo las Tablas de la Academia y los cuadros del grupo X-28 ejemplos claros de las virtudes de esa técnica, representan un equilibrio entre la presencia del negro, que a partir del dibujo plantea la organización dinámica del espacio, y el trabajo de calibración tonal que distribuye los planos del cuadro a partir de los colores vivos. Por otro lado, los cuadros de base negra que anuncian la austeridad cromática de las llamadas Pinturas Negras, implican unas condiciones muy distintas para el color y el tratamiento de los cuadros. La superficie se enfatiza y es más difícil plantear profundidad, pues desaparecen las resonancias cromáticas de la transparencia de un color sobre otro. Ganan las texturas, que se hacen más notorias, y las veladuras blancas o muy claras aplicadas sobre los colores oscuros ya secos. 
En este sentido, el cuadro Escena de disciplinantes de Buenos Aires proporciona un interesante punto de contraste técnico con los cuadros de la partida X-28. En primer lugar, es de menor tamaño, 51 x $57 \mathrm{~cm}$, lo que, sumado a las características de la base, obliga a fijarse más en la superficie y hace que se note más el rayado de las espátulas de caña, que en los otros cuadros tiende a verse matizado por la profundidad del espacio cromático interior. Así ocurre en los cuerpos desnudos de los flagelantes en el primer plano, construidos con materia de óleo denso y espeso, y también en los ropajes de las figuras de la izquierda. La materia es herida y lacerada literalmente por la acción de las espátulas. Además, en este cuadro no aparece la distancia y lejanía que permite respirar a los otros tres, que es un elemento de composición importante, pues el movimiento tiende a liberarse en esa dirección. Al contrario, dado que la distancia interior está clausurada por la oscuridad de la base, el arco detrás de la multitud se siente mucho más cercano, todos los personajes se aprietan en esa corta distancia, e incluso la luz al interior del arco, que debería plantear un espacio distante, se vuelve hacia la superficie al estar aplicada en seco sobre el negro del cuadro, lo que contrasta con la sensación de distancia que sí se produce detrás del arco en Baile popular.

De modo que, uno de los criterios para estudiar los cuadros de las cañas como grupo es diferenciar entre los que se acercan a los elementos pictóricos de las Tablas de la Academia, empezando por la base cálida y el uso del color y el espacio asociada a ella, y, en el otro extremo, los que se acercan a la técnica y la parquedad cromática de las pinturas negras. En las dos maneras de trabajar el negro es protagonista, pero de modos distintos. Contrastar las características de los cuadros de la partida X-28 con las de Disciplinantes es una magnífica oportunidad que ofrece el Museo Nacional de Bellas Artes de Buenos Aires, y que permite entender mejor la naturaleza del trabajo desarrollado por Goya en una y otra etapa de su obra.

\section{Las últimas series de la obra de investigación}

Antes de entrar a estudiar con mayor detalle los elementos pictóricos de los cuadros de Buenos Aires, conviene fijarse en otros dos grupos de entre la obra de investigación, que, si bien ya no son trabajados con las cañas, sí sirven para terminar de rastrear el desarrollo de dichos elementos en los diferentes momentos de la trayectoria de Goya, y el rompimiento que alcanza con las fórmulas representativas de la pintura de su época. Se trata de dos series posteriores al periodo de la Quinta del Sordo, casi al final de la 
vida del artista. Una serie de 6 tablas (Núm. 688 a 703, Gudiol, 1980, pág. 122), fechadas en 1825, todas de 31 x $20 \mathrm{~cm}$, permiten constatar hasta qué punto Goya se ha liberado de las convenciones de la representación clásica, desarrollando las posibilidades de la línea negra del dibujo, como pura construcción expresiva de la forma y la libertad absoluta del color, para crear simultáneamente materia y espacio. Lo que más sorprende es la austeridad de elementos con los que logra concretar la expresión: deja ver la textura del soporte y se vale de ella para sugerir el espacio a partir de manchados de grises. El dibujo establece la dinámica del movimiento de la escena y uno o dos colores secundarios son usados para dar cuerpo a las figuras, dejando que la materia pictórica defina el movimiento y la forma desde el mismo proceso de su aplicación. La necesidad del claroscuro ha desaparecido por completo, lo que da a estás tablas un carácter especialmente moderno, ya que ni siquiera aparecen las masas de negro y bruma luminosa, que tantas veces Goya utiliza y que implican una última referencia a la disposición de la luz en el cuadro.

Otros cinco lienzos de tamaños diversos y con el tema de las corridas de toros (Núm. 728 a 732, Gudiol, 1980, pág. 123), de los cuales el mayor tiene 64 x $93 \mathrm{~cm}$ y el menor 34 x $44 \mathrm{~cm}$, están entre las últimas obras atribuibles con certeza a Goya. En ellos se aprecia la misma soltura y libertad formal de las seis tablas antes referidas, pero acá el movimiento dinámico de la materia de óleo es aun más preponderante, al tiempo que pierde protagonismo la línea negra del dibujo. El pintor conoce tan bien las posibilidades formales de su tema, que se da el lujo de dejar que la materia de los colores, al ir siendo aplicados, vaya definiendo directamente la forma y el espacio. Es importante observar que la pérdida de protagonismo de la línea de dibujo permite que sí aparezcan de nuevo masas, tanto de negro como de luz brumosa, pero no en una relación de claroscuro, que Goya ha superado completamente, ni tampoco asociadas en modo alguno a la definición de la forma. La masa de negro actúa como un valor expresivo libre e independiente de las formas, que más bien establece la dinámica espacial del cuadro, enfatizando el movimiento de la materia del óleo que ocurre en las figuras, como se ve especialmente en Cogida de un picador y en Plaza partida. De otro lado, la bruma luminosa trabaja también como un valor expresivo independiente, asociado a una intensificación de la textura matérica, como se ve, por ejemplo, en Diversión en España, tanto en la textura de la arena, como en el cuerpo del toro blanco y las ropas de los toreros. 
De modo que Goya hasta sus últimos años lleva adelante una investigación profunda, explorando las diferentes posibilidades de los problemas pictóricos que le han interesado. Este recuento de cómo funcionan los elementos en los distintos momentos del desarrollo de la obra personal, permite entender y valorar mejor la importancia que tienen el manejo logrado en los cuadros de la partida X-28. En este punto, después de haber rastreado la evolución de dichos elementos y establecido valoraciones y relaciones entre ellos en cada serie de la obra personal, es posible puntualizar sobre los cuadros de Buenos Aires, reparar con detenimiento en lo que le ocurre a cada elemento, cómo funciona en relación con la experiencia de sensación que es cada cuadro y dimensionar así el nivel de intensidad pictórica que tiene lugar.

\section{Elementos pictóricos de los cuadros de Buenos Aires}

\section{a. El fondo coloreado}

Cada uno de estos cuadros empieza por un fondo de color rojizo bastante vivo, usado como base, que va a tener un papel importante en la creación del espacio y en liberar el color general de la dependencia del dibujo, lo que no quiere decir que las figuras van a emerger de este fondo, como ocurre normalmente en el espacio del barroco. Este color de fondo va a determinar la temperatura inicial de la que parte la construcción de la obra. Va a determinar, además, un posicionamiento respecto al uso de los planos: el primado del plano secundario y la producción de una distancia interior, donde ocurre el hecho de cada cuadro.

Es importante tener en cuenta esta distinción, muy general, para ubicar el trabajo de Goya en relación con el uso de los planos, dentro de las posibilidades que se han usado en la historia de la pintura. ¿Qué quiere decir el primado del plano secundario? Desde el punto de vista del plano, como ha señalado Wölfflin (1924) al estudiar el paso de la pintura renacentista al barroco, existen los pintores que hacen una distinción de planos en el interior del cuadro y, de otro lado, los que buscan el emparejamiento de la figura y el espacio: la unificación del plano. Para citar un caso de pintura de superficie, se puede pensar en la pintura de la antigüedad egipcia o griega, donde no hay profundidad, o también en la pintura abstracta moderna, como en el expresionismo abstracto, donde conscientemente se enfatiza la superficie del soporte. Lo opuesto ocurre en la pintura clásica, que usa una representación o sugerencia de perspectiva, creando un espacio 
interior, es decir, una distancia interna entre el primer plano y el fondo, entre los primeros planos y los planos secundarios; entonces, el hecho pictórico puede ocurrir en ese espacio interior. Ahora bien, se tienen dos opciones para establecer una jerarquía: o es el primer plano el que domina la estructuración de la obra y determina al segundo como ocurre en el Renacimiento- o es, por el contrario, el plano secundario el que domina. En el primer caso el cuadro se sustenta en un dibujo muy estructurado que ordena la acción desde el primer plano, como ocurre, por ejemplo, en Rafael o Miguel Ángel. En el segundo caso, es en el fondo, desde la distancia interior del cuadro, de donde surgen las figuras. Cuando prima el plano secundario, el pintor obtiene una distancia a recorrer desde el fondo hasta la superficie y es por eso por lo que el claroscuro se vuelve tan importante para el barroco, ya que se hacen surgir las figuras desde el fondo, modelándolas gradualmente por el contraste de la luz y el fondo oscuro, como pasa por ejemplo en Caravaggio o Rembrandt.

Sin embargo, existe una tercera posibilidad, como explica Deleuze (2007) en sus estudios sobre pintura, cuando intenta hacer una clasificación muy amplia de los tratamientos posibles del problema de los planos y, precisamente, caracteriza lo que ocurre cuando se usa una base de un color vivo. Vuelve a aparecer el dibujo en el primer plano, pero este ya no domina la estructura del cuadro, sino que las figuras se sitúan entre los planos mediante valores cromáticos en relación con el fondo coloreado. Esto abre la opción de que la oscuridad no tenga que estar necesariamente atada al fondo y así el juego de luz y sombra se puede desplazar entre un plano y otro, como ocurre, por ejemplo, en Rubens o Vermeer.

Lo que ocurre en Goya es muy particular porque él aprende a usar todas estas posibilidades, ya que está formado, tanto en el dibujo neoclásico, que recupera elementos del renacimiento, como en la tradición, muy arraigada en la pintura española, del claroscuro del barroco tardío. En los trabajos comisionados se ve a Goya usar tanto un dibujo preciso -que pone el foco en la figura del primer plano y la separa del fondo, como ocurre en la mayoría de los retratos- o contrastes marcados de luz y sombra, que añaden dramatismo a la acción y hacen surgir a la figura desde el fondo oscuro, como ocurre, en especial, cuando pinta escenas históricas. En su obra de investigación, como se ha visto, Goya prueba las dos vías, buscando investigar problemas diferentes en cada caso: la base de tierra oscura o directamente negra, como en la Escena de disciplinantes del Museo de Buenos Aires (Fig. 7), y la base de color vivo, como en los cuadros de la 
partida X-28. Normalmente, el trabajo del pintor se basa en determinar la estructura que sostiene y organiza el cuadro, es decir, una forma particular de ordenar y jerarquizar los distintos elementos pictóricos para construir el cuadro, lo que implica tanto encontrar el modo en que los elementos habitan la distancia entre el fondo y la superficie, como hacer salir del fondo dichos elementos. Lo que ocurre en estos cuadros es como si él se desentendiera del problema de estructurar la obra. Cuando usa la vía de la base negra, usa la luz como si fuera una materia que directamente construye la figura en el espacio, no modelándola o haciéndola salir del fondo oscuro, sencillamente la hace ocurrir y sostiene en esa acción, tanto la figura y como el espacio al mismo tiempo. En Escena de disciplinantes se ve un claro ejemplo, en los cuerpos y las ropas raídas de los hombres que se flagelan; también en los sombreros cónicos y en la luz contigua a ellos, que marca el interior del arco del puente; incluso en algunos ropajes de entre la multitud y en el manto blanco que envuelve la figura de la izquierda. Todo esto está construido con una masa pastosa de blanco aplicada con la espátula de caña, que enfatiza la superficie del lienzo, rozando la impresión de un alto relieve. Así, la fuerza expresiva de las figuras no se deriva del modelado de la luz, sino que la materia blanca luminosa esculpe los movimientos materiales de las figuras.

Cuando usa - como en el caso de los cuadros de la partida X-28- la vía de la base de color vivo, es la diferencia tonal la que va a generar en forma automática el espacio interior, pero todos los elementos quedan libres de cualquier función estructural. La primera condición es mantener la precisión tonal de todos los colores que van apareciendo, unos en relación con otros y con la base. Pero librarse del sistema de modelado de la luz tiene importantes implicaciones. En virtud de este fondo de color, tanto el blanco como el negro quedan liberados de la función de estratificar u organizar el espacio y ya ni siquiera tienen que ser entendidos como luz y sombra, ni van a tener esa relación de contraste y mutua correspondencia que supone el claroscuro, de modo que cada uno se manifiesta como un valor propiamente dicho, blanco y negro, cada uno con sus posibilidades propias y específicas y con su repertorio particular de tratamientos expresivos. El fondo de color supone una temperatura inicial para el cuadro, marca la atmosfera desde la que se van graduando o matizando las figuras en sus valores de color. Así que las figuras van ocupando espacios en el interior del cuadro, entre los planos, pero sin estar atadas al fondo, ya que la temperatura de color atraviesa los elementos que se van superponiendo, sirviendo como matriz de referencia que asigna 
valores específicos a todos los tonos de color para sostener los diferentes niveles del cuadro.

Al comparar, por ejemplo, la serie de las tablas de la Academia de San Fernando, en las que se usó una base de rosa vivo, con los cuadros de Buenos Aires, se nota cómo Goya va intensificando la libertad con la que usa el color y la manera como aprovecha esa libertad para aumentar el carácter expresivo de la forma. En la primera serie ya el color trabaja independientemente del dibujo, no existe el color rellenando el espacio del dibujo, más bien usa variaciones tonales de un mismo color para definir las figuras, como dibujando directamente con la pincelada suelta de color. En la segunda serie, sobre todo con el uso de las cañas para aplicar el color, aparecen impastos de color puro y además texturas muy violentas, resultado de un rayado intenso y muy fuerte a la hora de aplicar el color. Estos impastos en ocasiones corresponden a la forma de las figuras o la esbozan con gran habilidad, como ocurre en el vibrante movimiento de los cuerpos de Baile popular, que se despliega a través de las resonancias tonales y texturales de cada color aplicado, y que al mismo tiempo va esbozando, tanto las pieles, como las ropas de las figuras de los danzantes. Pero, también, son usados esos impastos cromáticos como pura materia expresiva, integrados a la solución de la atmósfera del espacio o enfatizando el ritmo del movimiento de la escena, sin participar directamente de la conformación de la figura, como ocurre en las llamas rojas y naranjas que se integran con el negro en Incendio de un hospital.

Se puede concluir que la libertad que Goya alcanza en estos cuadros en el uso del color, se fundamenta en el hecho de que la forma de las figuras no depende, ni del dibujo ni de la estructura de los planos, de la que prácticamente Goya se olvida, sino del hecho fundamental de hacer descansar la forma únicamente en el flujo de la materia de óleo, lo que implica asimilar el movimiento de la aplicación de la materia sobre el soporte al movimiento de las figuras en el espacio, resultando en la identidad entre movimiento de la materia pictórica y movimiento representado. Para decirlo en forma más precisa, no habría movimiento representado, solo el movimiento de la materia en su aplicación violenta sobre el soporte. En términos de color, eso implica que el flujo de cualquier color aplicado ya genera forma sobre el lienzo, y las condiciones de dicho flujo solo dependen de la relación entre los distintos elementos, materias y colores que se despliegan en el espacio del cuadro. 


\section{b. El negro}

El negro les ocurre a estos cuadros como una avalancha y como un estallido. En primer lugar, desde las primeras series de la obra de investigación, el trazo negro de dibujo adquiere la categoría de valor pictórico en sí mismo. A medida que Goya descubre que la materia puede generar por sí misma, desde su aplicación en el lienzo, el nacimiento de la forma, en lugar de hacer a un lado el valor del trazo, le otorga el lugar de un elemento expresivo independiente. El negro, en su calidad de trazo, es la herramienta primera para capturar los valores esenciales de "eso que el pintor ha visto" y que contiene el detonante a partir del cual germina la obra. Es la línea conductora que emparenta la pintura de Goya con sus dibujos y grabados, que le revela como un maestro de la sensibilidad para esbozar con el mínimo de líneas posibles el movimiento central y el ritmo, de cada figura y de cada cuadro.

En otro sentido, el negro encarna, conceptual y materialmente, la caída de la figura y la violencia pictórica asociada a esa caída, lo que corresponde a la inquietud mencionada por Gudiol, que parece ser el tema central de su pintura, el gran problema que Goya quiere dilucidar, llegando al fondo de esa violencia o llevándola a sus últimas consecuencias. Se manifiesta pictóricamente en el corrimiento, tanto de la figura en sí, como del movimiento de su acción, hacia una masa física del negro, que parece llamar, o incluso arrastrar cada cuadro hacia la oscuridad. Da la impresión de que, si el movimiento natural de uno de estos cuadros continuara, pronto todo el lienzo estaría cubierto de negro.

Ahora bien, estas dos maneras de aparecer en la tela del negro, como trazo de dibujo y como masa material a la que se dirige al movimiento final de las figuras, de ningún modo son independientes. Al contrario, aparecen como al comienzo y al final del movimiento de la figura. El trazo de dibujo negro inicia el movimiento, o, más precisamente, capta y sintetiza el momento inicial de ese movimiento que forzosamente va a terminar en el corrimiento de la figura hacia la masa de negro. De hecho, los trazos aparecen conectados a la masa de negro, como si salieran de ella. En ese sentido, el negro implica una temporalidad al interior del cuadro: el negro sería el movimiento de potencia singular que da inicio al tiempo interno de cada cuadro. Es en virtud del 
movimiento de explosión y arrastre que implica el negro, que cada elemento tiene su impulso y su resonar temporal dentro del cuadro.

Es importante tener en cuenta aquí el problema de la estructura y el sostenimiento de los planos. Esto solo es posible considerarlo comparando a Goya con pintores mucho más modernos, que se van a interesar en los mismos aspectos, como pasa con Cézanne. Es muy llamativo que la liberación de la materia pictórica de la dependencia del dibujo descriptivo y el claroscuro, solo se empieza a instaurar con el impresionismo, por unos pintores que necesitan prescindir totalmente del negro, buscando, a partir del color, reconstruir relaciones lumínicas, teniendo como referencia un entendimiento óptico de la descomposición de la luz. Así que, después del impresionismo, un pintor como Cezanne va a encarar la pintura de un paisaje, por ejemplo, como un caos fluido de materia pictórica y de matices de color, pero él mismo va a decir, en sus conversaciones con Gasquet (Doran, 1980), que primero necesita encontrar una especie de estructura que permita sostener los planos del cuadro, y pinta esa estructura usando, no directamente negro, pero sí tierras muy oscuras. Si miramos un paisaje de Cézanne podemos ver con claridad esa especie de armazón o esqueleto de tierra oscura, que parece retener las diferentes zonas de materia pictórica, evitando que todo el cuadro se derrumbe. Será necesario esperar hasta el expresionismo alemán de las décadas siguientes a Cezanne, para encontrar simultáneamente materia pictórica liberada del dibujo formal, coexistiendo en el lienzo con el uso directo del negro.

Todo lo anterior permite valorar mejor la osadía implicada en las decisiones de Goya en sus cuadros de Buenos Aires, al mantener simultáneamente la libertad de la materia pictórica y el uso de los colores vivos y las masas, tanto de negro, como de bruma lumínica. Pero, en contraste con Cézanne, Goya no tiene necesidad de establecer una estructura. Como se ha visto, usa el fondo cálido de color para establecer una temperatura inicial que proporciona un contraste de referencia a los colores, generando, automáticamente, distintos planos. En ese espacio generado aparece la gran masa de negro, como una potencia particular generativa y ordenadora del movimiento interno, pero liberado de la condición de fondo oscuro por el color vivo de la base. El negro establece las condiciones del espacio y el tiempo del cuadro, pero no es lo que ha generado el espacio ni lo tiene que sostener, por eso ocurre libre y limpiamente, como un movimiento de puro valor expresivo. 
El negro irrumpe siempre desde un lado y desde atrás, desde un punto en el fondo lateral del cuadro y marca una dirección de recorrido hacia el primer plano. Efectúa un rodeo, una rotación semejante al pliegue de una ola, encerrando una zona como una especie de centro, que puede estar ubicado o no en el centro del cuadro. En Baile popular, la masa del negro corresponde más o menos al gran puente, pero en Incendio de un hospital, es solo una gran mancha que tiene como centro el edificio en llamas y en Escena de guerra flota en el aire de todo el espacio, sosteniendo y envolviendo al grupo de figuras. El negro se apodera de un espacio que le es suyo, que en algunos casos ocupa casi todo el cuadro, pero siempre termina llenando el primer plano, escapando por el costado inferior del lienzo, con lo cual, el lugar desde el que se mira el cuadro resulta invadido por la penumbra. Así, el cuadro se ve desde el negro, desde una visualidad signada por el negro y por un espectador que se encuentra a sí mismo parándose en el espacio del negro. Desde la oscuridad, el negro es también una forma de mirada, y se establece un ir y venir entre la mirada desde la oscuridad del afuera y el movimiento del negro al interior del cuadro. Se trata aquí de concebir el negro como un valor visibilizador del que germina y que le da forma la visión; introduce el problema de los movimientos materiales en el cuadro y dispone la reacción de la mirada para la visibilización de esos movimientos.

Ahora bien, los otros elementos, en particular el grupo de figuras, se van generando, amarrando y sosteniendo en esa materia inicial del negro, incluso los que ocurren en el espacio central marcado por el movimiento de rodeo. El movimiento es la manera que tiene el negro de hacer visibles las potencias de violencia y caída que lo habitan, y desde esa visibilidad inicial se da forma a la ocurrencia de todos los elementos, no por un contraste con lo luminoso, ya que acá no opera el principio ordenador del claroscuro, sino por una germinación de lo visible que el movimiento del negro produce. Es una visibilidad que no opera por el reflejo de la luz, sino como palpando en la oscuridad. Es una visibilidad basada en la percepción del movimiento, si se quiere una visibilidad táctil, en suma, una visibilidad enteramente pictórica, de la que se desprende la necesidad de usar las espátulas de caña, precisamente para enfatizar el hecho de que es el movimiento de la materia pictórica el que hace visible, y no una correspondencia o referencia al modelo lumínico.

El movimiento ha ocurrido como hecho de una fuerza implacable e irresistible. No importa si se reconstruye como ráfaga catastrófica desde adentro hacia afuera, o como 
mirada ciega y oscura que va construyendo los elementos, palpándolos en la negrura de su visión. No importa cuál de esas dos direcciones se elija para reconstruir el movimiento al recorrer el cuadro, en ambos casos, el tiempo del movimiento es el origen del tiempo de la duración de cada elemento en el cuadro, una duración que se sostiene y se repite incesantemente en la duración total de la obra. Los elementos no resultan ser inmediatos, sino que cada uno tiene una ocurrencia y esa ocurrencia un transcurrir, un tiempo específico, que es un fragmento resonante del tiempo del movimiento explosivo inicial.

\section{c. La luz modulada como bruma}

¿Qué aparece para ocupar el espacio marcado por el rodeo del negro? Primero aparece la luz modulada como bruma. Hemos hecho énfasis en el hecho de que el fondo cálido de color libera tanto al blanco como al negro, de la función de establecer una estratificación del espacio basada en la relación entre uno y otro, conduciéndolos a una independencia y liberándolos de cualquier correspondencia recíproca. Cada uno es libre para instaurar el valor que le es propio, cada uno hace visible un tipo de movimientos específico, tiene su propia manera de ocurrir en el espacio y su propia manera de integrarse al movimiento general del cuadro. El negro funciona como materia espacializante que posibilita la visibilidad táctil y que tiene unos resultados en términos de mostrar los espacios, de introducir la figura y de situar a la mirada. El blanco aparece como una fuerza de lo sutil, habita el espacio, los resquicios que quedan entre la masa del negro, en la forma de una luz brumosa.

Esta luz no muestra, no define forma. Con los papeles invertidos, aquí la luz es una bruma que oculta, que no deja ver. Tiende a desdibujar a la figura. Luz y sombra son, en este caso, elementos no correspondientes ente sí y absolutamente separados de la forma. Goya ha dejado atrás la manera clásica de hacer corresponder la emergencia de la forma a una relación entre la luz y la sombra. Por el contrario, se trata de una luz que difumina y diluye la forma en un movimiento de lo brumoso. A diferencia del movimiento que ejecuta el negro, introduciéndose como fuerza explosiva del movimiento violento que arrastra hacia la caída, el movimiento de lo brumoso es lento y expansivo: recorre el espacio. El movimiento de la luz brumosa recoge todo aquello que flota en el cuadro, todo lo que se eleva y, al no tener peso, se escapa del arrastre del negro. Marca la dirección de movimientos sutiles que emergen desde detrás y desde las grietas e 
intersticios de la materia pictórica oscura, para, desde allí, dispersarse en el aire del cuadro. Su movimiento se pliega a la fuerza de una presión establecida por la relación entre los planos, desplazándose desde los puntos de mayor presión hacia los espacios más libres. Pero la misma bruma tiene también su movimiento interior expansivo, como una fuerza leve y apenas perceptible, que esparce desaparición y ocultamiento de la forma.

Una especie de viento parece animar el movimiento de la bruma desde su interior y agitarla en diferentes direcciones, haciendo necesario en este punto que aparezca de otra manera el trabajo de las cañas, ya que Goya reparte los blancos de dos modos complementarios: o como veladura repartida con el pincel o como una masa aglutinada, aplicada usando las cañas como espátula y luego rayando la superficie con la misma caña para marcar con una violencia cuidada y sutil, la dirección en que se reparte la fuerza de ocultamiento al interior de la luz brumosa, que, de hecho, no es en ningún caso una sola dirección, más bien, son direcciones que se entrecruzan e interfieren unas a otras. De modo que, en unas ocasiones, la luz funciona como una dirección que arrastra lentamente otros elementos como si los hiciera flotar en un espacio específico del cuadro. En otras partes, las direcciones cruzadas operan como una interferencia que toma el valor de una vibración, una especie de ruido visual que se manifiesta simultáneamente en la masa de la bruma y en el trazo de la mano del pintor, en los movimientos que él realiza con las cañas. Entonces, la vibración resulta ser a la vez visual y manual, o mejor, opera conectando el movimiento de la mano y el ruido visual resultante, construyendo una equivalencia entre lo táctil y lo visual.

Ahora bien, si se presta atención a los puntos de contacto, a las líneas de frontera que marcan el encuentro entre el movimiento de la masa pictórica del negro y la vibración de la luz brumosa, allí se van a manifestar toda una gama de valores, en función del tipo de relación que se establece entre los elementos en cada una de las distintas zonas del cuadro, donde se da ese encuentro. En algunos lugares hay una relación de contraste que implica una forma de influencia recíproca, un incremento coordinado de la intensidad de la fuerza de cada elemento, producido por la resistencia de la contraposición. Goya aprovecha esos contrastes para violentar aun más la materia del óleo que da cuerpo al grupo de figuras, enfatizando la vibración de estas, mientras flotan suspendidas por la luz, en instantes dentro de su movimiento de caída hacia el negro. Para ver un ejemplo de esto, es especialmente evidente en los movimientos de las figuras de los danzantes en 
Baile popular. En otras zonas, se produce una exclusión mutua, y allí va a ocurrir un aislamiento de los elementos que habitan uno u otro espacio, unas zonas de encierro. Como pasa en Incendio de un hospital, donde las figuras claramente están amarradas en la zona de la masa del negro y la luz brumosa marca el movimiento del aire azotado por la intensidad de las llamas. Existe, de hecho, una tercera opción, otras zonas donde negro y bruma se penetran mutuamente, se entrecruzan o, incluso, en unos puntos se funden, en mayor o menor grado, con preponderancia de uno u otro valor, lo que posibilita toda una gama de intensidades que comporta nuevas posibilidades y se hace necesario establecer una especie de modulación de esas intensidades para dar forma a los elementos. Las figuras de Escena de guerra han sido construidas de ese modo. Allí los movimientos que ocurren, tanto en la masa pictórica del negro como al interior de la luz brumosa, no se enfrentan entre sí, sino que se suman unos a otros, lo que puede resultar en una variación de la naturaleza de cada fuerza o en el surgimiento de una nueva intensidad.

\section{d. Los grupos de figuras}

La figura en los cuadros de las cañas nunca es una única figura sino un grupo de figuras. Esto no significa figuras diferenciadas que se relacionan entre sí en una acción narrativa. Al contrario, van a constituir un cuerpo múltiple que funciona como una zona indiferenciada, propicia para la visualización de todas las relaciones y contradicciones entre los distintos movimientos y fuerzas al interior del cuadro. Es la intensidad del movimiento la que hace perder a cada figura su condición individuada y las va aglutinando en torno a unas fuerzas que las hacen funcionar como un cuerpo integrado, cuya multiplicidad interna no se corresponde a la integridad de cada figura o a una adición de identidades, sino a determinados modos de accionar de fuerzas especificas al interior de una masa corporal de sensibilidad e intensidad variable, fluctuante. De esto se desprende que la acción que parecen estar realizando las figuras desde un punto de vista representativo, tampoco es la que determina su movimiento y disposición, ya que el movimiento de este cuerpo solo se rige por el trabajo y el conflicto de los distintos movimientos al interior del cuadro y sus fuerzas correspondientes, de tal manera que la acción representada permanece solo en la superficie como un remanente referencial.

El grupo de figuras es siempre dinámico. Aparece justo en la franja límite entre el movimiento del negro y el espacio centrado que el negro rodea y enmarca, donde ocurre 
la zona de borrado de la luz brumosa. En ese territorio limítrofe, el negro empieza a ser matizado en grises de color que continúan siendo ultra-oscuros y a su vez dan paso a una masa de penumbra que provee el material inicial del que están hechas las figuras. Si se tiene en cuenta el trabajo del trazo de dibujo del negro, que supone el esbozo preliminar que da inicio al movimiento de las figuras, se puede deducir que el movimiento del negro, como fuerza afirmativa que estructura la visualidad del cuadro, es también la fuerza primera de la que se origina la acción del grupo de figuras.

Ahora bien, si se recuerda que ese aquello que el pintor ha visto del que hablaba Bacon, ocurre precisamente en el grupo de figuras, es necesario que el cuerpo múltiple esté sometido a la acción de todas las fuerzas del cuadro, para que su deformación y movimiento hagan visibles las todas las confrontaciones que se generan entre ellas. Resulta, entonces, que para completar el movimiento de la figura se requiere primero de la libre irrupción de los colores vivos, que en estos cuadros aparecen con especial violencia y contundencia material, al ser aplicados y modulados con el uso de las espátulas de caña. Y se requiere también de la acción de la bruma de luz, que completa las figuras, pero deshaciéndolas en la ceguera de su luminosidad velada o en la vibración esquizoide del rayado de las cañas. De esto resulta que los movimientos así generados en el cuerpo múltiple no corresponden a la representación de movimientos humanos, más bien se oponen a dicha representación, la borran y la ocultan. Son movimientos delirantes de un cuerpo pictórico sometido a una violencia que en lugar de destruir al cuerpo lo genera y lo hace nacer del vértigo de su delirio. Se trata de una inversión de valores: de la oscuridad del negro se desprende una visualidad opaca, que hace cuerpo desde el movimiento en lugar de representarlo, mientras que de la luminosidad brumosa se desprende una desvisulización, que deviene generativa de lo pictórico propiamente dicho, lo no representacional. Es dentro de esas condiciones donde la materia del óleo, el color vivo aplicado físicamente como impasto, se hace puro cuerpo de óleo, resistiendo y deviniendo forma, entre la intensidad de dichos movimientos.

Teniendo esto en cuenta se comprende que sea en las figuras donde el trabajo de las cañas se despliega, se vuele frenético y violentamente generativo. La mano se libera de la dependencia o el dictado de lo visual; el rayado se intensifica hasta convertirse en impasto de óleo que es golpeado por las cañas sobre el lienzo, como si fuera el martillo de la fragua. Ahora bien, esto no solo ocurre con el impasto de óleo luminoso y blanco, 
sino especialmente en el impasto de color vivo. La violencia creciente del trabajo de las cañas en el cuerpo del grupo de figuras produce, cómo último delirio, esta materia de color vivo que, al ser aplicada a martillazos sobre el lienzo, termina por resonar en el fondo de color vivo que era la base, anterior a la aparición del movimiento del negro. Esta última vibración producida entre los colores resulta ser, en efecto, una vibración térmica, porque hace resonar la temperatura inicial del cuadro desde el fondo y a través de todos los planos; es como si se trajera a la superficie y al primer plano, el calor de esa calidez original, para que termine de cocinar, por así decirlo, los colores a los que el martilleo de las cañas va dando forma, fraguando. El resultado es que la carne del cuerpo múltiple corresponde, en su momento delirante, a la multiplicidad térmica y cromática del óleo.

Hasta aquí, el recorrido por las series de obras que conforman el trabajo de investigación personal de Goya, ha permitido hacer una justa valoración del funcionamiento y evolución de los elementos pictóricos que interesaron al artista: el gran problema de la figura que ocurre como cuerpo de experiencia formal, que acontece desde la visión oscura y táctil que el negro como valor implica, pero debiendo regresar necesariamente hacia la disolución; el gran problema de la caída de la figura, en particular la caída de la representación clásica de la figura. Esa caída, la vibración de la sensación que ocurre en ella y la producción de cuerpo que implica, eso es lo que Goya quiere pintar. En ese sentido su obra de encargo, que contiene los mismos valores pictóricos, pero amarrados entre las reglas de la representación clásica, se convierte en una constante referencia, un punto de contraste. En sus encargos Goya tiene que pintar lo que la sociedad considera bello y noble; en su obra personal aparece el lado oscuro, no solo porque temáticamente se fije en lo bajo social, sino porque pictóricamente se ve arrojado a los valores de la oscuridad, la violencia de la materia y el colapso de la figura.

¿Qué implicaciones teóricas y conceptuales tiene para la pintura posterior, incluso para la pintura contemporánea este trabajo? A partir de la revisión que se ha hecho hasta aquí de los valores pictóricos, pretendo poner a dialogar lo que ocurre en los cuadros de las cañas con ciertos lineamientos teóricos de autores que han desarrollado una perspectiva vitalista del arte, autores que se definen como herederos de la valoración nietzscheana. El propósito es dejar hablar a los cuadros de Buenos Aires, para que sus elementos aporten algunos puntos de expansión, en la construcción de conceptos alrededor del arte 
como experiencia de sensación. Pero antes de ello, resulta pertinente revisar algunos referentes del profuso análisis que se ha hecho de la obra de Goya desde una perspectiva de su contenido sociopolítico, análisis en el que, por supuesto, existe una amplísima bibliografía. Una sucinta revisión de algunos de los autores más citados permitirá situar esta perspectiva basada en el sentido y el contenido, para luego proponer como comentario alterno, un análisis de los cuadros de las cañas desde otra línea, como se ha dicho ya, pictoricista y vitalista. Una perspectiva que privilegie la sensación sobre el sentido. 


\section{Capítulo 2}

\section{De la idea a lo pictórico}

En su gran mayoría, el abundante trabajo teórico referente a la obra de Goya pone el énfasis en el valor temático de sus contenidos y el valor conceptual de su postura política. Como se analizó en el capítulo anterior, la trayectoria pictórica de Goya se inicia con su formación en la gran tradición del claroscuro español, al que supo matizar y corregir con elementos académicos del neoclásico y además vivificar con los temas y el tono pintoresco del rococó. Alcanzó la cima del reconocimiento de la sociedad española de su época, primero por su trabajo en los bocetos de los tapices de la Casa Real, luego con numerosos encargos para la Iglesia y para miembros de la Corte. Con el tiempo es nombrado Pintor de Cámara de la Corona, título acompañado de un estipendio vitalicio. Pero es en su obra de investigación personal, iniciada alrededor de 1793, donde va a desarrollar los elementos que le llevan a ser considerado uno de los primeros referentes históricos del arte moderno. Más allá de esto, cuando se repara en la relación entre su postura política liberal y humanista con el marcado interés por los problemas sociales de la época y la manera como esta observación se refleja en su obra, fácilmente se puede pensar en un planteamiento muy conceptual y conectarlo con la manera de trabajar que parece caracterizar al arte contemporáneo.

Resulta esclarecedor referir al respecto algunos ejemplos de entre la amplitud de trabajos teóricos, que sirven para evidenciar el énfasis generalizado de los estudios en el análisis ideológico y conceptual de la obra. Mencionaremos algunos de los más ampliamente citados, unos ya clásicos y otros que incluyen una revisión conceptual más contemporánea.

Refiriéndose precisamente a la época de los cuadros de las cañas, Vallentin escribe:

Tal vez es en estos momentos, cuando se repliega en sí mismo e ignora cuál será el porvenir de su país, cuando también se siente muy cerca del pueblo español, del hombre de la calle al que pinta dedicado a sus humildes tareas. Su técnica presagia las vías 
futuras. Se diría que el tema ha liberado a Goya, le ha inspirado audacias creadoras (Vallentin, 1994, pág. 233).

La autora establece una relación entre la libertad temática que implica para Goya el estar realizando una obra de investigación personal, una marcada atención del artista a situaciones que ponen el énfasis sobre las condiciones sociales de la época y la renovación de los elementos estéticos de su obra. Pero más allá de eso, Vallentin encuentra en este desarrollo de características formales de la obra, la manifestación de una profundización de sus ideas liberales y un mayor grado de posicionamiento ideológico:

Liberado ahora de las convenciones, Goya se inclina amorosamente sobre estas vidas oscuras, hechas de grandes esfuerzos y pobres recompensas. En este despertar de su interés hay cierta ingenuidad: descubre por sí mismo el problema social y se apasiona (Vallentin, 1994, pág. 234).

La dirección que toma la interpretación propuesta es clara: la raíz de la fuerza pictórica y expresiva de la obra personal de Goya es ideológica y, además, política; la pintura es catalogada como el vehículo comunicativo de una serie de declaraciones, que tienen esencialmente el valor de un posicionamiento conceptual y social. Incluso los valores pictóricos se encuentran, desde esta concepción, al servicio de la declaración política; hasta las decisiones cromáticas y expresivas van a estar explicadas por el deseo de reflejar adecuadamente una manera de concebir el estado en que se encuentran y las condiciones en que viven determinados grupos de la sociedad.

De hecho, la complejidad del discurso conceptual atribuido al trabajo de Goya va a ir avanzando a medida que se desarrolla la concepción teórica contemporánea. Ya por ejemplo Helman, en especial en Trasmundo de Goya (1983), profundiza sobre las raíces populares que se introducen en el trabajo del pintor y el valor que tiene, a nivel sociopolítico, el hecho de volcar la atención sobre lo oculto y subvalorado de su época y mostrarlo de manera fuerte y directa. Refiriéndose al inicio de la obra más personal, que convencionalmente se ha relacionado con la crisis de salud de 1793, Helman escribe:

En estas obras de capricho, como en la misma crisis espiritual de Goya, influyen los señalados sucesos contemporáneos, la crisis histórica de la Revolución Francesa y los terribles años que le siguen, aquel Terror que desata todas las fuerzas irracionales e inhumanas, latentes en los seres llamados humanos y racionales. El Terror fue, en efecto, uno de los monstruos engendrados por la razón, como lo eran, asimismo, las doctrinas abstractas y visionarias de los filósofos extremistas de Francia (Helman, 1983, pág. 142).

Ya no se trata simplemente de destacar declaraciones sociales reivindicativas de ciertas clases o denuncia de problemas localizados; más bien, el análisis de la autora está 
orientado a establecer paralelos y relaciones cualitativas y condicionantes, entre la obra del pintor y los desarrollos políticos e ideológicos.

Partiendo de este punto, Helman va a desarrollar esta tesis en al menos tres direcciones. Primero, en un sentido de reflexión humanista que sitúa las nuevas posibilidades formales de Goya en relación con la figura humana, como expresión de un discurso reflexivo respecto al fracaso de los ideales liberales y el consiguiente recrudecimiento de la violencia, que afecta a los sectores más vulnerables, tanto en Francia como en España. De otro lado, estableciendo una conexión directa entre los valores expresivos renovadores como el oscurecimiento, la violencia del trazo y el aumento de la expresividad, con un posicionamiento crítico frente a las instituciones que deberían estar liderando la recuperación de la sociedad, muy especialmente los estamentos religiosos. Por último, se postula que la aparición de lo oculto y lo marginal en las temáticas elegidas, tienen que ver con un interés por exponer a la atención de la sociedad aquello que ella misma ha decidido marginar, lo oculto, desde la práctica de brujería hasta el vicio y el entretenimiento más obsceno.

Ahora bien, en el trabajo posterior de un autor como Glendinning va a aparecer, más allá de explorar la relación entre el trabajo artístico y la ideología política o de la consideración de la manera en que la ideología puede influir y tomar forma en las decisiones creativas del artista, toda una teoría respecto a la manera recíproca en que el artista construye posicionamientos ideológicos renovadores desde el interior de su trabajo artístico. En su libro Arte, ideología y originalidad en la obra de Goya (2008), presenta la obra del pintor desde la concepción de todo un aparato ideológico y conceptual, que se va depurando a medida que este desarrolla su trabajo personal, que va a producir el equivalente a una declaración política de profundas repercusiones en el desarrollo ideológico de España e incluso Europa, durante el siglo XIX. Una diferencia que resulta especialmente relevante en la concepción de Glendinning, es que ya no establece, como lo solía hacer la gran mayoría de los autores anteriores, un punto de viraje entre el trabajo de encargos de los primeros años y la obra personal de finales del siglo XVIII. Antes bien, se concibe la obra como el desarrollo de un discurso reflexivo, que desde un principio deja ver posicionamientos políticos claros.

Siguiendo esta línea de pensamiento, Glendinning presenta los postulados esenciales de la ideología que Goya construye, incluso desde sus trabajos para los tapices de la casa real. Se puede leer, en primer lugar, una perspectiva crítica de la monarquía y de las 
clases dirigentes que la rodean, tanto en los motivos en los que introduce cambios sutiles, como en el tratamiento y la manera de presentar a los personajes de cada clase social. Esta perspectiva crítica corre paralela a una revisión de los valores sociales del pueblo español, que Goya va a ir recuperando y construyendo alrededor de elementos temáticos y estéticos renovadores. Son las ideas liberales y humanistas las que van a servir, según plantea el autor, para construir el posicionamiento de Goya respecto a los desastres de la guerra, tanto los relacionados directamente con la invasión por parte de Francia, como las olas internas de manifestaciones violentas que siguieron. A estos postulados, se suma una fuerte oposición a los abusos de la iglesia a través de la acción del Santo Oficio, que tanto afecta a España en la primera mitad del siglo XIX. Finalmente, la conclusión de Glendinning es que Goya parte de unos fuertes postulados conceptuales para construir una plástica original y renovadora, que anuncia los elementos del arte moderno; pero afirma que incluso la búsqueda consciente de dicha originalidad responde a un interés de carácter ideológico, en el sentido de querer producir un mensaje que pueda tener una mejor recepción y mayor repercusión en el pensamiento social de su medio.

Como se ha señalado, estos son solo unos pocos ejemplos de un gran cúmulo de trabajos e investigaciones que establecen las relaciones entre ideología y producción artística en el caso de Goya. No es posible desconocer la validez y pertinencia de estos postulados teóricos, que se desarrollan en una vía acorde con la visión contemporánea de la relación entre arte e ideas, o arte y política. Habiendo señalado lo anterior, se puede pasar a plantear la utilidad -en términos de una valoración de la posición de la pintura en la escena del arte contemporáneo- de añadir a esta manera de concebir el trabajo de Goya una concepción diversa o complementaria, que vuelva a poner el énfasis en lo pictórico en sí, como fuente y eje del trabajo del artista. Para lograr esto, considero necesario situarme en un marco teórico alterno al dominante, que, como se ha referido, hace del valor ideológico-conceptual el punto focal del trabajo artístico. Pasando a una línea teórica del estudio del arte más empírica y menos idealista, como la propuesta por autores tales como Deleuze, Lyotard, Rosset, Sontag o Cacciari entre otros, y valiéndose, además, de las declaraciones de pintores como Cezanne y Bacon, se puede encontrar esa otra mirada que plantea otros valores posibles, enriqueciendo y complejizando el análisis. 
Es posible hacer una síntesis inicial de lo que está implicado en esa dirección teórica diversa, a la que se adscribe esta investigación, planteando que la producción del hecho pictórico se opone a, y solo puede empezar por, el derrumbe de cualquier idea preconcebida o necesidad de transmisión de mensaje o sentido. A partir de esto, la pregunta sería: ¿cuál es el valor que puede tener lo propiamente pictórico, en un entorno como el contemporáneo, donde la producción y reproducción digital de la imagen y el énfasis que se pone el en el valor semántico y el posicionamiento político, dominan el imaginario de la producción artística? Sería necesario, para intentar contestar a esa pregunta, indagar desde el punto de vista de una lógica de la sensación, para identificar algunas características de estos valores puramente pictóricos y más aun, de qué modo pueden resultar pertinentes y relevantes para el arte contemporáneo, a pesar de que supongan una puesta en duda de la hegemonía de la lógica del sentido, que acompaña la conceptualización del arte. Si se propone, desde una mirada que parta de la obra misma, que Goya está interesado en un rompimiento con la imagen-cliché y con cualquier forma de representación, para dar lugar a la presentación del hecho pictórico, entonces se puede mirar desde otra luz las relaciones que la actividad pictórica tiene con el entorno social y político. Se pueden extraer valores conceptuales que van más allá de la ideología o de caracterizar al arte como vehículo o forma de comunicación de un ideario. El esfuerzo pictórico parece encaminado, desde esta luz, a traer los problemas éticos al terreno de la estética, con el fin de enfrentarlos o celebrarlos como puro devenir de los fenómenos, al tiempo que se propone violentar al pensamiento, al hacerlo salir de su zona de confort, es decir, del dominio de la idea y ponerlo a trasegar en los caminos de la lógica irracional de la sensación.

\section{Cuerpo y figura desde la no-representación}

En este propósito de identificar la naturaleza de los valores propiamente pictóricos en la obra de Goya, en particular en los cuadros de las cañas, y para además clarificar la relación entre la producción de ese acontecimiento puramente pictórico y el trabajo del pintor, es necesario referirse a una lista de conceptos que varios autores han desarrollado, como se mencionó antes, que apuntan a entender la pintura en particular, y la experiencia artística en general, como independiente y opuesta de la producción de la imagen/sentido y, por lo tanto, ajena al problema de la representación. Por ejemplo, el

concepto de lo figural, desarrollado por Lyotard, implica un rompimiento de los valores 
figurativo-representativos, que son sustituidos por la presencia de la figura como puro valor pictórico:

La posición del arte supone desmentir la posición del discurso. La posición del arte indica una función de la figura, que no está significada. Indica que la trascendencia del símbolo es la figura, es decir, una manifestación espacial que no admite incorporación por parte del espacio lingüístico sin que este quede alterado, una exterioridad que el espacio lingüístico no puede interiorizar como significación (Lyotard, 1979, pág. 32).

Acá se está oponiendo a la sensibilidad artística la posición del discurso, que se conecta con la construcción o el imperativo del sentido y con la imagen representativa. Cuando Lyotard invita a "tomar partido por lo figural", está implicando toda una declaración de intenciones en relación con el discurso y la lógica del sentido. Lyotard cuestiona la visión trascendente implicada a fin de cuentas por todo discurso, que hace corresponder al mundo como objeto del discurso que lo dice y también como objeto de una significación. El punto de vista del discurso implica, necesariamente, que más allá de la imagen, o mejor, en tanto que imagen, el mundo debe ser leído como el resultado de una significación. La realidad se asimila a un texto a ser leído e interpretado a la luz de su significación; la palabra es la que crea el mundo. Lyotard va a plantear al arte como la evidencia de aquello que se escapa al discurso, la diferencia: "lo dado no es un texto, hay en él un espesor, o mejor dicho una diferencia, constitutiva, que no debemos leer, sino ver; que esta diferencia y la movilidad inmóvil que revela, es lo que continuamente queda olvidado en el significar" (Lyotard, 1979, pág. 29). Ante la oposición planteada por el reino del discurso, que invita a leer detrás de la imagen su sentido, a considerar el mundo como una apariencia a la cual es necesario renunciar para alcanzar el sentido trascendente al que apunta, se hace necesario plantar lo figural, como la continua indicación de que el sentido no agota el espesor de la apariencia; hay una verdad en la apariencia más allá del sentido y la significación, verdad que solo puede ser expresada y experimentada sin alcanzar a ser significada. La verdad de la apariencia es el silencio y la sombra del discurso. De hecho, el discurso mismo posee un nivel en el que ocurre como apariencia y existe con un espesor que lo hace diferir de sí mismo y no ser él mismo reductible por completo a una significación.

El sorpresivo resultado al que arrastra esta constatación es que, a partir de experimentar la incesante diferencia del acontecer de la apariencia, el pensamiento, que tiene su lugar habitual dentro del discurso, es alterado y arrastrado fuera de los límites de la significación, fuera de sus propios límites; el pensamiento es forzado a tantear, a dar pasos de ciego, a arrastrase sobre planos de inmanencia, a crearse nuevas maneras de 
fluir él mismo tras el fluir de la apariencia. Ese sería el valor del arte, llevar el pensamiento fuera de los límites de la lógica del sentido. Pero, para esto, se hace necesario empezar por declarar que el mundo no se agota como imagen de un texto, como ilustración de un texto. Oponer lo figural a la figuración. La pintura se opondría a ser ilustración figurativa que remite a un significado. Deleuze llega a afirmar: "Diría que la lucha contra el cliché es la lucha contra toda referencia figurativa y narrativa. Un cuadro no tiene nada que figurar y nada que contar" (Deleuze, 2007, pág. 65). Un cuadro nunca se refiere a algo externo, como si quisiera dar cuenta de una verdad o de algún tipo de declaración asimilable a un grupo de datos o a una declaración de sentido; desde el punto de vista de la lógica de la sensación, un cuadro nunca significa nada. El cuadro es la ocurrencia de un devenir, un desenvolvimiento puramente análogo de una materialidad de óleo, un acontecimiento que hace visibles las violentas relaciones entre las fuerzas, intensidades y potencias que lo constituyen, que están implicadas en su ocurrencia. Solo desde ese valor del suceder de un devenir un cuadro entabla, posteriormente, relaciones diversas con otras experiencias, incluso con formas del pensamiento y del sentido. Solo secundariamente se puede referir a, o conectar con, fragmentos de discurso o de sentido; solo residualmente puede asociarse a la representación de un modelo, tema o motivo, y ser susceptible de una interpretación en términos ideológicos o conceptuales.

En la misma línea, Bacon habla de su experiencia con la pintura. Dice que el enemigo de la pintura es la imagen positiva que el pintor planea previamente hacer y que el objetivo debe ser, en cambio, lograr "una extraordinaria reelaboración irracional de esa imagen positiva", con miras a "destapar el mayor número posible de niveles de sentimiento" (Sylvester, 2007, pág. 27). Todas estas declaraciones van en la vía de rescatar para la pintura un valor interno e inmanente, la producción de lo propiamente pictórico. La relación que desde los griegos impuso el pensamiento a la pintura al entenderla como mímesis, tiene como última consecuencia que se exija de una obra de arte la referencia a un sentido externo identificable. Representar implica proveer información sobre una realidad externa a la obra misma y siempre manteniéndose en el horizonte de la lógica del sentido. La lectura apropiada de una obra, desde ese punto de vista, implicaría leer los elementos que la constituyen para identificar la información que nos provee sobre aquello a lo que hace referencia. Ya Sontag, en su célebre texto Contra la interpretación (1984), ha denunciado la trampa implicada tanto en atacar, como en defender a la pintura desde la perspectiva mimética. 
Desde una lógica opuesta, la lógica de la sensación, que es afín al concepto de Lyotard de lo figural, un cuadro no representa nada, su objetivo no es proveer información sobre una realidad externa. Antes bien, el cuadro es la producción de un hecho, un acontecimiento creativo, a partir de la sensación de una experiencia, de unos presentimientos, de unas posibilidades; es la producción de un hecho puramente pictórico, un movimiento que implica unas fuerzas o potencias internas inseparables a su propia ocurrencia. Eso no quiere decir que un cuadro no se pueda insertar en un entorno social, ni produzca efectos en el mundo del sentido, al contrario; el caso es que su inserción y los efectos que produce no pueden entenderse como una simple provisión de datos o reproducción de clichés de imágenes dadas, preconstruidas. Teniendo en cuenta que un cuadro es la creación de un hecho particular en relación con una experiencia de la sensación, este tiene el valor de poner en movimiento el pensamiento en nuevas direcciones que lo empujan fuera de los límites de la lógica racional, o como se citaba de Lyotard, poner una y otra vez al pensamiento frente a aquello que queda olvidado y se escapa del significar. Ese es el gran valor que Nietzsche encuentra en el arte: posibilita que el pensamiento se mueva del ámbito al que usualmente se encuentra asociado, esto es, al de la razón y el sentido. ¿Existe un más allá del mundo del sentido? Para Nietzsche la forma de mostrar ese más allá y de conectarse con él, es el arte. El arte es la actividad humana que afirma la vida como puro juego de apariencia, como puro juego estético; esta definición nietzscheana del arte, planteada por Deleuze en Nietzsche y la filosofia (1971), suministra de hecho, el punto de partida para las concepciones desarrolladas por el propio Deleuze, y para todo un grupo de autores que son afines a esta línea de pensamiento, que queremos llamar empírica y vitalista, como los que aquí se citan: Guattari, Lyotard, Sontag, Rosset y Cacciari.

En los cuadros de las cañas lo figural ocurre en el grupo completo de figuras, cuya materialidad es desarrollada desde la ocurrencia del hecho pictórico, haciendo de los cuerpos un solo cuerpo múltiple, cuerpo de óleo, establecido como disposición de elementos que desarma la lógica discursiva. De este modo, lo figural se aparta del procedimiento de referencia y de señalamiento de una exterioridad, que implica el sentido, porque la acción de las figuras ya no es la acción narrativa que se convocaba en el tema, sino la acción de las fuerzas al interior del cuerpo figural, que encarna el hecho pictórico. El cuerpo se instaura, entonces, como zona indiferenciada, aunque estructurada; maquinaria que hace visibles las fuerzas implicadas en su ocurrencia, al tiempo que propone e inserta desplazamientos de sensación en el dominio del 
pensamiento. La presencia de lo figural implica que el problema que Goya pretende tratar se resuelve en la misma manifestación de la figura como experiencia sensible, que se dice a sí misma en su propia presencia. Es inevitable recordar al respecto las palabras del mismo Goya sobre la libertad que encontraba en su obra de capricho, para desarrollar esos problemas de la invención a que no daban lugar las obras encargadas.

Incluso la invitación de Lyotard, que consiste en reemplazar la figura representativa, que corresponde a la forma del sentido por lo figural como forma de la sensación, se compagina también con las declaraciones de Cezanne en su famosa conversación con Gasquet (Doran, 1980, pág. 136), respecto de la catástrofe que expulsa del cuadro las imágenes previas que, de no ser borradas del cuadro, imposibilitan la aparición de lo pictórico. Cezanne también entiende que la pintura nunca ha tenido nada que ver con representar algo externo al cuadro, antes bien, sugiere que el pintor debe derrumbar en el cuadro la imagen preconcebida del modelo, el mundo del dibujo debe hundirse en un cataclismo para que luego pueda nacer un nuevo período verdadero, lo que correspondería a la producción del hecho pictórico. Frente a una manzana de Cezanne o un grupo de árboles, por ejemplo, no estamos frente a una representación de la manzana o el árbol; la manzana de Cezanne solo conserva una "semejanza no semejante" (Deleuze, 2007) con la manzana real; es una manzana puramente pictórica y su presencia moviliza al pensamiento en direcciones que no tiene que ver, para nada, con la manzana real. Si aun se usa la palabra manzana para referirse a ella es solo por un formalismo, una manera de decir; en último término, la referencia a la manzana real persiste solo porque permite constatar cuán lejos se encuentra la manzana pictórica de la primera.

En los cuadros de las cañas el hecho pictórico implica la aparición del cuerpo múltiple, que une en un único flujo de fuerzas al grupo de figuras, para lo que debe extirpar primero la individualidad de cada figura, que se volvería narrativa al entrar en contacto las otras. Una vez conquistado el cuerpo múltiple como señal de instauración del hecho pictórico, los cuerpos son sometidos a la acción de las fuerzas, se hacen materia sensible que responde a las potencias que ocurren en el hecho pictórico, resultantes en intensas deformaciones, en el golpear violento del pintor sobre la materia del óleo (no hay que olvidar que son cuerpos de óleo), y que va a disparar el pensamiento en múltiples direcciones, muy lejos ya de la escena representada. Se puede relacionar aquí el concepto de cuerpo sin órganos (trabajado por Deleuze y Guattari a partir de Artaud, en 
Mil mesetas, 2004,) que implica la anulación de la organicidad de un cuerpo a favor de la deformación, tanto interna como externa, que permite la generación de nuevos órganos. En los cuadros de las cañas, el cuerpo múltiple cumple esa función de anular la organicidad interna de cada figura, con el fin de aglutinar todo el grupo de figuras y, en virtud de la violencia que las fuerzas ejercen sobre su materialidad, no solo pierden sus órganos, en el sentido de que la organicidad del cuerpo se interrumpe, sino que al cuerpo pictórico en su movimiento se le hacen nacer, aquí y allá, cabezas, brazos y piernas, troncos que se contorsionan o que se suman unos a otros. A veces no hay ni cabezas ni brazos, sino que una cabeza es más bien un grito, y ese grito atraviesa los distintos cuerpos del cuerpo total, y pone a gritar a los brazos o a las piernas. O puede pasar que una pierna sea un golpe y ese golpe hace brazos de dolor en otras partes del grupo, o brazos que se ponen a bailar como repercusiones del golpe. Los nuevos órganos no solo son transitorios y móviles, sino que también son órganos compartidos que le pertenecen a la totalidad de las figuras. Este es el tipo de movimientos y el tipo de estados que puede tomar este figural-compuesto, con el que Goya trabaja en los cuadros de la partida X-28.

Ahora bien, la movilidad de flujo que permite la transmutación de unos órganos en otros e incluso el cambio de naturaleza de una figura a favor de lo figural es llamada por Deleuze: devenir. Devenir plantea la relación que se produce entre la disposición de los cuerpos individuales y la actividad de las fuerzas que se los disputan y que ocurren en todos estos nacimientos de órganos transitorios. El concepto se refiere, tanto a la acción de la fuerza que ejerce la deformación, llevada hasta el límite de la transformación, como a la disposición de la materia, en este caso materia pictórica, de plegarse al movimiento de esta fuerza. En pintura, un devenir ocurre cada vez que un elemento del cuadro se acerca a un punto donde dos o más fuerzas se cruzan; un devenir posibilita el encuentro de planos distintos y la influencia recíproca de los planos, que implica diversas formas de traspaso de materia pictórica entre un plano y otro, con el consiguiente cambio de naturaleza o de modo vibratorio de dicha materia.

¿Cómo se sitúa en el cuadro la ocurrencia del cuerpo múltiple? En el hecho pictórico de los cuadros de las cañas, Goya ha llegado a una libertad tal del manejo de las posibilidades pictóricas, para permitir que el flujo de la materia pictórica ocurra por sí mismo, como única condición generativa de las formas y dé inicio a las posibilidades del acontecimiento. En un segundo momento, aparece el movimiento de rodeo que 
desde la mirada transporta la potencia del negro. La relación de sostenimiento que se genera entre estos dos momentos suministra una especie de armazón, que sostiene los planos y permite su diferenciación, es decir, la distancia entre el primer plano y los planos secundarios, el espacio interno en el que sucede el flujo de materia pictórica movimiento que, en general, va desde los planos del fondo hacia los primeros planos-. Esta especie de estructura que aparece plantea una disposición de elementos que, si bien tiende a moverse en una dirección específica, señala en realidad un rango de coordenadas probables y, de este modo, mantiene siempre la posibilidad de variaciones y vibraciones de todo tipo. Así, la estructura del espacio y la ocurrencia del cuerpo múltiple se generan mutuamente, ocurren de modo interdependiente y no puede existir una sin la otra.

De hecho, hay necesidad de esta relación entre producción de espacio y flujo de materia cada vez que varias fuerzas se entrecruzan en una misma porción de materia pictórica, relación que va a consistir en una forma de estructura predictiva de posibilidades de hecho, lo que Bacon define como "una especie de diagrama" (Sylvester, 2007); allí se limpia y marca un área libre del dominio del discurso, en la que ahora puede ocurrir el devenir. Se establecen en cada caso unas coordenadas posicionales, unas líneas posibles de paso y una jerarquía que indica cuáles fuerzas van a dominar y cuáles van a ser dominadas. En los cuadros de Buenos Aires esa relación espacial entre el flujo de materia y la potencia del negro ha situado al cuerpo múltiple en el límite entre el negro y la bruma lumínica, de manera que los cuerpos quedan abiertos a todos los posibles devenires. Pero otras relaciones de diversas intensidades ocurren también al interior del cuerpo múltiple, variando las maneras de conexión de modo que, por ejemplo, los golpes devienen abrazos o los abrazos devienen gritos; pero también los golpes pueden devenir rayados y martillados de las cañas, manchas de color, impastos de óleo, ecos de la temperatura de la profundidad del cuadro, haciendo vibrar la estructura de fondo que sostiene los planos. Brazos, cabezas y piernas en movimiento devienen bruma, desaparición; en la bruma, la luz deviene ocultamiento.

Hasta aquí se ha postulado en forma muy específica, que el eje de la producción de la sensación en la obra personal de Goya está en lo que ocurre al grupo de figuras que deviene cuerpo múltiple. Ahora es necesario aclarar la relación de este cuerpo con el acontecer en el cuadro del hecho pictórico y su relación con los conceptos de fuerza, potencia e intensidad. Sobre este punto voy a aventurar una discrepancia con la 
definición de pintura que ha propuesto Deleuze, ya que podría conducir a una valoración limitante de lo que ocurre en los cuadros X-28.

\section{Fuerzas, potencias e intensidades}

Lo esencial es que en el cuadro ocurra efectivamente el asunto, el acontecimiento, el hecho pictórico, para nombrarlo con la expresión de Deleuze en Francis Bacon. La lógica de la sensación y en Pintura. El concepto de diagrama (1984 y 2007). Es la razón de ser del cuadro, ya que al ocurrir este hecho hace del cuadro algo creativo, vivo, mientras que si no ocurre el cuadro se queda, o como una imagen de pura representación, o como un conjunto de manchas caóticas en las que nada se distingue. El hecho pictórico tiene el doble logro de desterrar la imagen representativa y de arrastrar al pensamiento hacia las posibilidades creativas de la sensación que en él ocurren. Ahora bien, a partir de ahí Deleuze va a proponer una definición de la pintura: hacer visibles fuerzas invisibles, mediante la modulación del color sobre una señal de espacio (2007, pág.168 y 169); y propone que el pintor logra hacer esa modulación al encontrar su propio diagrama, que Deleuze propone como la manera específica que encuentra cada pintor de plantear y graduar las posibilidades dentro de la modulación. Esta definición permite a Deleuze desarrollar una clasificación de las características generales que dicha modulación ha adoptado en distintos momentos la historia de la pintura, caracterizando a su vez el trabajo de los pintores específicos, que estudia como ejemplos.

Ahora bien, la definición resulta un tanto problemática, porque puede conducir a algunas generalizaciones erróneas, que dificultan estudiar un trabajo como el de Goya en los cuadros de Buenos Aires. En primer lugar, decir que pintar es hacer visibles fuerzas invisibles, puede entenderse como una definición bastante vaga, ya que cualquier fenómeno material implica una visibilización o manifestación de fuerzas. Pero el problema principal sería que conduce a la idea de que el trabajo del pintor se refiere a algo que está por fuera del cuadro, como si fuera la manifestación visual o el dar cuenta de un más allá, implicado por las fuerzas invisibles. Esto reintroduce una consideración similar a la de la representación, que pone al cuadro de nuevo en la posición de ser vehículo para mostrar o comunicar algo más. Todo lo contrario, como afirma Bacon, un cuadro no cuenta nada y no se refiere a nada más que su propia ocurrencia, su propio hecho (Sylvester, 2017, pág. 61). Es cierto que en un término posterior esa materia de 
sensación puede entrar en relación con otras, con el pensamiento o con la cultura, influir y ser influido, pero esas relaciones posteriores nunca implican que el cuadro sea una forma de transmisión de un contenido. La pintura no hace visible una fuerza o potencia externa a ella, más bien ocurre como acontecimiento táctil y visual, el hecho ocurre como problema pictórico y por lo tanto como problema del tacto y de la materia que deviene visualidad. Goya remarca este hecho al necesitar de las cañas para alcanzar la intensidad que requieren estos cuadros, el martillado y restregado de la materia del óleo.

Tampoco el pintor busca un diagrama, como si necesitara o buscara generar un sistema con el que modular las posibilidades. Es verdad que cada pintor se interesa por unos muy pocos problemas específicos, dentro del infinito abanico de problemas que la pintura ofrece; cada pintor acecha, revuelve una y otra vez su problema, dentro de una misma zona de posibilidades; pero no porque busque ordenar una formulación, sino porque lo que ha previsto o presentido, el asunto o el hecho de su obra, lo lleva a tantear en una zona específica de posibilidades, a recorrerla una y otra vez, a fin de hacer ocurrir el máximo de hechos posible, dentro de ese problema que lo ocupa. Goya necesita volver una y otra vez sobre ese mismo problema de la caída de la figura, el grupo que surge del negro y vuelve al negro o se deshace en la bruma de la luz. No hay un diagrama como preparación de las posibilidades, porque el pintor trabaja directamente sobre ellas y la pintura ocurre en ese juego de posibilidades sobre las que vuelve una y otra vez.

Con respecto a las fuerzas, es importante reiterar que son inseparables del fenómeno en el que ocurren. El cuadro es la ocurrencia de un hecho que se presenta con sus propias fuerzas, con unas potencias o intensidades que resultan propias al problema que le ocupa. ¿De qué tipo son esas fuerzas, potencias o intensidades? Kafka dice que el arte se hace a causa del presentimiento de unas fuerzas, "las fuerzas de la muerte que están ya, justo ahora, llamando a la puerta" (Wagenbach, 1989). Cezanne describe un momento pre-pictórico, en el que el pintor va al paisaje y se sumerge en el presentimiento del caos que percibe en el fondo de este; dice que vuelve con "los ojos enrojecidos” (Doran, 1980, pág. 135). Desde el punto de vista de la lógica de la sensación, la pintura nunca se trata de representar al modelo, el modelo no es un modelo a seguir y más preciso seria llamarle motivo, como lo hace Cezanne. Así que el pintor se para frente al motivo y presiente la posibilidad de acción de fuerzas ultraviolentas y generativas, que lograrían extraer la experiencia particular, el hecho de sensación, desde 
el fondo del caos. El pintor percibe las fuerzas, no con la visualidad de la imagen común, sino con la visualidad manual de la pintura; prevé en el motivo la posibilidad de ocurrencia del hecho pictórico. Entonces, en el momento de pintar, el motivo tiene que desaparecer ante la acción de las fuerzas, ser borrado como imagen representativa, para luego reaparecer en el hecho del cuadro como materia de la acción de las fuerzas, como una especie de carne pictórica, una materia cuyo flujo produce las formas y genera el espacio y el tiempo del acontecimiento, justamente como Goya lo ha logrado en los cuadros de la partida X-28.

Por este motivo, se pueden señalar y enumerar las fuerzas implicadas en los cuadros de las cañas. Las fuerzas no pueden estar antes del hecho, más bien serían como características y condiciones del hecho y señalarlas es marcar direcciones y vectores específicos dentro del hecho. Primero estaría la potencia espacializante correspondiente al negro, que emerge desde el fondo del cuadro y marca un territorio de recorrido que conecta con el primer plano, para atrapar la mirada y conducirla a habitar el nuevo territorio, el paisaje deformado y desolado, cuya profundidad no se basa en la perspectiva de la imagen, sino en la separación de planos que resulta del movimiento de rodeo que la oscuridad ejecuta. En este territorio, la mirada es obligada a proceder de manera inversa al mirar del ojo que se apoya en la luz, que moldea los contornos de las formas haciéndolas corresponder a distinciones de claro y oscuro, ya que aquí la visión se trasforma en tanteo dentro del espacio no-visual que implica el negro.

Para hacer una correcta valoración de lo que implica la fuerza de la oscuridad en Goya, es posible referirse a la intuición de Rosset sobre una oscuridad semejante, que él encuentra en la obra de Balzac:

El juego de los espejos en el que se agitan los hombres de La comedia humana es solo un breve aplazamiento de la impenetrable oscuridad de la cual la novela los arrancó un instante. En efecto, la noche es el personaje principal de las novelas de Balzac, como también de las de Proust y Céline. Su presencia silenciosa e invisible reina como ama y señora desde el comienzo hasta el final de la obra; y es como un fondo constante sobre el cual se despliegan las luces breves de la vida de los hombres que solo adquieren sentido y relieve en relación con ella (2012, pág. 42).

Como en la obra de Goya, el negro aparece al comienzo y al final de toda acción. Así en los cuadros $\mathrm{X}-28$, es la oscuridad desde la que se mira la escena, la que va a abrir el espacio no representativo, donde la acción de los cuerpos y la violencia que se ejerce sobre ellos forzosamente ocurre como acontecimiento de valor estético; de hecho, los 
cuerpos son arrastrados por la acción en una caída que solo puede terminar en el regreso a la oscuridad.

En efecto, el negro en Goya es la fuerza del movimiento telúrico de tremenda violencia, pero esa violencia funda y estructura el territorio. La visualidad queda entonces sometida a una visualidad manual que implica necesariamente el movimiento: se mira moviéndose, desplazándose, palmo a palmo, por el territorio. El transcurso de movimientos sucesivos con los que la acción manual recorre y construye en forma simultánea el espacio y los elementos, comporta también una nueva manera de condensar el tiempo en el cuadro: pintar es una acción que comporta un tiempo específico y testimonia una duración de la presencia corporal; a su vez, convoca a la mirada a recorrer ese mismo transcurso: el ojo sigue a la mano a través del tiempo del cuadro.

De lo anterior se puede concluir que la acción del negro en los cuadros de las cañas ejecuta una fuerza que determina el hundimiento y colapso de la representación visual, pero a la vez se manifiesta como fuerza generativa de una nueva visualidad. Pero la generación del nuevo universo táctil y pictórico no está completa sin la acción de otras fuerzas generativas. Como contenidas en el interior de la primera fuerza de la oscuridad, estaría, por ejemplo, la fuerza generativa que aglutina a las figuras alrededor de la acción y en un segundo momento la fuerza, paralela a esta, que deriva de la acción la unidad del grupo de figuras en un solo elemento figural. Esta segunda fuerza generativa, derivada de la violencia del rompimiento inicial, se manifiesta ya en la aparición del blanco brumoso y en el trabajo de las cañas y ocurre en la zona limítrofe entre el negro y el espacio interior del cuadro ocupado por dicha bruma luminosa, justo allí donde la acción va a convocar la aparición de las figuras. Porque la acción del cuadro hace necesaria la aparición de las figuras, lo que es inverso a decir que el pintor necesite a la acción como hilo narrativo que justifique la presencia de figuras.

De hecho, uno de los problemas más complejos de la pintura, según Bacon (Sylvester, 2007, pág. 61), consiste en hacer caber a varias figuras, o todo un grupo de figuras, en un único hecho pictórico. Bacon va a decir que el peligro siempre presente es que al haber varias figuras tiende a colarse una narración en el cuadro, y la pintura nada tiene que ver con narrar. De ahí se deriva la necesidad de una segunda fuerza interior que controla las condiciones de generación de las figuras, ya que extrae de la acción misma la unidad de todas las figuras en un solo cuerpo figural múltiple. Goya deja ver el 
trabajo de esa fuerza unificadora porque, en estos cuadros, el movimiento interno de la acción regula el surgimiento, las posiciones y deformidades de las figuras, rompiendo las reglas internas de cada figura y haciéndolas depender de un único conjunto de reglas que rige el movimiento del grupo. La fuerza que genera este cuerpo figural produce una carne común, derretida y maleable, para un único cuerpo múltiple de hombres y mujeres que danzan, que huyen del fuego, que golpean y son golpeados, que hieren y son heridos.

También en la aparición de la bruma luminosa va a ocurrir la acción de otra fuerza, la fuerza silenciosa y sutil que corresponde al trazado repetitivo y caótico en la bruma y que deshace lentamente las otras fuerzas en ella misma, porque las conduce hacia su desaparición en la visualidad absoluta de la luz que ciega. Es una fuerza que emborrona, disuelve y destruye, pero que ejerce su violencia sin brusquedad alguna, la violencia de una lenta caricia.

En conclusión, el cuerpo figural es el eje, el objeto y el ejecutor, al mismo tiempo, de la acción del cuadro, ya que se encuentra atado a la violencia estructural-táctil del negro, pero tiende, en el desarrollo deformante de la acción, a estirarse y deshacerse en la dirección de la luz brumosa, que parece llamarlo a retornar a la indeterminación del caos. El grupo de figuras se tambalea entre no llegar a ser acción diferenciada, quedándose pegado a la violencia del negro o deshacerse en la violencia sutil de la bruma luminosa. Por eso se hace necesario el trabajo de otra fuerza que impida el escape o la desaparición de este cuerpo múltiple, portador de la acción del cuadro y, por lo tanto, del hecho pictórico. Dicha fuerza corresponde a los martillazos de impastos de color vivo, que bruscamente completan el grupo figural y lo retienen en el espacio de influencia de la acción.

Es necesario notar que los martillazos de color establecen un juego de ecos y resonancias cromáticas con el fondo de color de la tela, que se deja sentir detrás del negro, de modo que los colores resuenan atravesando y haciendo vibrar la estructura y cada uno de los planos del cuadro. La recuperación de conexión con el fondo provoca una especie de retroceso, o una recreación, del momento anterior al origen y de la temperatura de color primigenia, porque cada tono de los colores vivos y pastosos, que completan las figuras del cuerpo múltiple, da una medida específica de vibración con relación a esa temperatura. Es, además, paradójico que esta fuerza convocada en un primer momento para fijar las figuras y permitirles resistir a la tensión entre la acción 
del negro y la de la bruma luminosa, en realidad las someta a una nueva violencia. Si bien, en un primer momento, cumple con la función de mantenerlas atadas a la acción, recurriendo a una relación cromática que las conecta y amarra, atravesando los planos hasta el fondo del cuadro, al final se revela como otra tentativa de destruir la unidad de las figuras, ya que la violencia con que las cañas golpean el color parece querer hacer estallar al hecho pictórico en un resonante caos de colores y en una explosión de simple expresividad. Los cuadros de la partida X-28 están justo al límite de la pura expresión abstracta, en la que toda figura se desharía en su propia expresividad.

Llegados a este punto conviene reiterar que la enumeración de fuerzas y potencias internas que ocurren en el hecho pictórico solo pretende marcar unos caracteres que se hacen evidentes después de que hecho ha tenido lugar, que de ninguna manera se refieren a condiciones manipuladas por el pintor previamente. El cuadro ocurre como la experiencia de sensación lo dicta, traspasa al pintor porque este ha presentido, se ha posicionado con una cierta sensibilidad ante su problema. Lo que sigue es precisar las condiciones e implicaciones de dicho posicionamiento para el caso de los cuadros de las cañas, para luego pasar a valorar las posibilidades conceptuales que se derivan de la experiencia del hecho pictórico en términos de producción de sensibilidad.

\section{El posicionamiento del pintor y las posibilidades de hechos}

En este momento resulta esclarecedor volver de manera crítica sobre los conceptos de modulación y diagrama, que Deleuze trabaja en relación con el problema de la pintura, para distinguir lo que de ellos se hace problemático en relación con Goya, pero también porque al revisar de dónde vienen estos conceptos, es posible encontrar unos planteamientos básicos que sirven para orientar la valoración del posicionamiento del pintor y sus repercusiones, en términos de experiencia y de límites de pensamiento, que es uno de los objetivos que se plantea esta investigación. El nombre de su concepto de diagrama Deleuze lo encuentra en unas declaraciones de Bacon: "Los trazos se hacen y tú estudias el asunto como si fuera una especie de diagrama y ves dentro de este diagrama las posibilidades de hechos de todo tipo que se plantean" (Sylvester, 2007, pág. 55). Entonces el punto inicial es que el problema que al pintor le ocupa despliega una serie de posibilidades de ocurrencia del hecho, que son al mismo tiempo posibilidades de intensidades y potencias para cada elemento, en relación con los otros elementos en el cuadro. 
Ahora bien, lo que lleva a Deleuze a conformar el concepto de diagrama es plantear que sobre esta serie de posibilidades de intensidad, el pintor puede graduar y situar los niveles de flujo de los elementos, de manera similar a la que se modula la amplitud de onda o la frecuencia en una transmisión de radio, lo que implicaría que cada una de estas series o líneas de posibilidades funcionará como una escala de variación, conformando un diagrama, una manera de ordenar y relacionar las posibilidades. Esto es solo cierto parcialmente y solo para algunos pintores. Por ejemplo, Bacon parece poner sus figuras sobre esas líneas de posibilidades, para luego probar estirarlas y deformarlas hasta encontrar el punto de tensión que corresponde a su hecho pictórico. Cezanne, por usar otro ejemplo de Deleuze, trabaja a partir de pequeñas secciones de color, parecidas a comas, en las que los tonos y matices van generando una amplia sucesión de gradaciones, muy precisas. Allí, en cierta medida, se puede hablar de modulación; pero, en cambio, los cuadros X-28 de Goya difícilmente corresponden a este modelo de avanzar por tanteo sobre una línea gradual de posibilidades. Aquí los elementos más bien aparecen de manera súbita: la línea de dibujo, el círculo negro, el martillar de los colores vivos sobre el cuerpo de figuras. Los elementos surgen ya definidos, con una violencia e intensidad que dan la sensación de una tremenda lucha entre ellos por el control del cuadro. Esto está relacionado con el hecho de que, en los cuadros de las cañas, Goya ha llegado a la necesidad de plantearse y hacerse disponibles un nuevo tipo particular de posibilidades de hecho, distinto al que empleaba en sus cuadros de encargo, que debían apegarse en mayor medida a los cánones de la representación clásica. No se trata solo de que aparecen un nuevo conjunto de elementos pictóricos, sino de que el hecho pictórico solo puede ocurrir desde una línea de posibilidades nuevas y particulares, pero que no se ajustan al esquema de la modulación. Los cuadros de las cañas instauran las posibilidades de una nueva violencia pictórica que se ejerce sobre un cuerpo múltiple que ya no corresponde a las coordenadas de la representación. Esta violencia significa, no la deconstrucción o deformación de las coordenadas de la representación, sino la generación creativa de un nuevo tipo de visualidad.

En efecto, más que intentar confeccionar un diagrama para su trabajo, el pintor es forzado por su previsión del hecho a adoptar una forma específica de posicionamiento: una disposición a favorecer un cierto tipo de posibilidades, una manera particular de conectarse con las posibilidades del hecho y trabajar con ellas para hacer posible su aparición. Además, la postura que el pintor adopta implica la primacía de unos 
elementos sobre otros, ya que entre los distintos elementos y las posibilidades de hechos asociadas a ellos se establece un tipo particular de relaciones de valores, de jerarquías de peso e influencia. Se constituye una jerarquía interna de los valores en el cuadro, resultado de los elementos y fuerzas que tal o cuál posicionamiento favorece.

Si bien en el caso de ciertos pintores, resulta útil entender el posicionamiento que adoptan en relación con los conceptos de modulación y diagrama, y en el caso de otros no parece funcionar, lo que sí se hace fundamental -y este es el punto básico de partida tanto para Deleuze, como para todos los autores de esta estética vitalista de la que venimos hablando- es que la pintura debe oponerse siempre a la representación y al cliché. Para ello se necesita primero introducir una bocanada de caos, que conduzca al derrumbamiento del mundo visual pre-pictórico -el de la imagen dada, el discurso y el sentido- que permita luego el surgimiento de un nuevo orden, propio al caos, que sería un orden puramente pictórico. ¿A qué se refiere esta imagen dada? Desde el punto de vista de Deleuze, se refiere a la representación de ideas: “¿Qué son las ideas completamente hechas de la pintura? (...) Existe una palabra que se ha impuesto para designar aquello de lo que está llena la tela antes de que el pintor comience: cliché. La tela ya está llena de clichés" (Deleuze, 2007, pág. 55). De modo que, al enfrentarse a la tela aparentemente blanca, el pintor en realidad se enfrenta a una serie de ideas hechas. Tienen que ver, en primer lugar, con la información representativa que suministra el modelo y con todos los datos asociados a cómo debe verse la imagen de tal o cual tema. Pero estas cosas no tienen nada que ver con el surgimiento de un orden puramente pictórico que posibilite, desde una lógica de la sensación, la nueva forma de experiencia a la que el cuadro apunta.

¿De qué se trata un cuadro? ¿De qué se tratan por ejemplo los cuadros de las cañas? Al mirar los cuadros de Buenos Aires, podemos ver cuatro escenas: unos hombres que se flagelan ante la multitud reunida para una procesión, el incendio de un hospital, bandoleros atacando a un grupo de personas en el campo y un baile popular. Estos serían los temas en apariencia, pero, al mismo tiempo, se tiene la sensación clara de que los cuadros se relacionan íntimamente entre sí, como si se trataran de lo mismo. ¿Por qué? Porque la manera como Goya ha pintado los cuadros induce a la conclusión de que no estaba buscando una representación más o menos fiel de cada escena en la realidad; estaba pintando otra cosa, un hecho puramente pictórico que él tenía que hacer ocurrir, o al menos intentar hacer ocurrir en el cuadro. En todos estos casos el pintor ha previsto 
algo, una posibilidad de que algo le ocurra a la figura, una violencia por ejercer, una caída. Solo así se entiende la aparente variedad temática de las escenas, que en realidad funcionan como coordenadas de punto de partida y cuya relación inicial con el modelo en el mundo real es necesario destruir.

Teniendo eso en cuenta, se hace evidente la razón por la cual, desde el primer momento, el posicionamiento del pintor implica necesariamente la entrada de una bocanada de caos.

El momento pre-pictórico: clichés y nada más que clichés. La necesidad de un diagrama que va a remover, que va a limpiar el cliché para que de ahí salga algo, siendo el diagrama solo una posibilidad de hecho. El cliché es el dato, lo que está dado. Dado en la cabeza, dado en la calle, dado en la percepción, dado por todas partes. Ven entonces que el diagrama interviene como lo que va a remover el cliché para que la pintura salga (Deleuze, 2007, pág. 60).

Se hace claro, entonces, el propósito de que el caos provoque el derrumbamiento y el emborronamiento del cliché representativo: que la idea preconcebida, la imagen dada, incluso esa imagen original que pueda tener el pintor en su cabeza tiene que colapsar y ser arrastrada fuera del cuadro. La razón es que la representación de cualquier idea, puesta como finalidad de la pintura, imposibilitaría el acontecer del hecho pictórico y el cuadro estaría muerto.

De otro lado, existe, también, el riesgo opuesto de que el caos se tome todo el cuadro y lo estropee, que se vuelva una masa informe donde no ocurre el hecho pictórico. Es por eso por lo que pintar es tan difícil y el pintor tiene que atravesar por un camino de abismos a lado y lado, siempre con el riesgo de que el cuadro se malogre. Se tiene que lograr el establecimiento de posibilidades de hecho para que las formas del cuadro ya no se adecúen a formas preconcebidas, ni a ningún tipo de datos externos; solo van a deformarse y reformarse en función de las fluctuaciones de las fuerzas que ocurren en la experiencia, al interior del cuadro mismo. Entonces sí ocurre el hecho pictórico.

En los cuadros de Buenos Aires Goya logra la irrupción del caos, el derrumbamiento del cliché representativo y la generación de unas condiciones iniciales, que sostienen las posibilidades de hecho, mediante el uso del negro. Primero está el color vivo que proporciona la temperatura inicial. Funciona como una plancha de fundición para los elementos. Pero aun sobre ese color vivo podría tenerse la tentación de recurrir a la representación. Para conjurar este efecto Goya recurre a la irrupción del negro, que viene desde el fondo, arma una especie de estructura y termina saliendo por los bordes 
del primer plano. Esta irrupción del negro implica el fin de las posibilidades representativas: ya el cuadro se tiene que tratar de otra cosa, algo pictórico tendrá que ocurrir. Pero el otro riesgo está en que el negro terminara tomándose todo el cuadro, lo que significaría que el caos lo ocupa todo y el posicionamiento del pintor no logra hacer germinar el hecho pictórico; el cuadro no sería más que manchas terriblemente oscuras.

De modo que el negro aparece como fuerza caótica que derrumba los preconceptos representativos y al mismo tiempo como fuerza productora espacializante, que instaura un nuevo tipo de mirada. Lo logra al invadir el espacio del primer plano y rebosarlo, ocupando así el plano externo desde donde el cuadro se mira. También es cierto lo contrario, porque el movimiento puede interpretarse en el otro sentido: el negro parte desde afuera, desde la mirada, ejecutando un movimiento hasta el fondo. Ver desde el negro, desde el ocultamiento, con un modo de visión pictórica que posibilita el tantear en la oscuridad como nueva manera de ver y que implica toda una inversión de valores que sustituye lo visual por manual. En el dominio de la representación se quiere hacer corresponder el cuadro al imperativo de la mirada, y para eso se usa la luz que recorre los contornos de los elementos y los fija en el lugar de la forma correcta, lo que la mirada espera ver. Con el negro, Goya destierra la mirada como si tirara un puñado de tierra, en todo caso tierra de óleo, en el ojo que mira el cuadro. Es en ese punto donde se corre el riesgo de que la mirada se quede ciega y el cuadro se vaya al abismo, entonces es necesario hacer nacer del negro una nueva forma de visualidad que va a consistir en palpar lo que ocurre en el óleo. La mano enseña al ojo a ver de nuevo.

¿Qué es lo que nace de allí? ¿Qué es lo que va a hacer germinar esta visualidad manual? La correspondencia entre el cuerpo múltiple y la ocurrencia de fuerzas espacializantes. El negro destierra la representación e instaura una forma de ver manual y una estructura relativamente blanda que asigna los planos de espacio. Pero para que germine el hecho pictórico de la relación entre cuerpo y fuerzas, es necesario el uso de las cañas. Soltar el pincel y empuñar la caña revela, como también lo hace el uso del negro, el esfuerzo consistente por liberar a la mano de la dictadura del ojo, invertir la dictadura para que la visión siga a lo manual. Con las cañas se multiplican las posibilidades, se abre el rango de variación de la intensidad del trazo, del movimiento y de su vibración interna. A partir del trabajo de las cañas se instalan zonas de intensidades aumentadas, nuevas posibilidades de variación. De un lado, la variación del trazo puede llegar hasta un rayado casi aleatorio, donde la mano se desboca a la deriva o se tranza en movimientos 
repetitivos insistiendo, una y otra vez, en un mismo punto del cuadro. De otro lado la violencia del óleo martillado sobre lienzo; el pigmento más grueso que es restregado en la superficie y maltratado bajo la acción punzante y destructiva de la caña, allí donde, justamente, esa materia de óleo empastado corresponde a la carne de los cuerpos sometidos a las fuerzas generativas y deformadoras en el cuadro.

\section{EI hecho pictórico como producción de lo sensible}

¿Qué es lo que se busca producir la pintura? ¿En qué consiste el hecho pictórico? Si se toma, por ejemplo, el caso de Cezanne, él va a decir que el cuadro empieza por una estructura, posterior a la catástrofe que supone cortar con la imagen representativa. Describe esa estructura como el establecimiento y sostenimiento de los planos del cuadro, surgida de una geometría de la tierra. Lo que ocurre es que ha visto unos problemas específicos, unas posibilidades de hecho. El hecho pictórico no ha ocurrido, pero ya es posible en la tela gracias al borrado de las imposturas representativas previas y al surgimiento de, lo que él denomina, una estructura. Entonces sí surge el hecho:

De súbito una lógica aérea, coloreada, reemplaza la sombra, la terca geometría. Todo se organiza, árboles, campos, casas. Veo. A través de manchas. El cimiento geológico, la labor preparatoria, el mundo del dibujo se hunde, se desmorona como en una catástrofe. Todo desaparece y se regenera por la obra de un cataclismo. Nace un nuevo periodo. ¡El verdadero! Metido en él ya no hay nada que se me escape, todo es denso y fluido y a la vez natural (Doran, 1980, pág. 157).

En esta etapa empiezan a surgir todos los colores en escalas de grises, pero aclara que son grises vivos del color, los agrisamientos que surgen de mezclar un color con su complementario y jugar con las variaciones de tonos y matices. Cezanne dispone estos grises de forma tal que funcionan como múltiples escalas ascendentes o descendentes, que se van a desplegar a través del cuadro, creando líneas de fluido de variación, es decir, una modulación de color en el sentido más físico e inmediato. Pero de ningún modo se puede sacar de allí una fórmula de la pintura. Es verdad que, en el caso particular de Cezanne, su problema, se relaciona con una estructura de dibujo, que le sirve para separarse de la imagen representativa y que sostiene y distribuye los planos del cuadro, y se arma una especie red de casillas para la gradación del color. Esos son los problemas de Cezanne, lo que él ve. En otros pintores hay otros problemas y las cosas pasarán de otro modo, pero lo que importa es que esos asuntos problemáticos que 
interesan a cada pintor lo conducen a adoptar una cierta posición, y ese posicionamiento lo conduce a un tipo específico de posibilidades de hechos.

En el caso de Goya en los cuadros de las cañas, parte de un color cálido de fondo y usa el negro para esbozar el espacio y las figuras, con una línea de dibujo que se aparta de la representación para favorecer la libertad expresiva. También el negro aparece como esa masa que hace un rodeo, dejando al cuadro ser visto desde la penumbra. Pero, a diferencia de Cezanne, Goya no usa el negro para armar una estructura de planos que prepare el espacio para las secuencias de tonos de color; más bien usa la distancia entre el fondo cálido y la masa de penumbra negra que rodea desde el primer plano, para dejar que el flujo de materia vaya produciendo espacio y construyendo las figuras a medida que surge. En los cuadros de la partida X-28, específicamente, alcanza una completa potencia y libertad esta producción por el flujo de la materia de óleo, y Goya consigue una pintura intensa, violenta y muy directa. El predominio del flujo de materia conduce a imponer la visibilidad táctil, manual, que se refiere a la lectura que hace el ojo de la intensidad de la acción de la mano y el cuerpo del pintor, que queda registrada en la violencia ejercida al aplicar el óleo en el soporte. Es en este punto donde se conecta lo que pasa en Goya con las palabras de Cezanne, que refiere ese momento en que se instalan las posibilidades de hecho como un nuevo modo manual de la visión: "veo, a través de manchas"; y dice que ya en el momento del aparecimiento del hecho pictórico "todo es denso y fluido". Usando las posibilidades de hecho que se abren desde el posicionamiento que le marca su problema específico, el pintor arma zonas de fluido que la materia de óleo física y manualmente va a recorrer, donde los diferentes niveles de densidad del óleo ofrecen grados distintos de resistencia y potencia, expresados en el movimiento y tanteo de la mano. La intensidad de ese nuevo periodo, "el verdadero" lo llama Cezanne, que corresponde al acontecimiento del hecho pictórico, puede llevar al pintor a instancias extremas, como pasa en el caso de Goya al cambiar el modelado del pincel por el rayado y golpeteo de las cañas. Concretamente, en el uso de las cañas Goya hace coincidir el color y la luz en una variación especifica de la intensidad de la fuerza. Las cañas ejercen una violencia que se hace particularmente palpable en el óleo, a partir de la cual se construyen variaciones y movimientos que dan sustancia y suceso al hecho pictórico.

Ahora bien, ya se comentó que fue Bacon quien, hablando de su caso particular, llamó diagrama a la línea de posibilidades que se abren con el derrumbamiento de la imagen 
representativa, y que Deleuze designa como un orden correspondiente al caos (2007, pág. 91). Concretamente, Bacon relaciona esa invocación del caos con la actividad del azar, pero aclara que deberá conducir a un nuevo tipo de orden; dice: "Yo quiero una imagen muy ordenada, pero quiero que venga por azar" (Sylvester, 2007, pág. 43). Su procedimiento parte de hacer tachones y marcas, alejarse lo más posible de las intenciones representativas. Pero ¿cómo se llega de ahí a un orden? ¿Cuál sería la forma y cuáles las características de dicho orden? Es aquí donde va a aparecer la idea de diagrama: "Los trazos se hacen y tú estudias el asunto como si fuera una especie de diagrama y ves dentro de este diagrama las posibilidades de hechos de todo tipo que se plantean" (Sylvester, 2007, pág. 55). Se abre ya la posibilidad de que aparezca el hecho pictórico, eso que va a ordenar la imagen usando las fuerzas del azar. Bacon pasa a poner un ejemplo que explica ese proceso:

Si piensas en un retrato, puede que en un momento hayas puesto la boca en alguna parte, pero de pronto veas a través de ese diagrama que la boca puede ir cruzando la cara y, en cierto modo, te gustaría mucho poder hacer un Sahara de la apariencia en un retrato... hacerlo muy parecido, pero como si tuviese las distancias del Sahara" (Sylvester, 2007, pág. 44).

Entonces, lo que Bacon llama diagrama se compone de unas líneas de posibilidades, sobre las cuales él puede modular o graduar la deformación de sus figuras, y estas, necesariamente, van a comportarse de manera elástica y fluida. Es de ese material del que físicamente están compuestas las posibilidades de hecho, que Bacon procede a graduar y a situar. De nuevo, haciendo la comparación con Goya, vamos a encontrar que sus problemas son distintos, ya que, en su caso, las marcas expresivas del dibujo y el flujo de materia de óleo en las figuras corren con completa libertad y fuerza, y no se determinan entre sí; de modo que no hay una gradación de color, como en Cezanne, ni una modulación de la deformación de la figura, como en Bacon. Solo el flujo de la materia le da, de manera directa y violenta, forma al cuerpo de figuras, que es el centro del problema del cuadro. En esa libertad del flujo y de la línea, es donde se puede situar el "orden correspondiente al caos", en el caso de Goya.

Por otra parte, un orden correspondiente al caos difiere necesariamente de un sistema de equivalencia, formado desde la lógica del sentido que hiciera corresponder una serie de variaciones de signos codificados a una específica lectura semántica. Por el contrario, se trata de una estructura más o menos flexible, que se constituye con base en amarres transitorios y fluctuantes, usando líneas de fuga planteadas desde el rompimiento generado por la irrupción del caos. Es, por utilizar una forma decir, un orden siempre 
desordenado, el orden en el desorden, que se conecta a una lectura de las series de variaciones al interior de la sensación y constituye una lógica de la sensación. ¿A dónde apunta el esfuerzo por alcanzar ese tipo de orden? Bacon responde: “ ¿No se trata de que quieres que una cosa sea lo más real posible y al mismo tiempo profundamente sugestiva o que abra profundamente áreas de sensación distintas de la simple representación del objeto que pretendes hacer? ¿No consiste en eso todo arte?” (Sylvester, 2007, pág. 44). Así, el hecho pictórico solo responde a las necesidades expresivas de la lógica de la sensación.

Otro aspecto llamativo es que a Bacon parece preocuparle que solo pueda usar una figura aislada cada vez y no integrar varias en un mismo hecho:

Creo que desde el momento en que aparecen varias figuras, entras automáticamente en el aspecto narrativo de las relaciones entre figuras. Eso crea de inmediato una especie de historia. Siempre conservo la esperanza de conseguir hacer un cuadro con gran número de figuras sin una historia (Sylvester, 2007, pág. 57).

Es evidente que el gran enemigo de la pintura es, para Bacon, el contenido narrativo, porque pintar no es ilustrar una idea y un cuadro no tiene nada que contar o narrar. Un cuadro busca hacer posible la ocurrencia de un hecho, que genere y explote expansivamente, nuevas líneas de sensibilidad. Si se introduce la narración se reintroduce el cliché y a Bacon le preocupa mucho lo que ocurre al poner varias figuras juntas. Él trabaja aislando las figuras para lograr desarmar su organicidad y reducirlas a zonas maleables, aptas para el traspaso de las fuerzas.

En cambio, lo que ocurre en los cuadros de las cañas es que se conjura toda posibilidad de relaciones narrativas entre figuras independientes, porque las transformaciones y variaciones de cada figura participante, son una manifestación de la experiencia de un único cuerpo múltiple. Es la experiencia de este cuerpo, no el resultado de un contenido narrativo, lo que unifica a las figuras. Resulta reveladora la declaración de Faure sobre la pintura de Goya:

Los grupos aparecen inesperadamente distribuidos por un certero instinto armónico, entre bloques de sombra, luces refulgentes y sutiles transiciones que graban en la memoria formas no muy bien definidas, pero sí una alucinación persistente: como un fluido cuya sustancia se deslizara por doquier, revelando la vida interior en la negra cavidad de un ojo, en la curva de un hombro, en un brazo enhiesto (Faure, 1994, pág. 322).

Resulta muy precisa la enumeración que hace el autor de los elementos que encuentra como característicos de la pintura de Goya en su madurez, elementos que se pueden encontrar plenamente configurados en los cuadros de Buenos Aires. De hecho, la acción 
de las cañas hace notar de manera más contundente, el fluido de esa sustancia que se desliza en el continuo devenir del traspaso de las fuerzas entre los elementos, revelando la vida interior que corresponde, en la lógica de la sensación, a la instauración de la experiencia interna del cuadro. Incluso Faure señala las dos vertientes desde las que se puede abordar la producción de lo sensible en estos cuadros: de un lado, pone de relieve la acción del negro que parte desde la mirada y recorre de afuera hacia adentro en un movimiento de rodeo; de otro, las deformaciones y variaciones de los miembros del cuerpo múltiple; brazos, piernas, cabezas, todos en movimiento, envueltos en una ráfaga de deformaciones violentas, que conducen a la figura a la aniquilación, entre las luces refulgentes, el trabajo sutil de invisibilización por parte de la luz brumosa.

En comparación con el fluir natural de la violencia que Goya parece conseguir al interior del cuerpo múltiple, resulta sorpresivo que Bacon encuentre tanta dificultad en pintar grupos de figuras sin que aparezca un componente narrativo. La respuesta al parecer radica en que el punto de partida de Bacon es el aislamiento de la figura. Mientras que, en el caso de Goya, es precisamente a partir del establecimiento del cuerpo múltiple desde donde se anula el componente narrativo, pues las figuras son despojadas de su especificidad individual y de su organicidad, en favor de la fluctuación de las fuerzas en el grupo.

A partir de este entendimiento se hace posible, y resulta útil, valerse otro concepto formulado por Deleuze y Guatari, en Mil mesetas (2004) que ellos han aplicado a la creación artística: el de acontecimiento, que en este contexto se puede hacer corresponder a la noción de hecho pictórico, y puede imaginarse como un nodo o eje conector que permite el traspaso de fuerzas de un plano de inmanencia a otro. En virtud del acontecimiento, un elemento cualquiera puede mutar la especificidad de su valor y establecer conexiones y flujos con planos que le eran ajenos a su naturaleza en primer término. En el acontecimiento un elemento puede atarse a otro elemento de naturaleza distinta, lo que transforma el valor de ambos y permite el traspaso de fuerzas entre los planos distintos a los que cada uno pertenecía inicialmente. Puede imaginarse como un choque de dimensiones, que genera una alteración en las leyes físicas de cada dimensión, provocando anomalías, deformaciones y fluctuaciones en las escalas de valores de cada dimensión. Esta es la razón por la que la experiencia artística puede movilizar el pensamiento hasta los límites del sentido y atravesarlos: porque se vale de la experiencia de la sensación de unas determinadas fuerzas para crear transvaloraciones 
que van a movilizar el pensamiento hacia lo que antes no podía ser pensado, por hallarse fuera de determinados límites de valoración.

Ya en su libro de 1984 sobre la obra de Francis Bacon, Deleuze (1984, pág. 72) establece una relación entre acontecimiento y pintura a través del accidente: el acontecimiento en la pintura va a estar relacionado con el remplazo de la representación, por el movimiento de caída y la deformación a la que es sometida la figura en el accidente. La forma pictórica habla, no sobre la esencia de un modelo a representar, sino sobre el continuo de fluido y cambio que ocurre en el accidente; la forma pictórica crea las reglas, puramente estéticas, que hacen del accidente, como acontecimiento, un caos ordenado sobre el traspaso vibratorio de las fuerzas.

En los cuadros de las cañas, la sensación construye cuerpo y, simultáneamente, es continuidad en el devenir de los cuerpos. El cuerpo múltiple funciona como nodo o eje del traspaso de fuerzas entre planos distintos. De un lado, se tienen inicialmente unas figuras y una acción a representar, luego una catástrofe de la representación en la irrupción del negro que transforma los valores internos de la noción de visualidad, desde lo representativo hacia lo manual, como índice de la fluctuación de la experiencia. La acción inicial desaparece a favor de la visualización de otra acción, la caída del cuerpo en la violencia del accidente, del hecho pictórico. Esta es la potencia del acontecimiento.

\section{Hacer pintura a martillazos}

En este punto se pueden empezar a concretar valores conceptuales particulares, que corresponden a la caracterización del hecho pictórico en los cuadros de la partida X-28. Primero hay que resaltar la sensación que tiene el pintor de que el pincel no alcanza para transmitir la intensidad específica para este grupo de cuadros; el uso de las cañas implica una forma particular de intensidad. El tipo de acción manual sobre la masa de óleo que se consigue al trabajar usando las cañas, su fuerza particular y la violencia que ejerce sobre la imagen, dan cuenta de la calidad y potencia de las fuerzas implicadas en el hecho pictórico. En segundo término, es necesario hacer notar la relación entre el trabajo de las cañas y el uso del negro, como el otro elemento primordial que participa de la constitución de estos cuadros. El negro es un elemento que está en el centro, no solo de esta pequeña serie, sino de toda la producción pictórica personal de Goya. El 
negro como valor y potencia constructiva, que ejerce la creación en forma de una violencia tenaz. Una violencia creativa, productora de actos de vitalidad. Además, el uso del negro permite a Goya situar la mirada del cuadro desde la penumbra, lo que genera una visualidad que no se corresponde a la de la representación, es más bien, la visualidad que la mano enseña o impone al ojo. Como lo dice Faure, refiriéndose a la relación entre la categorización que hace Goya de la mirada y las posibilidades generativas de la violencia que ejerce:

Los ojos son unos agujeros de sombra abiertos por el indefinido pensamiento. Esto ya lo había visto Velázquez. Goya acrecienta el misterio, pues su forma es instantánea, una impresión fulgurante, un instante rápido y hondo fijado en un parpadeo, una sombra ardiente que acumula sobre el segundo furtivo cuantas fuerzas recónditas y espontaneas existen (Faure, pág. 327).

En un solo movimiento intenso y violento, el negro de Goya destroza y destierra el cliché de la representación, fija los elementos en el sostenimiento de una estructura visual basada en la acción de la mano sobre la materialidad del óleo y hace explotar sobre ella la acción de fuerzas recónditas, las fuerzas invisibles que convierten a la pintura en una zona indeterminada de producción de sensación. Como también señala Faure, aquí el pensamiento se encuentra en un estado de indefinición: tras la catástrofe de la idea, el pensamiento queda como suspendido a la espera del hecho pictórico, al que luego se va a enfrentar, no como un contenido de datos informativos, sino como una experiencia perceptual y afectiva que lo hace explotar hacia líneas de fuga que recorren aquello que se escapa al dominio de la lógica del sentido. En resumen, en Goya el negro es bocanada de caos, fuerza constructiva, y, al mismo tiempo, acción de visualidad manual, que da lugar al nuevo tipo de generación de la experiencia que su ocurrencia implica.

El problema específico que Goya enfrenta en estos cuadros es encontrar algo que se pueda contraponer a la violencia visual y generativa del negro, para evitar que esa única fuerza se tome todo el cuadro, a fin de hacer lugar para la acción, tanto de la luz como del color, de modo que se pueda avanzar desde el simple ejercicio de una fuerza creativa y lograr el hecho pictórico en toda su compleja interacción de fuerzas de intensidades variables. Aquí es donde encaja el trabajo de las cañas. Se trata de una forma de manipulación que somete al óleo a intensidades distintas, el óleo es martillado sobre el soporte, rayado, rasgado. La acción de las cañas funciona a favor de la transmisión de la vibración interna de los elementos, que, en virtud de esa acción, se traspasa de unos elementos a otros constituyendo un ritmo específico. 
En este sentido es pertinente tener en cuenta las ideas sobre el papel del ritmo y la vibración que aporta Bacon y la definición del carácter manual de la modulación expuesto por Cézanne, postulados que Deleuze recoge (2007, pág. 89-93). Este carácter manual implica un conflicto y un traspaso de poder entre el ojo y la mano dentro de la acción pictórica. En un primer momento existe una imagen dada, que es el cliché de cómo debe pintarse tal tema. A veces este cliché se encuentra en la idea previa del propio pintor. Entonces en este primer momento la mano trabaja como sirvienta del ojo, pues la visión le dicta a la mano el camino a seguir para la imitación de la idea. Tanto Cézanne como Bacon, hacen énfasis en la necesidad de derrumbar y desterrar del cuadro esta idea-cliché, que se traduce en el dominio previo de lo visual. Es necesaria una revolución de la mano, una mano que, a partir de la irrupción de una bocanada de caos, encuentra el carácter de su propia vibración. Esta acción reconfigura las relaciones de poder al interior del cuadro y ahora es el ojo el que tiene que seguir la mano, lo que desemboca en la construcción de una nueva forma de mirar, ya libre de la tiranía de la imagen-idea, una mirada que persigue la vibración y el ritmo del cuadro, porque encuentra allí la forma visual que construye el aparecer de las fuerzas que se enfrentan o se ponen en juego en cada cuadro.

Es necesario enfocar y clarificar muy bien la relación entre el traspaso del dominio de la visión del ojo a la mano y la instauración de una visión manual y la importancia que toma la vibración; porque la vibración es el resultado material y perceptivo de la acción de lo manual: el trabajo pictórico recorre la materialidad del óleo, los planos del cuadro y los elementos pictóricos, únicamente en forma de vibración. Ahora bien, el resultado natural del trabajo de la vibración es la producción del ritmo. El ritmo trabaja como una forma de señal afectiva y perceptiva, que se traspasa indistintamente de un plano a otro, estableciendo territorios comunes entre los planos, aunque estos permanezcan más o menos separados por el sostenimiento estructural del cuadro. Pensar un territorio así construido por la acción del ritmo, conecta con el concepto de rittornello de Deleuze y Guatari (2004, pág. 313), ya que la vibración del cuadro se equipara a la tonada o cancioncilla que se repite y que construye el territorio que siempre regresa, a partir de su ritmo. Ese espacio que retorna, que continuamente vuelve territorio habitable la experiencia de la acción de las fuerzas, se encuentra en la base de toda creación artística. 
Con este concepto presente, para clarificar la naturaleza y el valor de la producción afectiva y perceptiva del trabajo de Goya con las cañas, es posible referirse también a las investigaciones de Bateson sobre las diferencias entre el lenguaje analógico y lenguaje digital, entre la transmisión relacional de la experiencia y la transmisión a través del código. En especial en Pasos hacia una ecología de la mente (Bateson, 1998), se parte de la diferenciación entre lo que ocurre al querer transmitir un contenido analógico, que se define como un continuo físico y fluido de variaciones, comparado con la codificación que hace un lenguaje digital de cantidades discretas, que pretenden traducir solamente intervalos de dicho flujo. Ahora bien, Bateson dice que el lenguaje digital, como todo lenguaje humano hablado y escrito, es un sistema que se basa en hacer corresponder sentidos y símbolos, dentro de un contexto establecido previamente entre los que comparten el uso de cada código, y en el que los símbolos pueden no tener relación física o de semejanza con las cualidades del fenómeno al que señalan. El problema surge cuando interviene un interlocutor que desconoce las convenciones del código. Por otra parte, como ejemplos de comunicación analógica Bateson estudia los medios de comunicación animal, que se basan en la transmisión de elementos cibernéticos y paralingüísticos, es decir utilizan materiales físicos específicos susceptibles a variaciones continuas para referirse a experiencias que son de la misma naturaleza: intensidades de volumen, gruñidos, posturas físicas, etc.

De allí Bateson hace seguir dos conceptos que son muy valiosos para el entendimiento de la experiencia de la pintura. En primer lugar, hace notar el hecho de que, si bien el lenguaje digital humano se desarrolla con posterioridad y es evolutivamente más complejo que los lenguajes analógicos, no sucede lo que cabría esperar y es el reemplazo de un medio obsoleto por uno novedoso; en otras palabras, el lenguaje digital no ha reemplazado al analógico. De hecho, en la experiencia humana el lenguaje analógico se ha seguido complejizando y tomando las más variadas formas, de lo que solo se puede concluir que existen tipos de experiencia y tipos de contenido que el lenguaje digital no logra codificar, precisamente porque se trata de fenómenos no susceptibles a ser codificados. En este punto ya se puede establecer directamente la conexión con el arte como lenguaje analógico: la música, la pintura, las artes del cuerpo, incluso la literatura, están hechas de elementos analógicos que corresponden a experiencias de variación continua. Desde ese punto de vista, no procede interrogar este tipo de manifestaciones respecto de un significado o un sentido, ya que no se trata de un código al cual hacer corresponder una significación; más bien son la presentación de 
una experiencia de la sensación que debe ser experimentada directamente para que produzca efectos en los interlocutores.

En segundo lugar, Bateson plantea una conclusión muy útil en cuanto a la naturaleza del contenido que puede transmitir el lenguaje analógico; dice que siempre se basa en expresar condiciones de relación y jerarquía. Lo que expresa el lenguaje analógico, ya que su materia es un continuo de variación física, es la acción de unas fuerzas y la manera como las diferentes fuerzas que participan de un fenómeno se van a relacionar entre sí, esto es, la jerarquía que se establece entre ellas, es decir, cuáles fuerzas son las que dominan y cuáles son dominadas; además, cómo se manifiesta dicha dominación y cómo se manifiesta el ser dominado. Esas sí serían preguntas procedentes para hacerse ante un fenómeno del lenguaje analógico, como puede ser una pintura, por ejemplo.

El problema que surge a la hora de enfrentarse a la experiencia de la pintura es que el lenguaje digital, la lógica del sentido, ha sometido a la pintura a una camisa de fuerza teórica en relación con la representación. Primero se acusa a la pintura de ser una mala representación de la apariencia, que desvía de la esencia, y luego se le exige una correcta técnica de la representación, a fin de, al menos, proveer una construcción de significado de alguna utilidad. Este problema teórico en relación con el arte, que ya se inicia en la concepción de la filosofía griega, es el punto de partida de la reflexión que hace Cacciari en El Dios que baila (2000), a propósito de la implicación que tiene para la filosofía, el hecho de que la actividad artística apunte a llevar al pensamiento fuera de los límites del sentido:

\footnotetext{
La poesía constituye el "no" de ese logos, el "no" que ese logos oye absolutamente desterrar y que se niega para siempre a devenir o a volver a devenir, ese "no" que lo define en sus propios términos y en su propia timé. Si penetrara en la polis, si participara de la Utopía filosófica, sería como si negara el principium firmissimum: ese "no" prohibido, que el logos quiere asegurarse de que no existirá jamás, terminaría por expresarse en el interior de la esfera delimitada del logos. Y el logos, entonces, en el interior de sus propios límites, sería a la vez sí mismo y diferente de sí, sería y no sería al mismo tiempo (Pág. 10).
}

De modo que, al salirse del juego de la representación y de la corrección, la pintura obtiene un poder que amenaza la supervivencia misma del logos, del sentido. O podemos postular, con Cacciari mismo y los otros autores que aquí llamamos nietzscheanos y vitalistas, que la pintura abre los límites del pensamiento, con las posibilidades continuamente múltiples de la aparición de la diferencia en el seno mismo del sentido. 
Pero, teniendo en cuenta la persistencia de la exigencia de significación e ideología impuesta sobre la pintura, se hace necesario que el pintor empiece su trabajo por conjurar la relación representativa con la experiencia de pintar. A este respecto, el tipo de trabajo de Goya en los cuadros de las cañas consigue romper con la transmisión digital de datos informativos, presente en el discurso narrativo y en la construcción de la imagen cliché como idea previa a la experiencia, e introducir en cambio un tratamiento propiamente análogo, que se sustenta en variaciones físicas de los materiales y opera en términos de una experiencia de las relaciones entre las fuerzas. Lo logra porque destruye la visualidad, haciendo partir a la mirada desde el oscurecimiento en el negro, operando la vibración de luz y color por el trabajo de las cañas, lo que desemboca en un tipo de mirada que sigue a lo manual, una mirada que trabaja desde el ritmo y que conduce al negro desde el ocultamiento hacia la creación del espacio.

En esta dirección, al someter al escrutinio un grupo de obras como los cuadros de las cañas, lo correcto es preguntarse qué fuerzas son las involucradas en el hecho sobre el que trabaja el pintor, cómo se relaciona la actividad de las fuerzas con la ocurrencia de elementos pictóricos y en qué se apoya el pintor para sostener una estructura de planos y una disposición de elementos, permitiendo que las fuerzas del caos atraviesen el cuadro sin derrumbarlo, para que algo pueda salir de este: el hecho pictórico. Sin duda se puede afirmar de los cuadros de las cañas lo que Deleuze afirma de Bacon, que "sigue siendo cezanniano por el extremo empuje de la pintura como lenguaje analógico" (Deleuze, 1984 pág. 70). Goya anticipa la vía de Cezanne y Bacon, porque él también hace avanzar a la pintura en la dirección del lenguaje analógico. La integración del grupo de figuras en un solo cuerpo múltiple, que convierte la violencia en fuerza generativa de los miembros corporales, no tiene nada que ver con el código de un lenguaje digital. Acá materia pictórica y materia corporal se identifican una en la otra provocando un continuo devenir, un continuo caer, que genera y consume órganos y otras zonas indiscernibles de cuerpos, a una velocidad de vértigo. Pero el logro más alto de Goya en el desarrollo del lenguaje analógico de la pintura es que invierte las relaciones del blanco y el negro con el claroscuro y con la producción de las convenciones clásicas de la visión representativa. La nueva visión manual que Goya impone implica que el negro enseña a la mano a ver y pone al ojo a seguir a la mano, mientras en el otro extremo de esta inversión el blanco aparece como ceguera lumínica que transporta la vibración, mientras que los flujos materia pictórica responden a los sistemas de presión de las 
fuerzas, al interior del cuadro. Finalmente, el blanco y el negro, liberados de su función descriptiva, actúan como colores propiamente dichos y se despliegan en el espacio solo como valores cromáticos, entrando en relación con el fondo de color vivo y generando la aparición de los colores vivos del primer plano, que confluyen en la máxima vibración manual de las cañas y la máxima deformación generativa del acontecimiento en el cuerpo múltiple.

Así, el hecho pictórico como caso de la producción de lo análogo, funciona de forma contraria a un codificador. No regula asignando casillas discretas que segmenten el movimiento de flujo de las fuerzas, haciéndolas corresponder a una intención preconcebida de cualquier tipo. Contrario a eso, establece líneas de fuga como posibilidades de variación del flujo de los elementos, que solamente van a responder a la acción de las fuerzas, que se actualiza en el momento de su paso a través del cuadro. Es por eso por lo que el hecho pictórico no puede transportarse de un cuadro a otro, tiene que volver a ocurrir en cada cuadro, aunque se trate de problemas del mismo tipo, por ejemplo, para todos los cuadros de las cañas. ¿Qué es lo que se hace posible al final, en la ocurrencia del hecho? En los cuadros de las cañas esto es el martilleo violento del color-cuerpo-múltiple. Goya hace pintura a martillazos, golpeando con las cañas el color vivo e integrando lo figural en el movimiento vibratorio de caída del cuerpo múltiple. 


\section{A modo de conclusión:}

\section{Violencia pictórica. Celebración de la vida como juego estético.}

Revisando ahora la pregunta que sirvió como punto de partida a esta investigación, respecto a la necesidad que llevó a Goya al uso de las cañas en estos cuadros de la partida X-28 y los valores conceptuales-pictóricos que se derivan de lo que ocurre a partir de esa decisión, puedo decir que las conclusiones tienen que ver con la identificación del flujo de materia pictórica con el acontecimiento que tiene lugar en el movimiento del cuerpo múltiple. A su vez, esta identificación conduce a la liberación de la estructura clásica de la forma, a la independencia resultante de los elementos pictóricos, que ya no tienen que acomodarse a dicha estructura y a la posibilidad que se abre para que el pintor pueda volver, una y otra vez, sobre el problema de la caída del grupo de figuras y la violencia pictórica asociada al tratamiento del cuerpo de óleo en dicha caída.

Es evidente que los cuadros de las cañas están llenos de un marcado interés por la violencia. Hay violencia en los temas, lo que puede referirse indistintamente a un episodio de la guerra, a una escena de tortura voluntaria por creencias religiosas o a un desastre accidental, como la furia de un incendio. Pero esto no quiere decir que la pintura de Goya esté tomando la función de representar la violencia de su época, analizarla, denunciarla, o hacer cualquier declaración de tipo ideológico sobre ella. Incluso, si ese fuera el interés, al menos parcialmente del mismo Goya, la pintura forzosamente lo aleja de tal interés. En realidad, el valor que tiene para el pensamiento lo que produce el hecho pictórico, incluso su valor político e ideológico, no puede subsumirse a las declaraciones de significado. La pintura no tiene nada que ver con significar. Bacon lo dijo de una forma muy clara:

Cuando se habla de violencia en la pintura, es algo que no tiene nada que ver con la violencia de la guerra. Es algo que se relaciona con la tentativa de reproducir la violencia de la propia realidad, de las sugerencias dentro de la imagen misma, que solo puede transmitirse a través de la pintura (Sylvester, 2007, pág. 73).

Palabras que arrojan luz sobre los cuadros de las cañas, porque así se puede entender que una escena de guerra tenga la misma violencia pictórica que un baile popular bajo 
un puente. Lo que Bacon dice, implica que un cuadro siempre que quiere presentar de la forma más expresiva posible eso que el artista presiente de una imagen, las posibilidades de hecho, para transportar eso, como él quiere hacer, "directamente al sistema nervioso" (Sylvester, 2007, pág. 43). Al llevar al extremo la vía análoga, en contraposición a la codificación digital del lenguaje y el sentido, se va a producir necesariamente la violencia pictórica.

Esta situación por la que el pintor se define, fuera cualquier categorización semántica de los hechos, fuera de cualquier intento de dar explicación o sentido, más que el reconocimiento del puro valor estético de su ocurrencia, nos vuelve a traer sobre la valoración de Rosset (2012, Pág. 40) respecto a la obra de Balzac: "Frente al horror Balzac está a sus anchas", como Goya frente a la violencia sobre la figura, porque "la simple noción de ser es suficiente para repudiar toda consideración normativa, causal o justificativa", porque se parte de la premisa de que el artista "se resuelve a no intentar comprender o juzgar nunca a sus personajes". Con esa misma disposición Goya mira, desde el negro, al mismo centro de la violencia, con la ventaja que le da apreciar la caída de los cuerpos como el problema central de su propia pregunta estética, más allá de cualquier intento de juicio del sentido.

Al mirar de nuevo los cuadros X-28, encontramos al pintor que ejerce él mismo la violencia sobre el cuerpo que quiere pintar: hay violencia en el rompimiento que efectúa el negro de la imagen representativa y hay violencia en los martillazos y rayones de las cañas, con los que Goya parece querer hacer saltar los elementos por encima de sí mismos, para integrarlos a una vibración más profunda y vital. De nuevo, la violencia real nada tiene que ver con la violencia pictórica. ¿Qué implica esto para el trabajo del pintor? Que las fuerzas de la muerte se transforman en fuerzas vitales y creativas al interior del cuadro, al interior de una obra de arte. Que cuando el cuadro, ya concluido, entra en contacto con el mundo del sentido y con su lógica, no trae un mensaje, no tiene nada que decir, sino que presenta la violencia de una vibración y que puede excitar al pensamiento fuera de sus límites. Entonces la pintura violenta al pensamiento mismo, lo empuja a un terreno que no le es favorable, lo arrastra hacia lo oscuro, para hacerle sentir eso que, en tanto pensamiento, siempre se le tiende a escapar: el fluir de las fuerzas vitales del que todo fenómeno es síntoma y manifestación. Esto recuerda las palabras de Kafka en una carta a Max Brod: "Lo que cuenta finalmente no es lo visible, es captar, detectar, las potencias diabólicas del porvenir que golpean a la puerta, que 
golpean ya a la puerta" (Wagenbach, 1989, pág. 182). En los cuadros de las cañas Goya logra detectar esas fuerzas y manifestarlas en el hecho pictórico, están ahí, justo ahora, interpelando al pensamiento, incitándolo a que se esconda o a que abra la puerta.

Tanto Cacciari, como Deleuze o Lyotard, desarrollan la filosofía nietzscheana sobre el arte en una dirección que se puede definir con el término de vitalismo. El arte celebra la vida como juego, sin otro motivo que el acontecimiento y producción de lo estético. Su actividad vital implica un relanzamiento del pensamiento más allá de los límites de la razón, ya que el pensamiento es forzado a recorrer y cartografiar el devenir de los materiales y territorios donde ocurre la sensación.

Los cuadros de las cañas son un ejemplo de dicha experiencia. En ellos la violencia pictórica transmuta el hecho violento real, más allá de su problematización racional, para convertirlo en pura vibración creativa pictórica, en valor productivo de lo vital. Las fuerzas de la muerte que rondan al artista son transmutadas, por la actividad pictórica, en fuerzas vitales que dan germen a nuevas formas de vibración de la vida. Una celebración trágica, en el sentido nietzscheano, que hace germinar el júbilo de la creación, desde las entrañas del dolor y la oscuridad. 


\section{Apéndice}

\section{Ilustraciones}

Todas las ilustraciones son copia del catálogo de Gudiol, en su edición de 1980 referenciada en la bibliografía. De igual manera, la numeración y toda la información reseñada corresponden a dicho catálogo. La única excepción son las figuras 1 a 8 , que corresponden a fotografías tomadas directamente en Museo Nacional de Bellas Artes de Buenos Aires, y se nombran de acuerdo con la información de la ficha del museo.

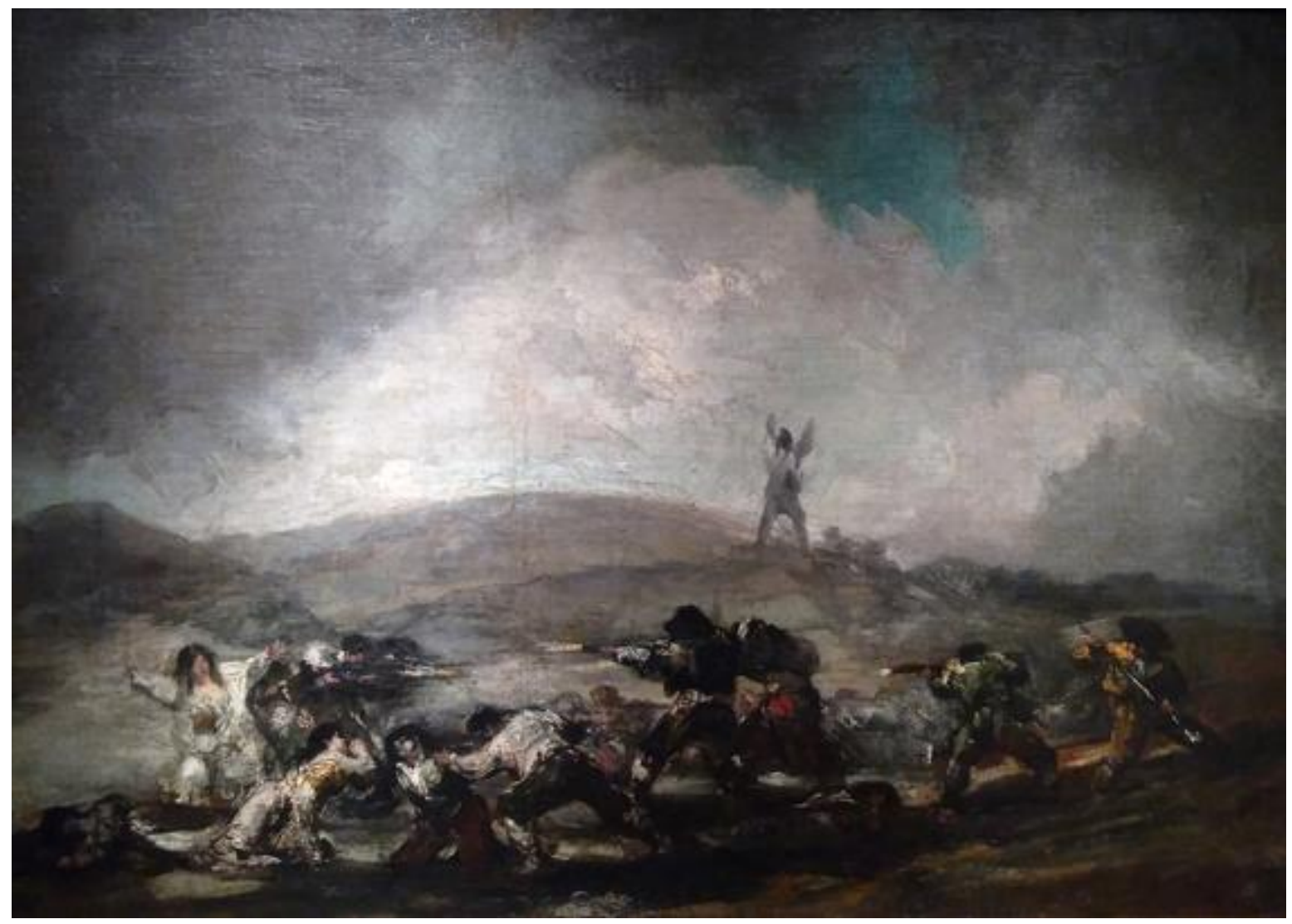

Fig. 1 Escena de guerra, óleo sobre tela, $72 \times 95.5 \mathrm{~cm}$ 


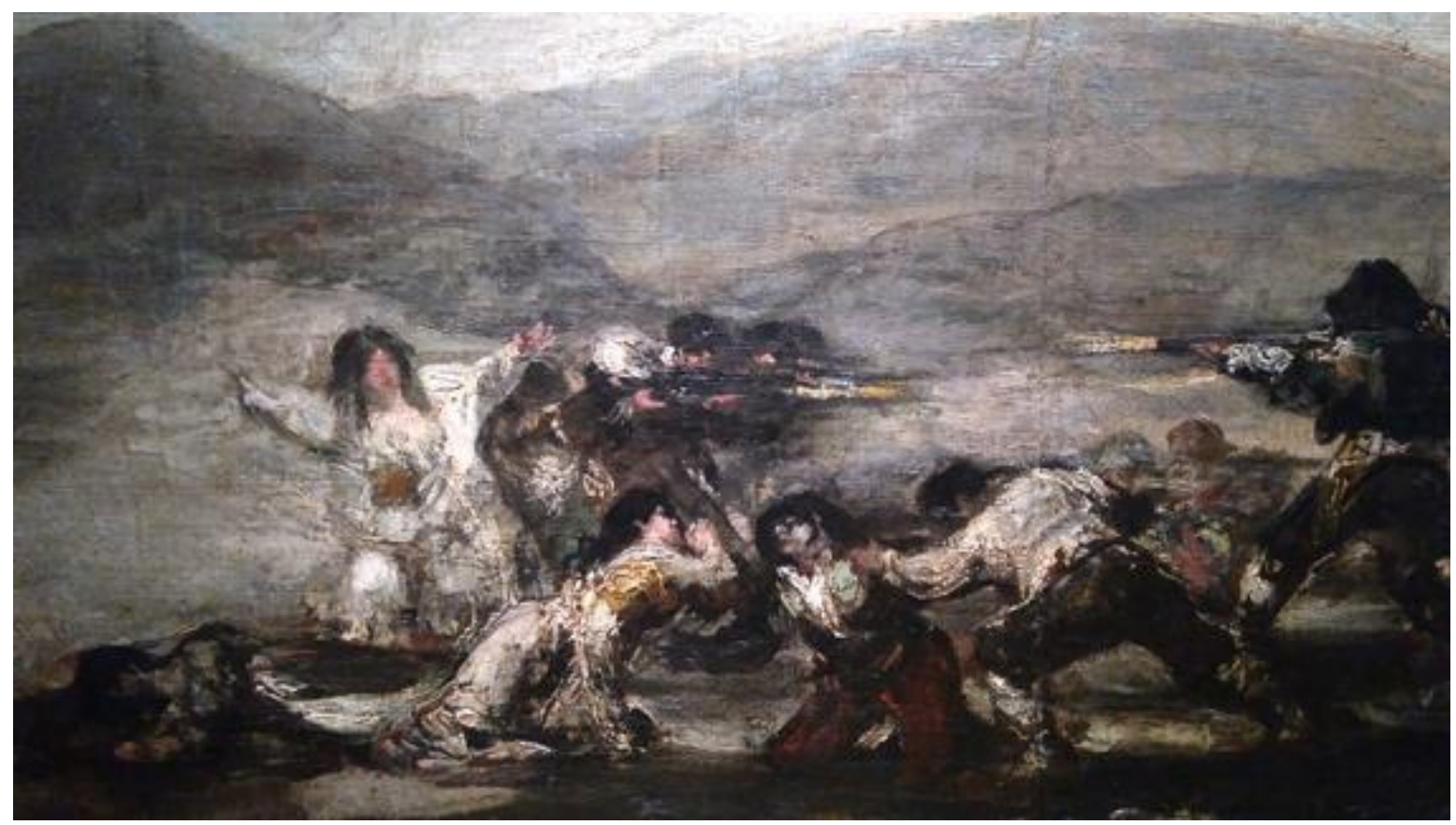

Fig. 2 Escena de guerra, detalle

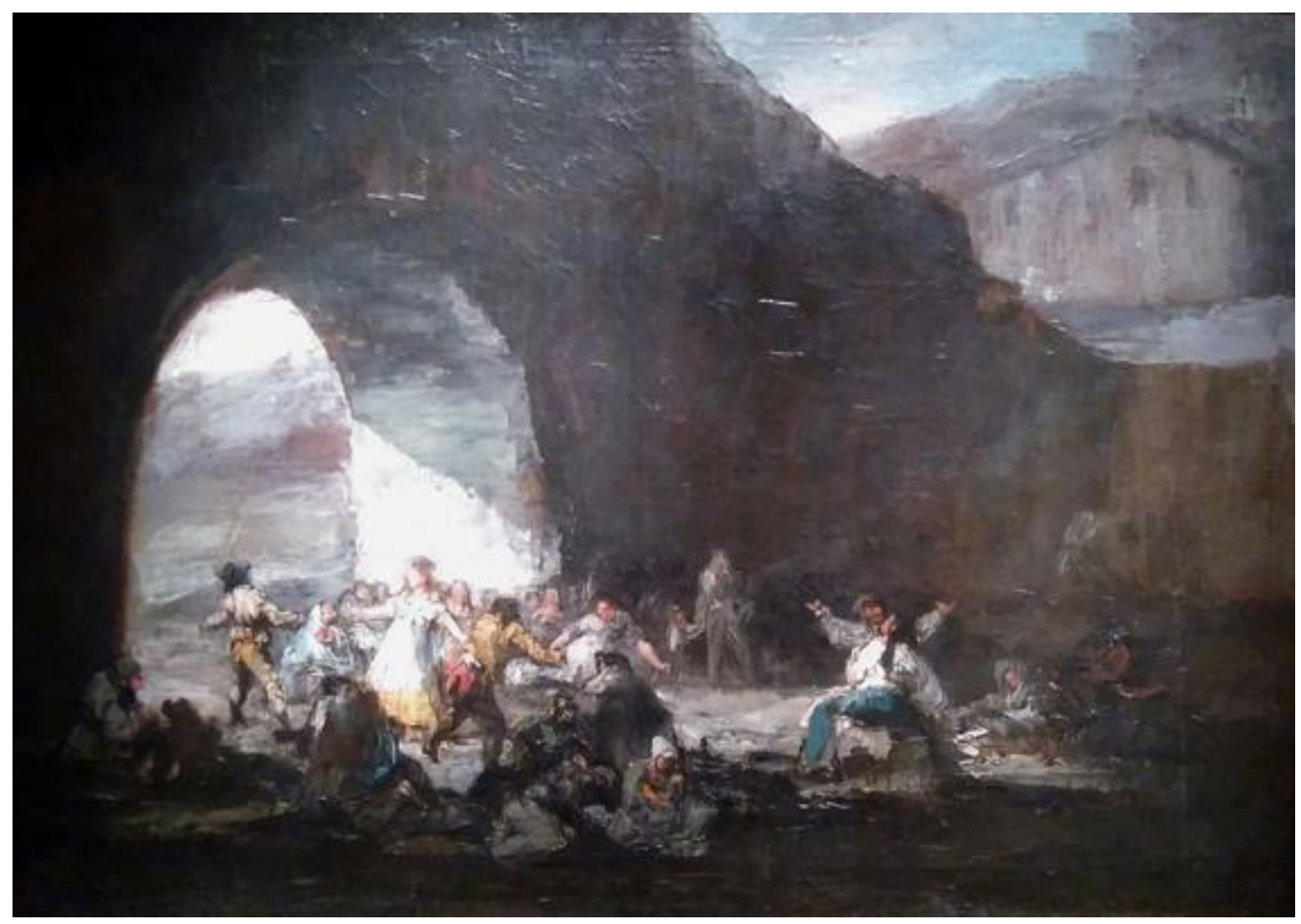

Fig. 3 Baile popular, óleo sobre tela, $72 \times 100 \mathrm{~cm}$ 


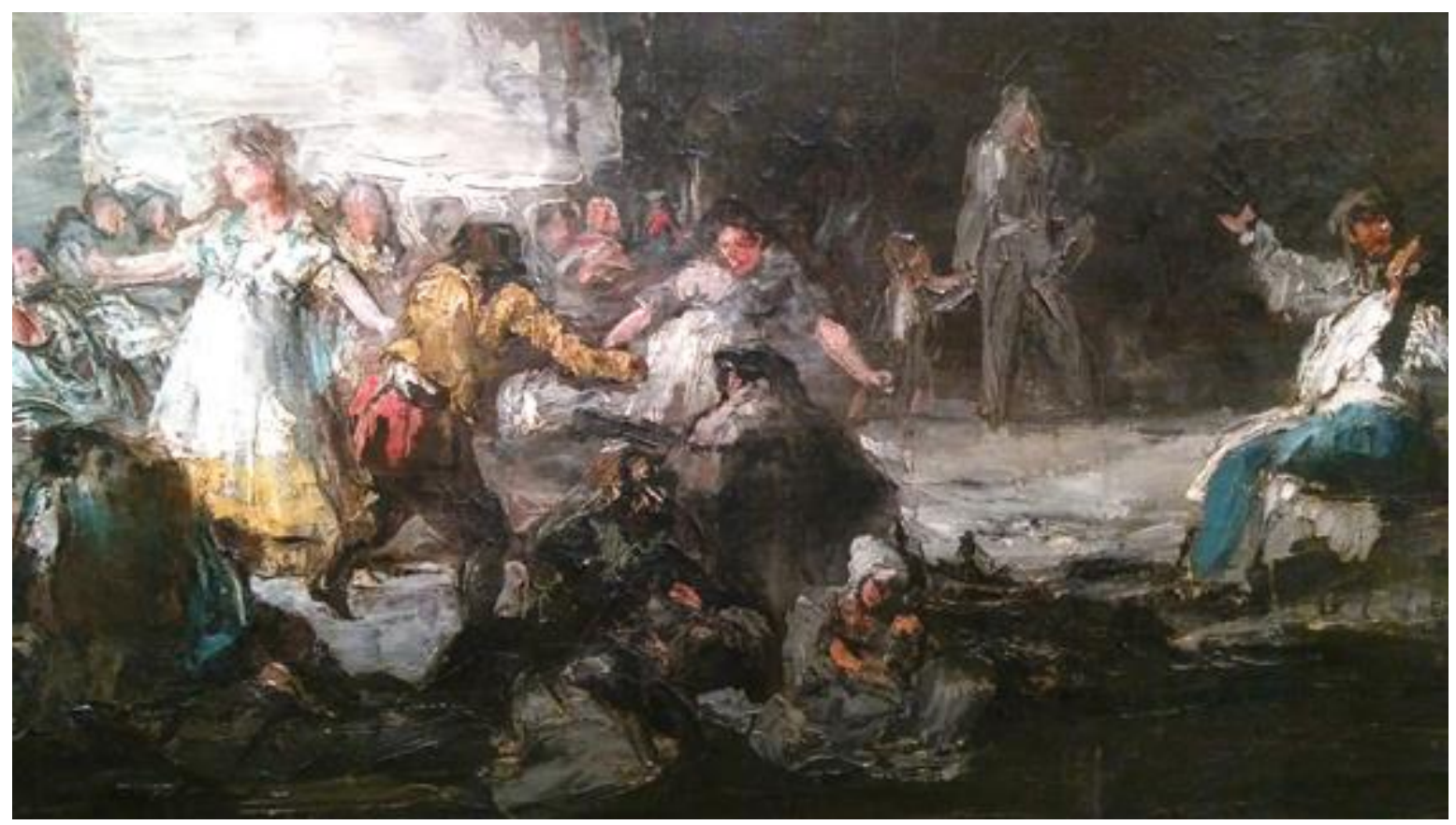

Fig. 4 Baile popular, detalle

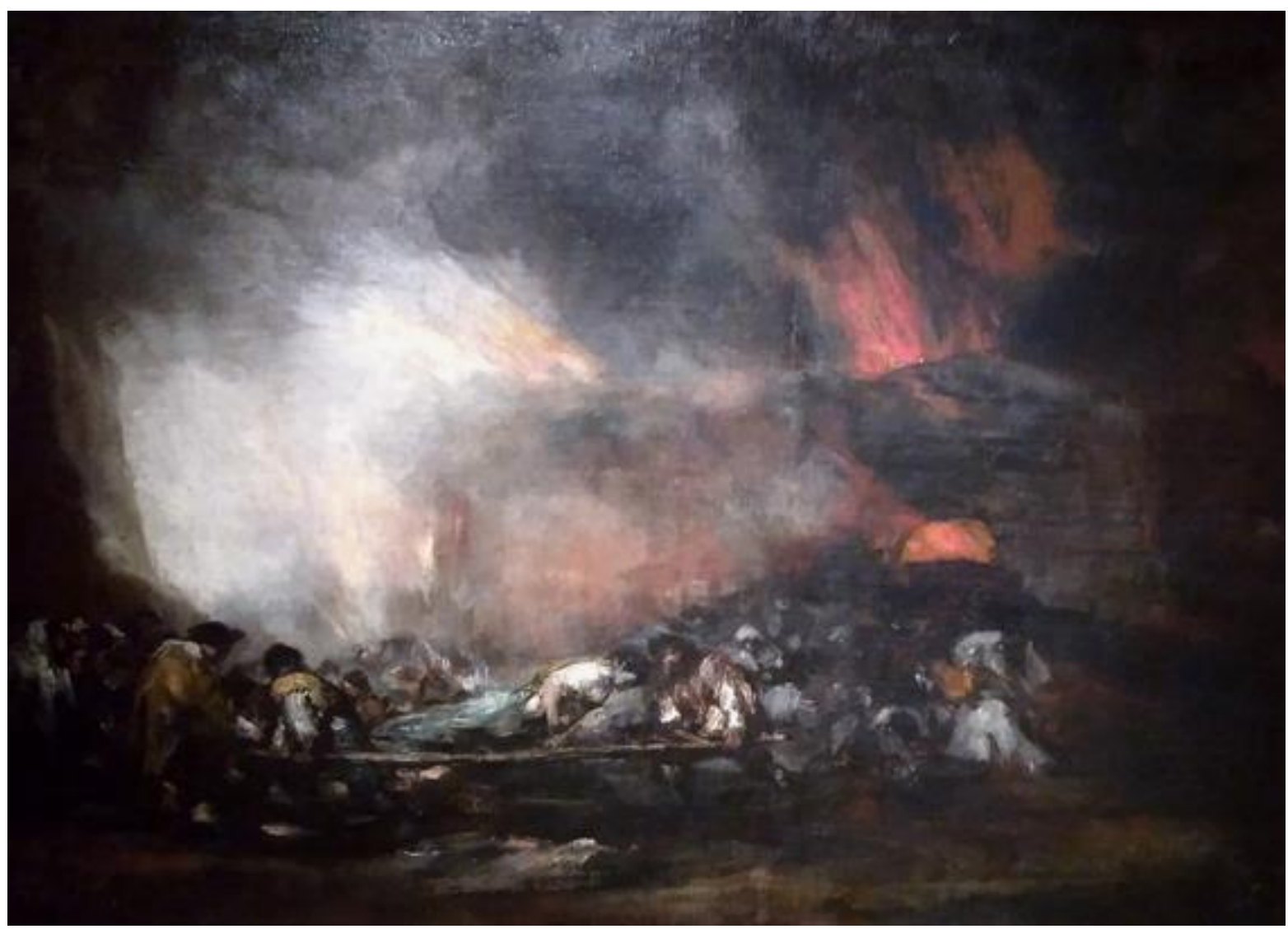

Fig. 5 Incendio de un hospital, óleo sobre tela, 72x99cm 


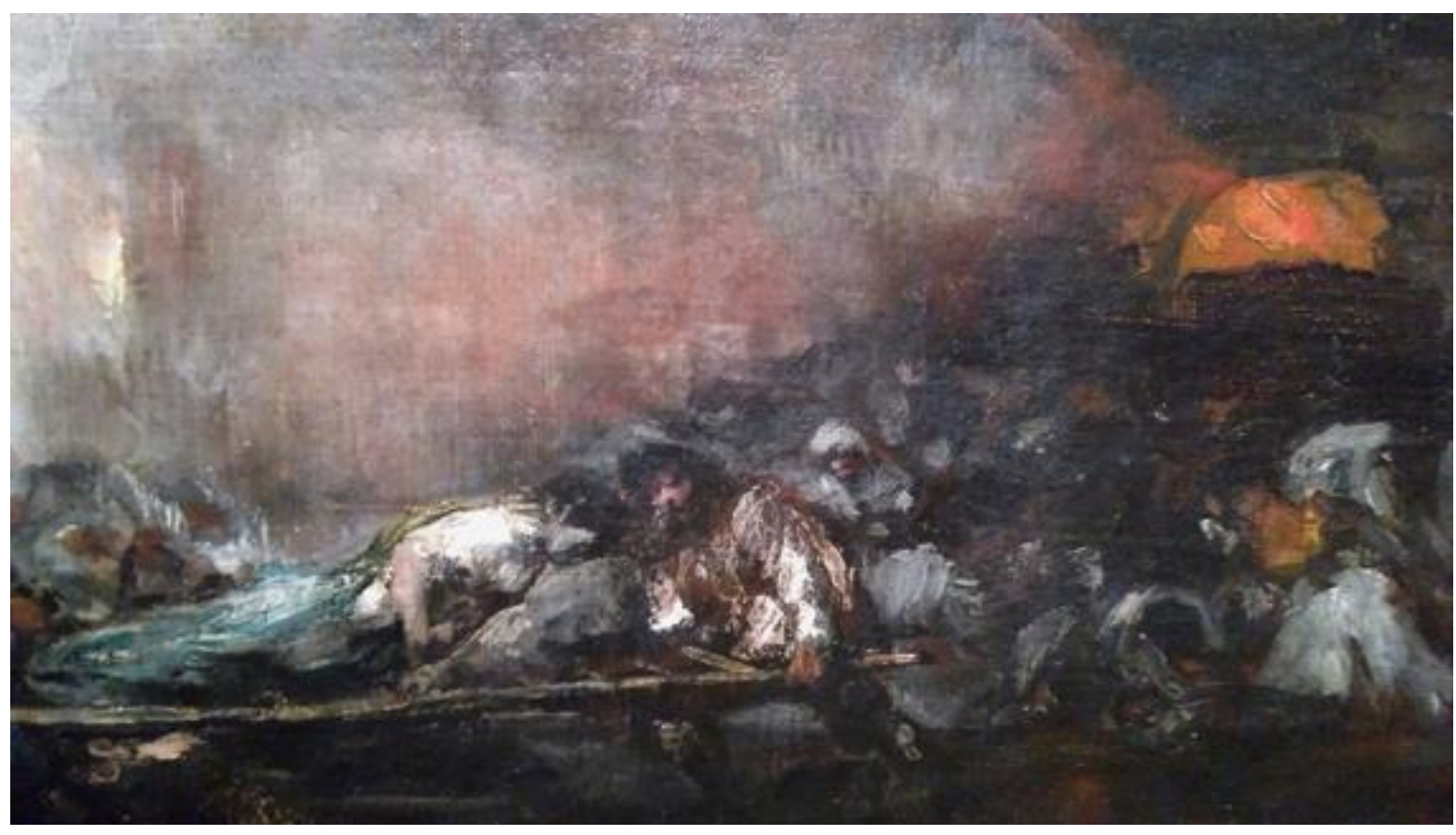

Fig. 6 Incendio de un hospital, detalle

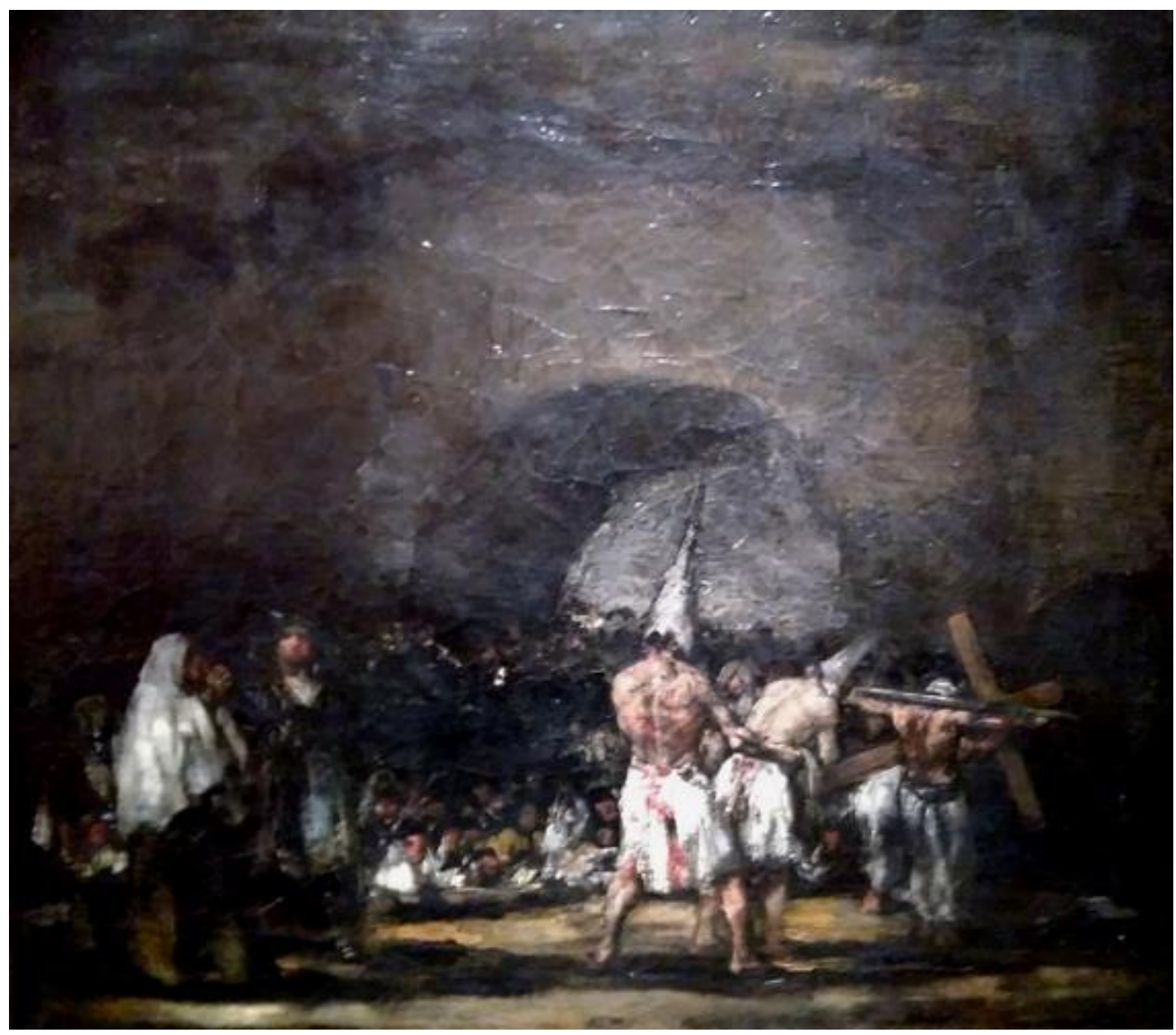

Fig. 7 Escena de disciplinantes, óleo sobre tela, $51 \times 57 \mathrm{~cm}$ 


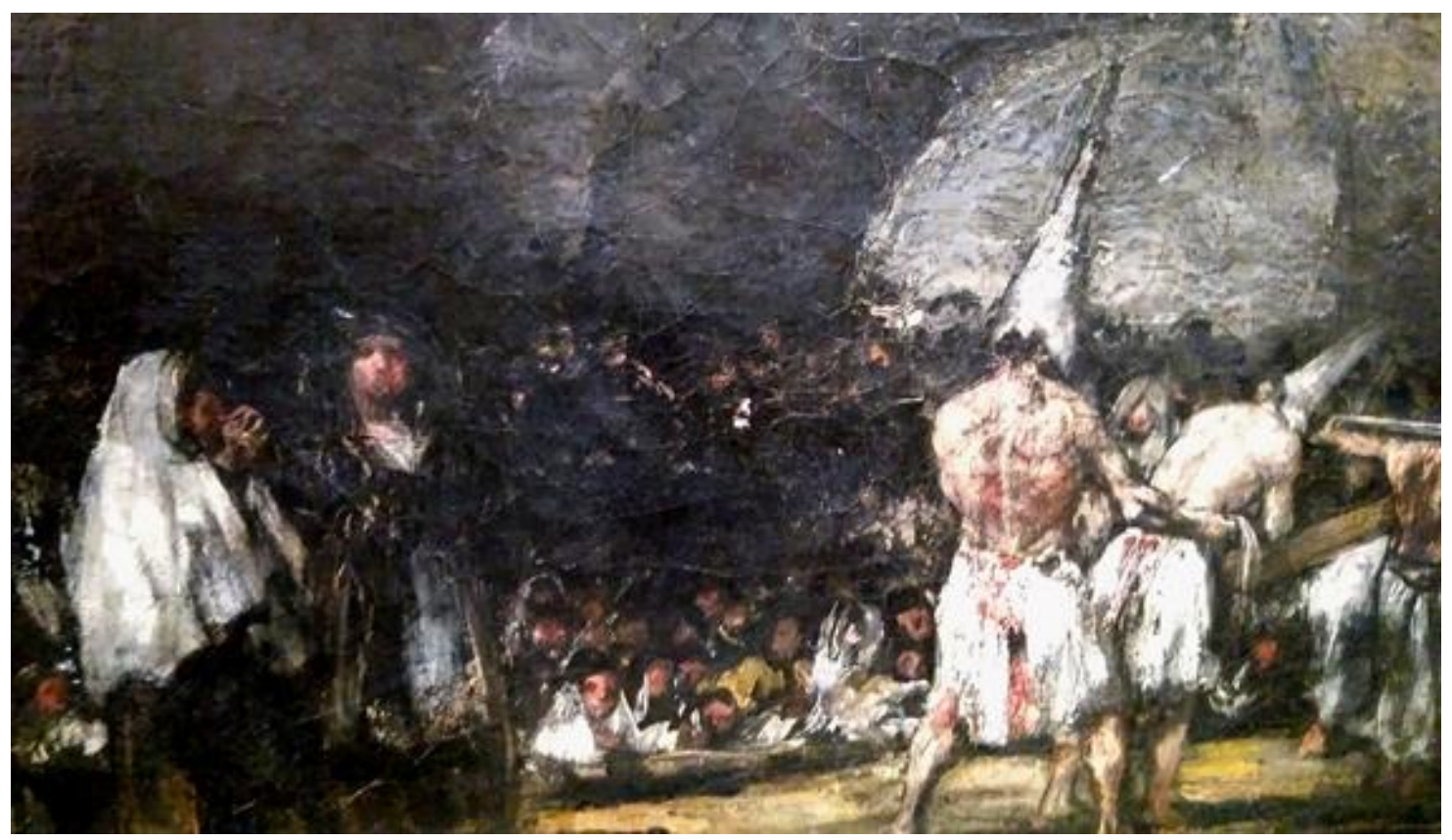

Fig. 8 Escena de disciplinantes, detalle

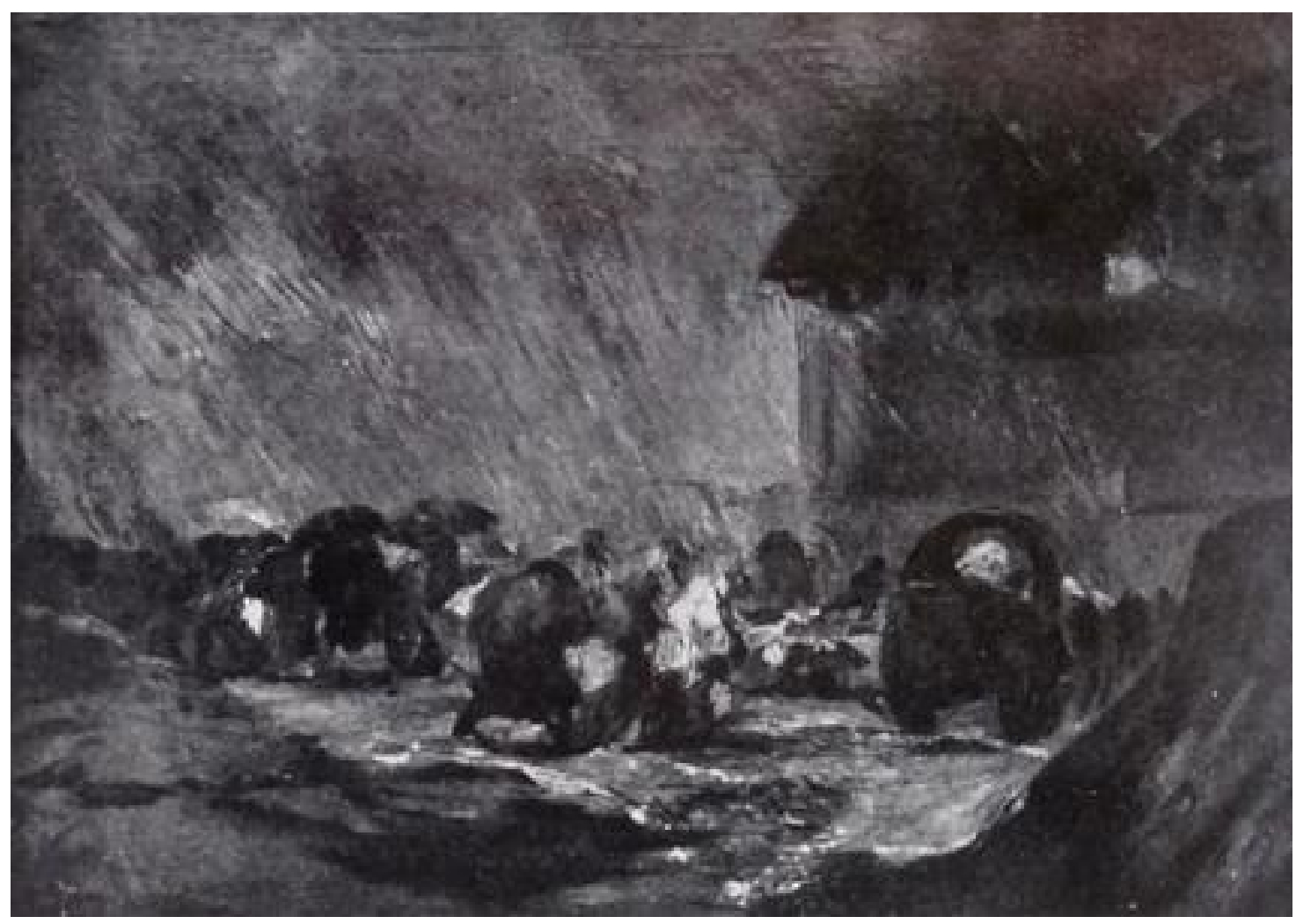

583. El huracán, óleo sobre tela, 98x126cm 


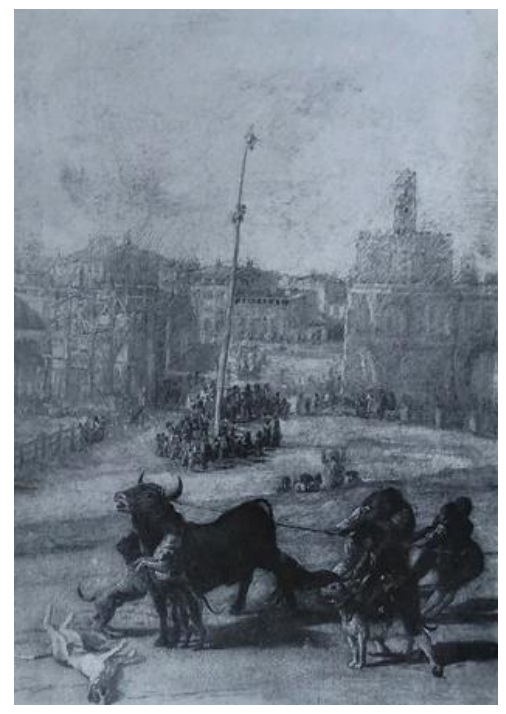

300. Captura de toro, óleo sobre hojalata, $43 \times 31 \mathrm{~cm}$

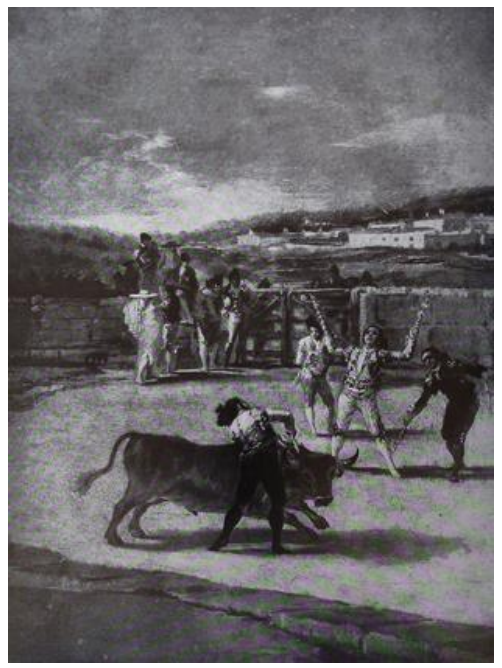

301. Suerte de banderillas, óleo sobre hojalata, $43 \times 31 \mathrm{~cm}$

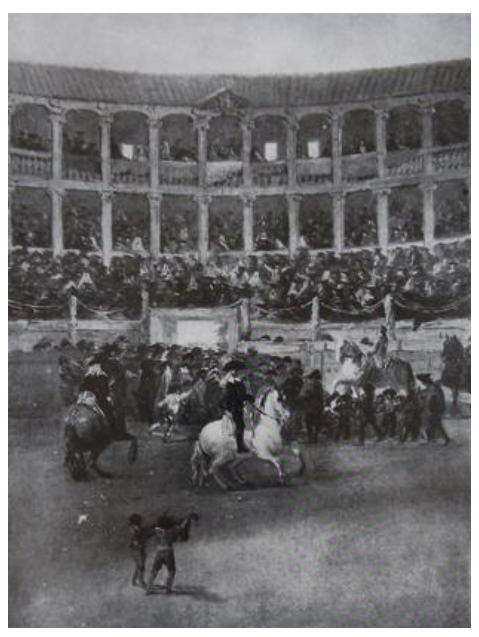

302. Despejando la plaza, óleo sobre hojalata, $43 \times 31 \mathrm{~cm}$ 


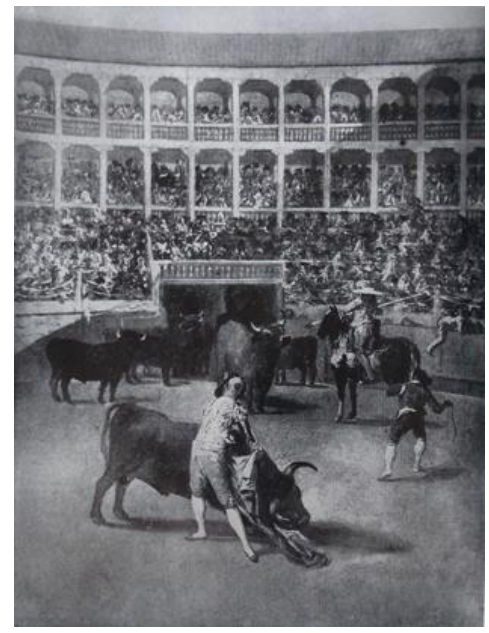

303. Toreando de capa, óleo sobre hojalata, $43 \times 31 \mathrm{~cm}$

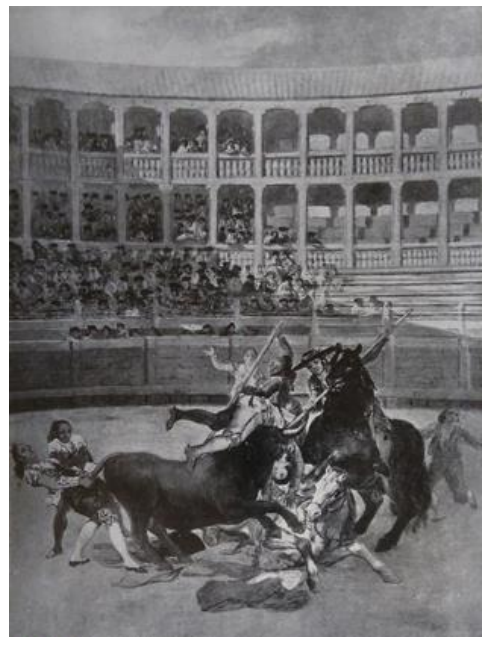

304. Cogida del picador, óleo sobre hojalata, $40 \times 30 \mathrm{~cm}$

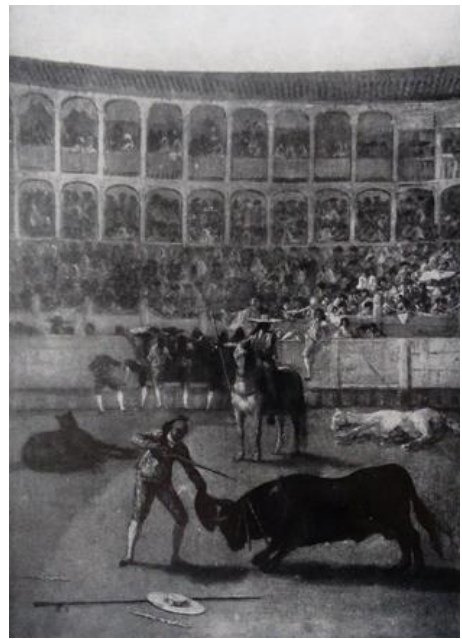

305. Pedro Romero en la suerte de matar, óleo sobre hojalata, $43 \times 31 \mathrm{~cm}$ 


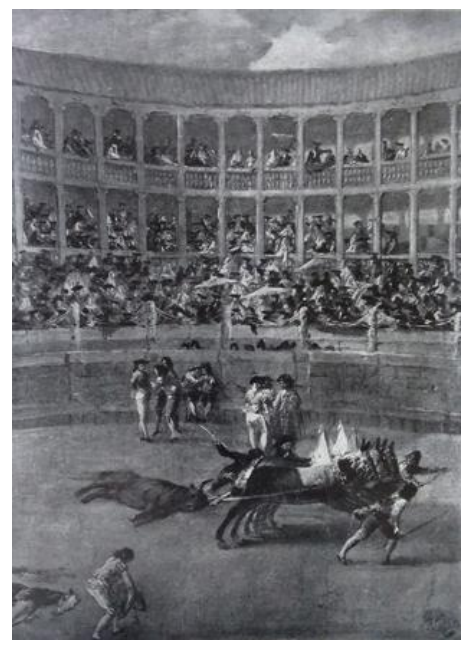

306. Arrastre del toro, óleo sobre hojalata, $43 \times 31 \mathrm{~cm}$

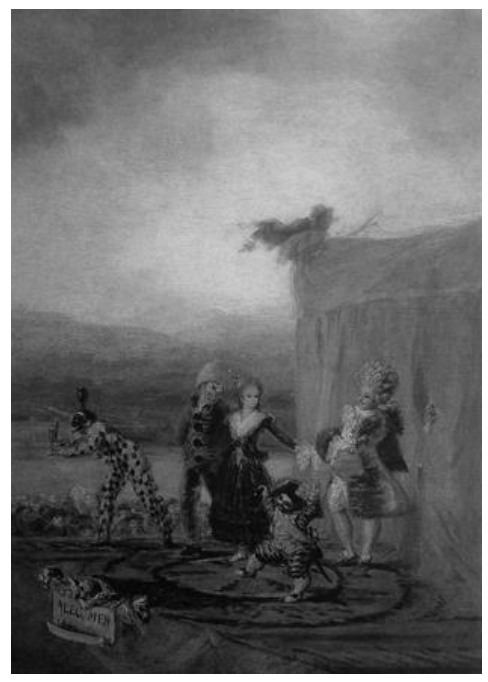

307. Cómicos ambulantes, óleo sobre hojalata, $50 \times 32 \mathrm{~cm}$

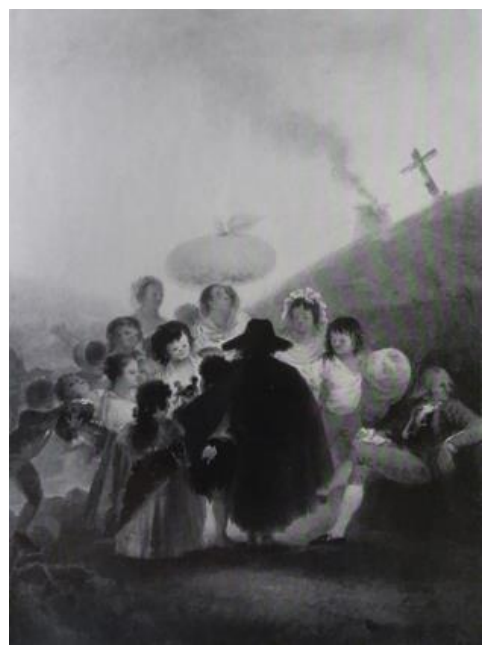

308. El vendedor de muñecos, óleo sobre hojalata, $42 \times 32 \mathrm{~cm}$ 


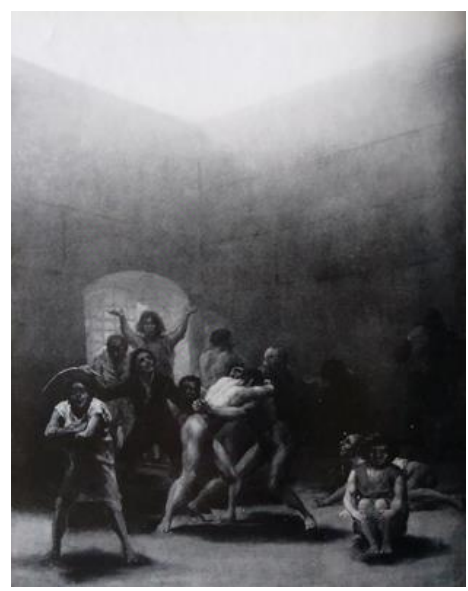

309. Corral de locos, óleo sobre hojalata, $46 \times 31 \mathrm{~cm}$

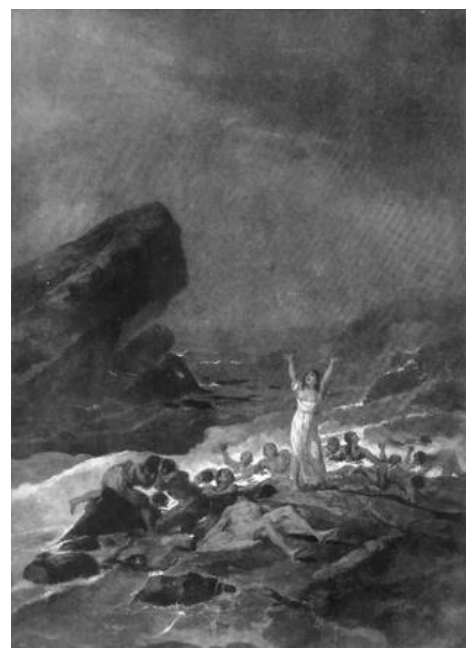

310. Naufragio, óleo sobre hojalata, $50 \times 32 \mathrm{~cm}$

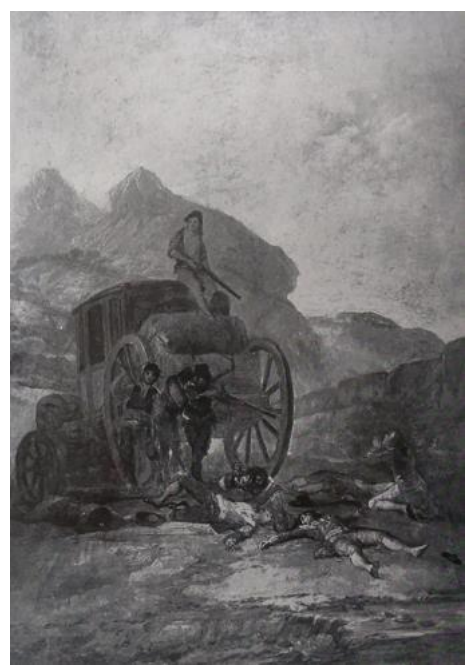

311. Bandidos asaltando un coche, óleo sobre hojalata, $50 \times 32 \mathrm{~cm}$ 


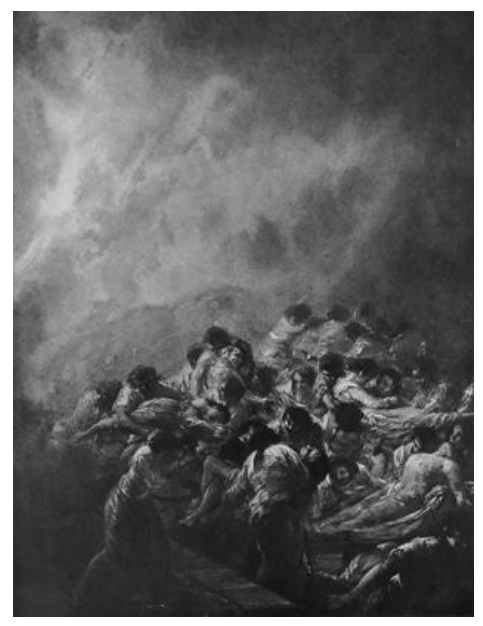

312. Incendio, óleo sobre hojalata, $50 \times 32 \mathrm{~cm}$

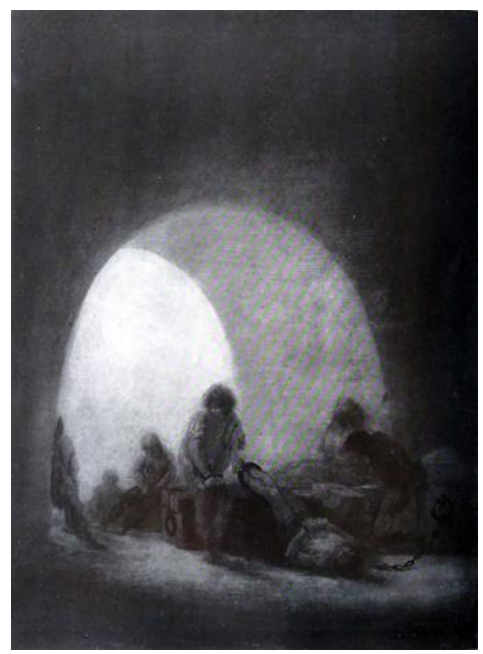

313. Interior de una prisión, óleo sobre hojalata, $47 \times 31 \mathrm{~cm}$

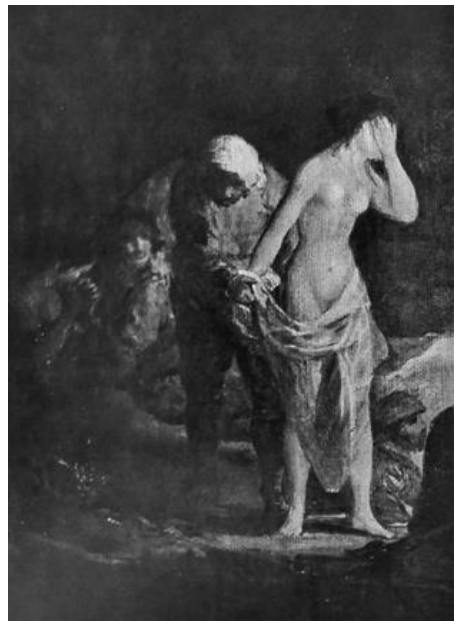

329. Bandidos desnudando a una mujer, óleo sobre tela $41 \times 32 \mathrm{~cm}$ 


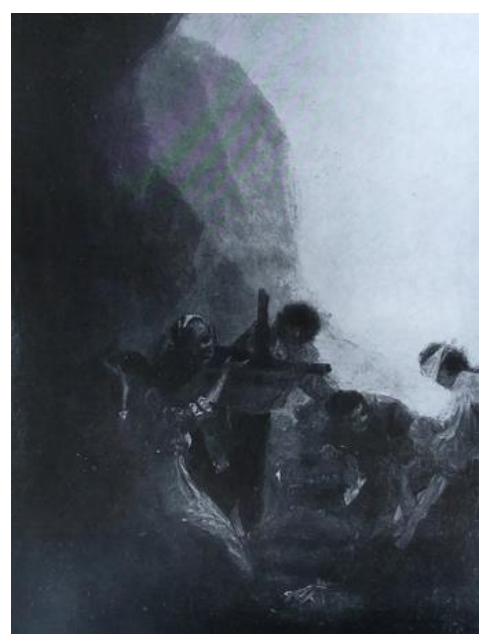

330. Bandidos fusilando a unos prisioneros, óleo sobre tela $41 \times 32 \mathrm{~cm}$

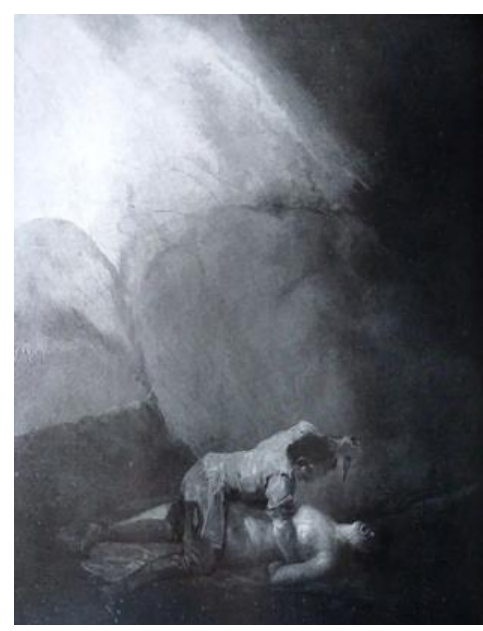

331. Bandido apuñalando a una mujer, óleo sobre tela $41 \times 32 \mathrm{~cm}$

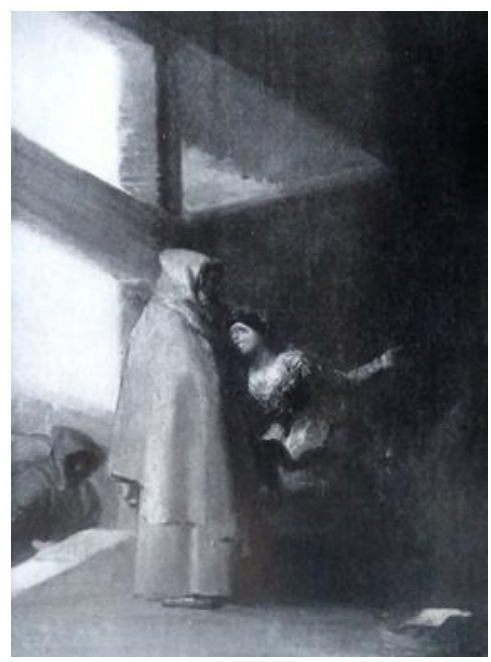

332. La visita de los monjes, óleo sobre tela $41 \times 32 \mathrm{~cm}$ 


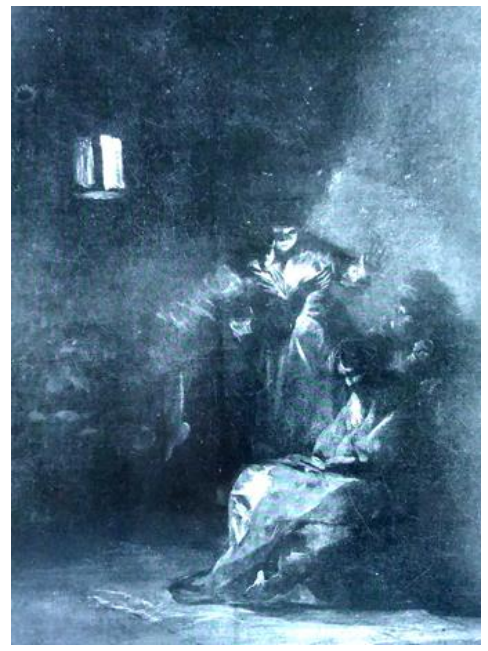

333. Escena nocturna, óleo sobre tela $41 \times 32 \mathrm{~cm}$

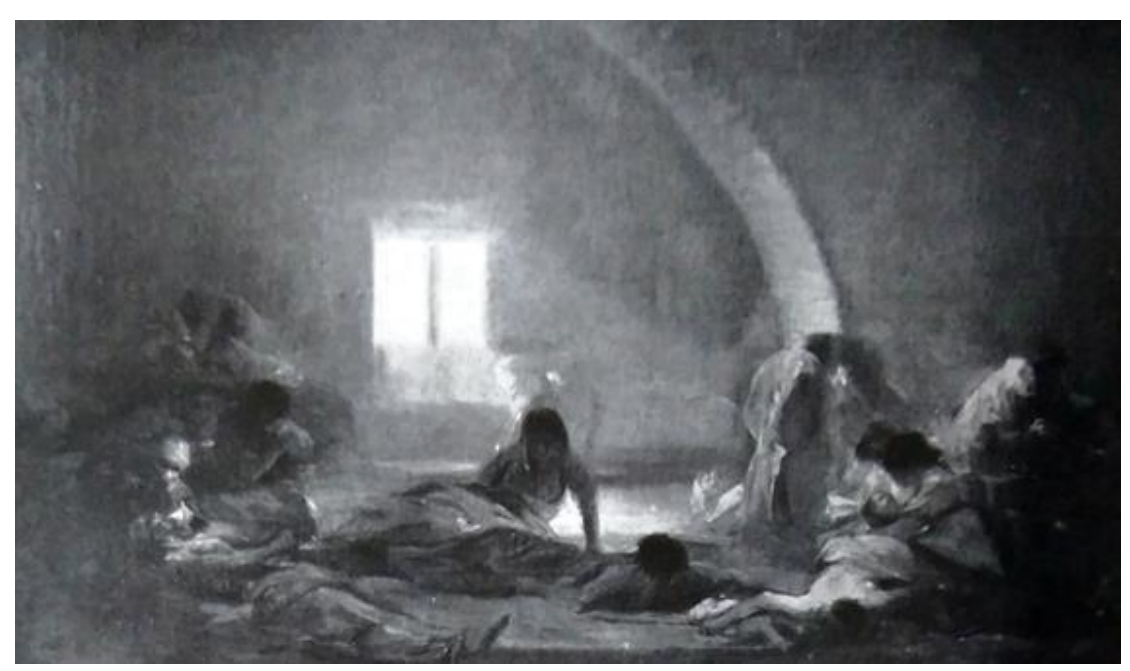

334. Hospital de apestados, óleo sobre tela $41 \times 32 \mathrm{~cm}$

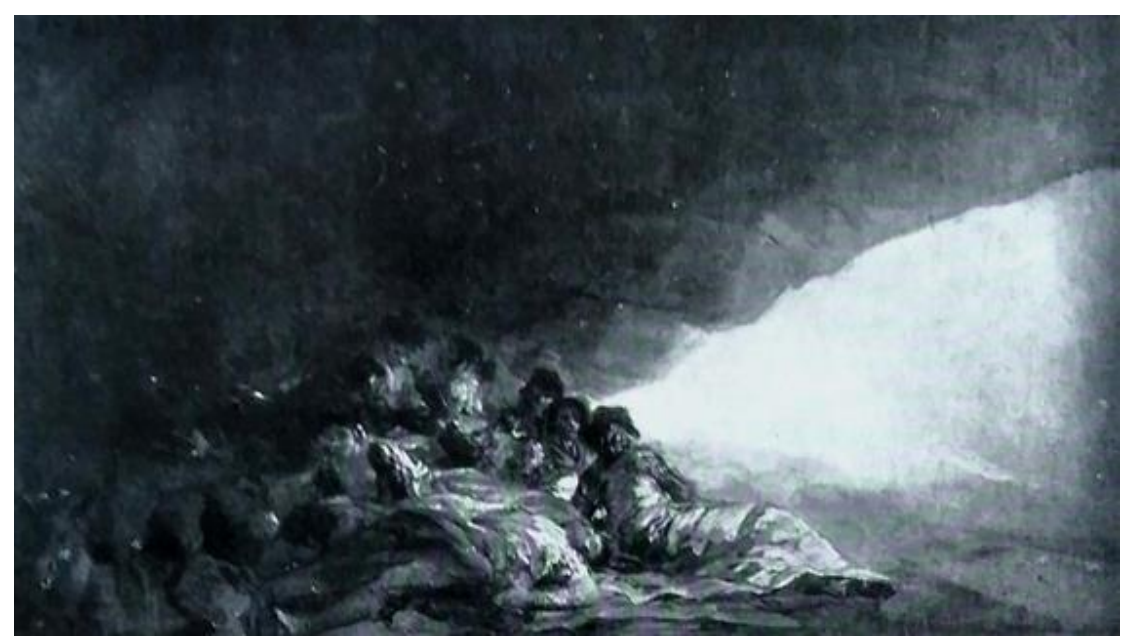

335. Contrabandistas en una cueva, óleo sobre tela $41 \times 32 \mathrm{~cm}$ 


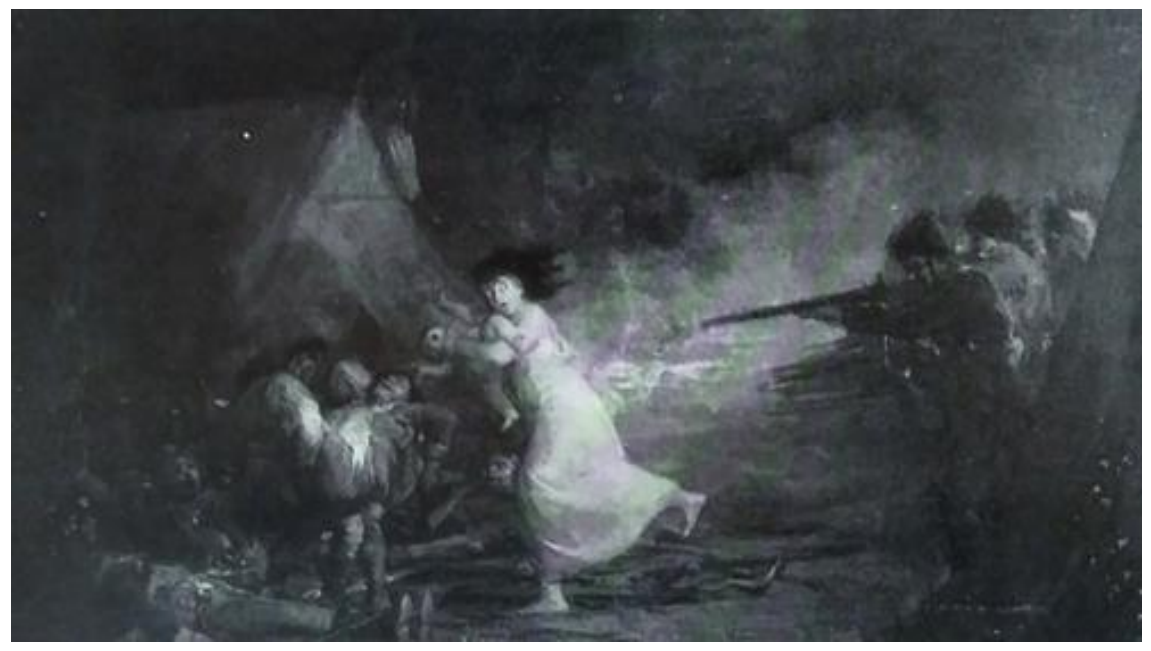

336. Asalto a un hospital de guerra, óleo sobre tela $41 \times 32 \mathrm{~cm}$

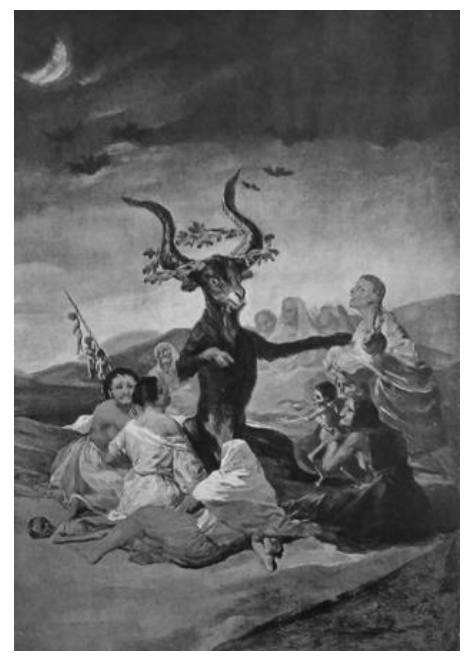

349. Aquelarre, óleo sobre tela, $43 \times 30 \mathrm{~cm}$

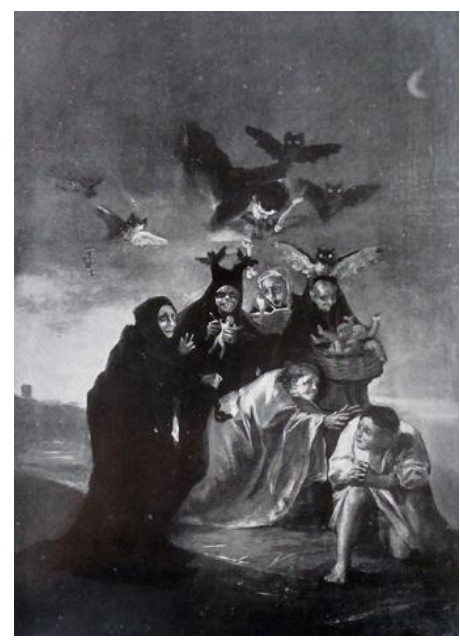

351. Conjuro, óleo sobre tela, $43 \times 30 \mathrm{~cm}$ 


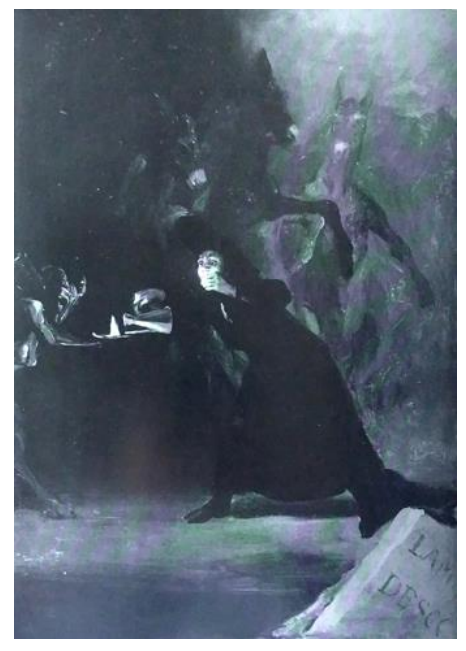

352. La lámpara del diablo, óleo sobre tela, $43 \times 30 \mathrm{~cm}$

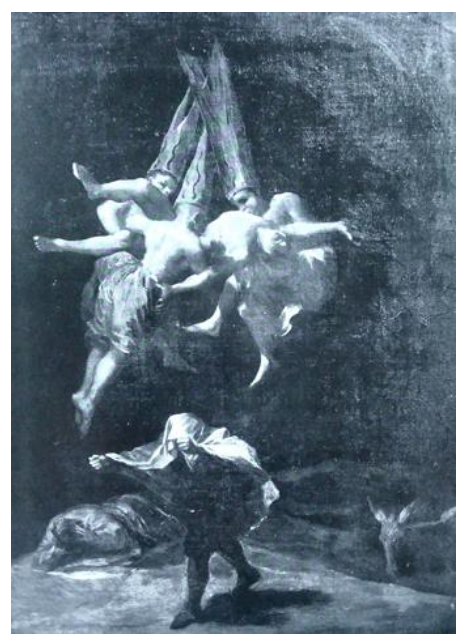

353. Brujos por el aire, óleo sobre tela, $43 \times 30 \mathrm{~cm}$

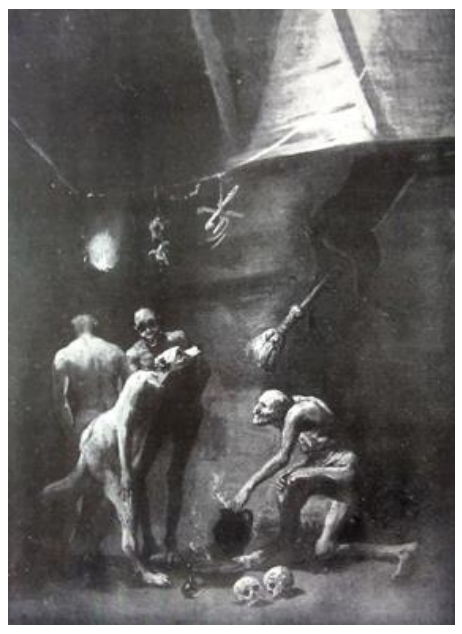

354. La cocina de las brujas, óleo sobre tela, $43 \times 30 \mathrm{~cm}$ 


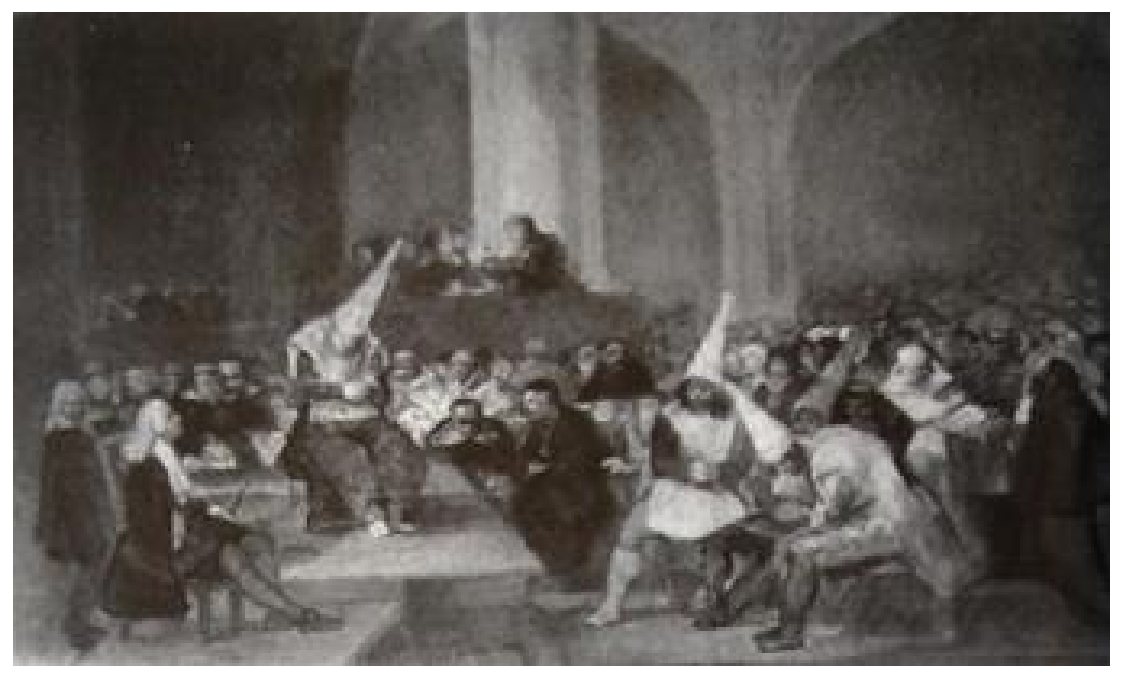

498. Tribunal de la inquisición, óleo sobre tabla, $45 \times 72 \mathrm{~cm}$

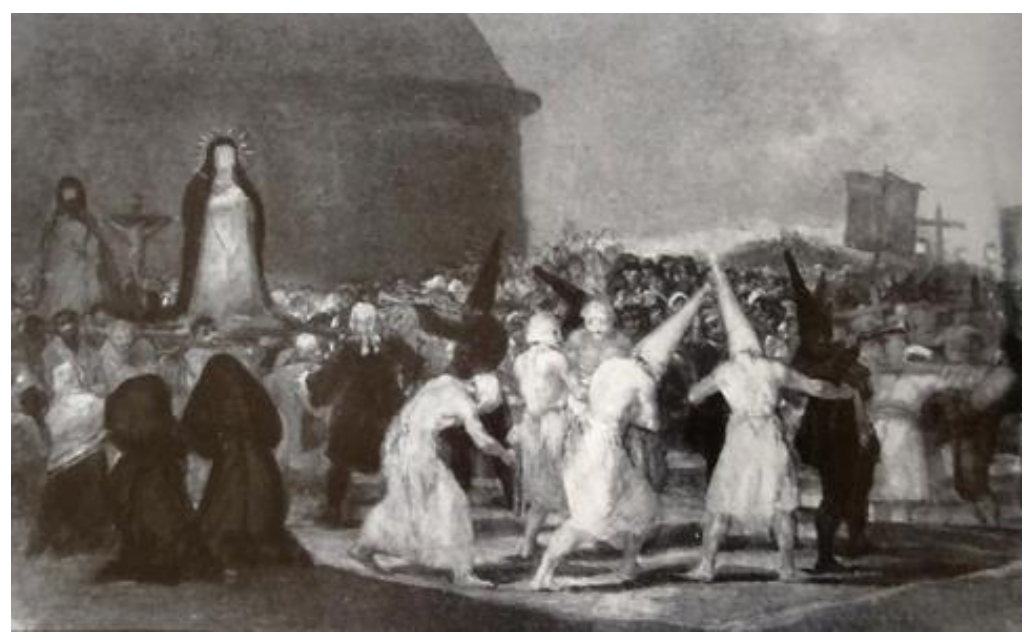

499. Disciplinantes, óleo sobre tabla, $45 \times 72 \mathrm{~cm}$

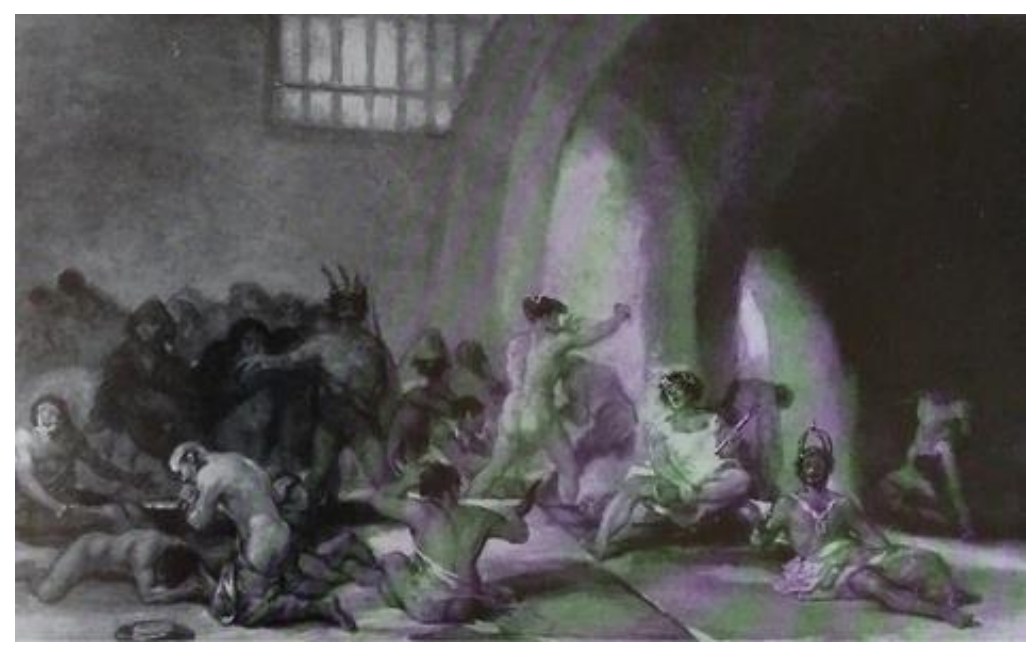

500. Casa de locos, óleo sobre tabla, $45 \times 72 \mathrm{~cm}$ 


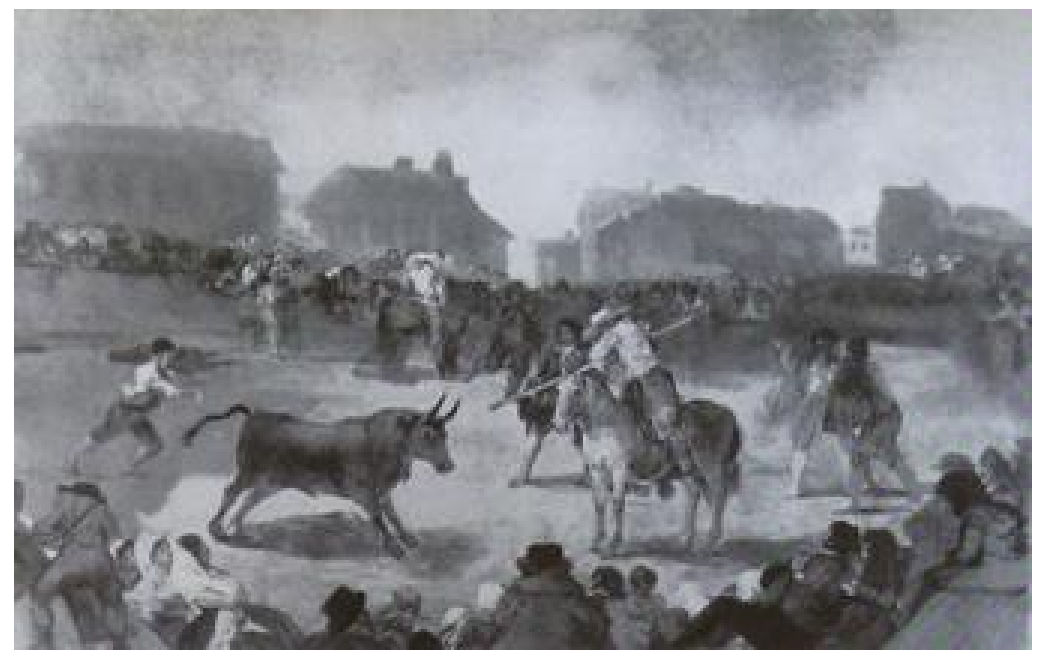

501. Corrida de toros, óleo sobre tabla, $45 \times 72 \mathrm{~cm}$

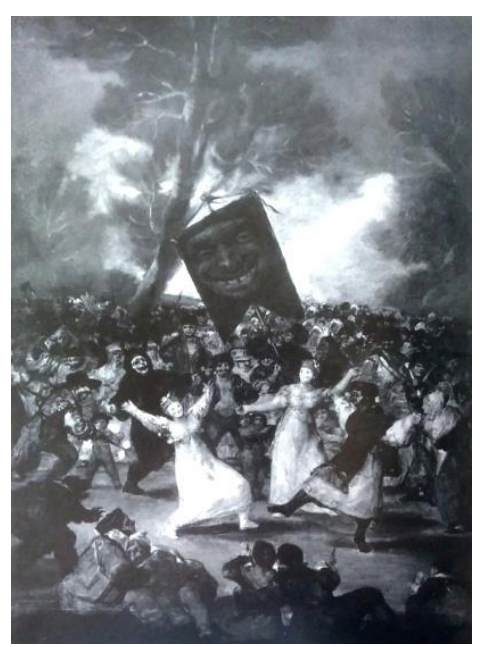

502. Entierro de la sardina, óleo sobre tabla, $83 \times 62 \mathrm{~cm}$

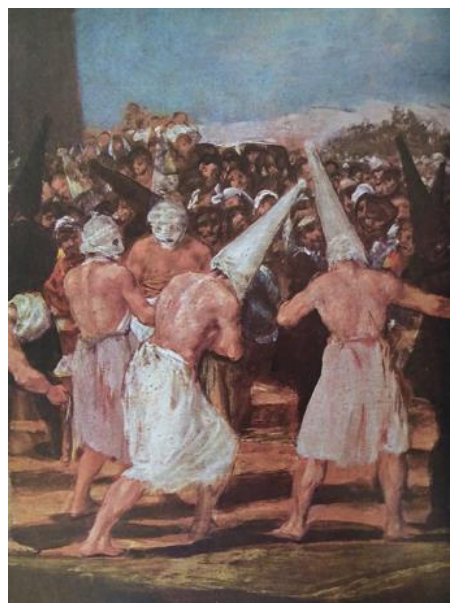

499. Disciplinantes, detalle 


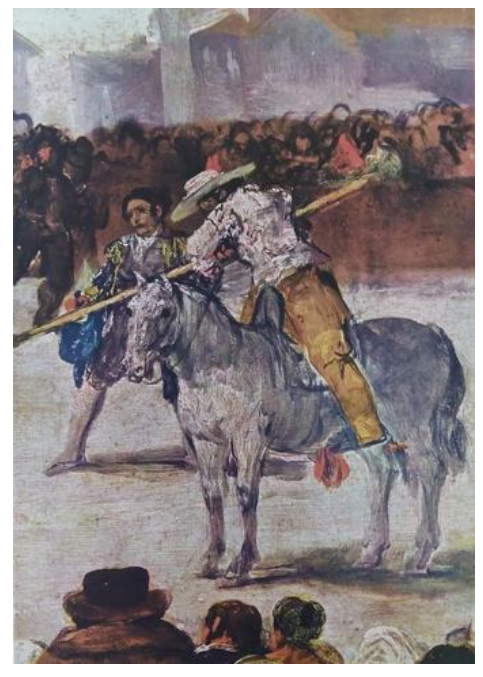

501. Corrida de toros, detalle

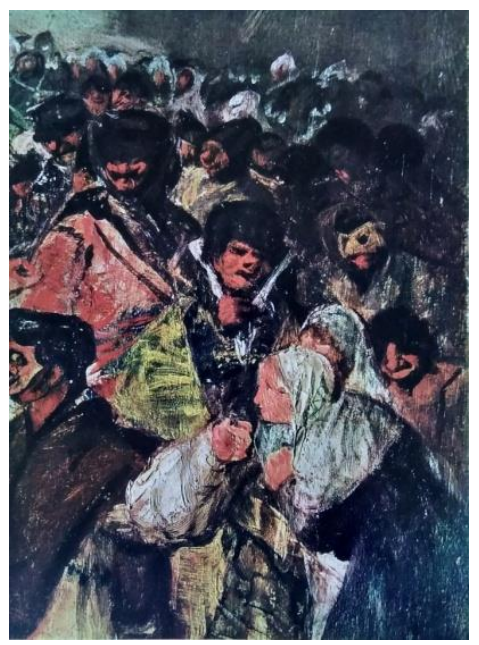

502. Entierro de la sardina, detalle

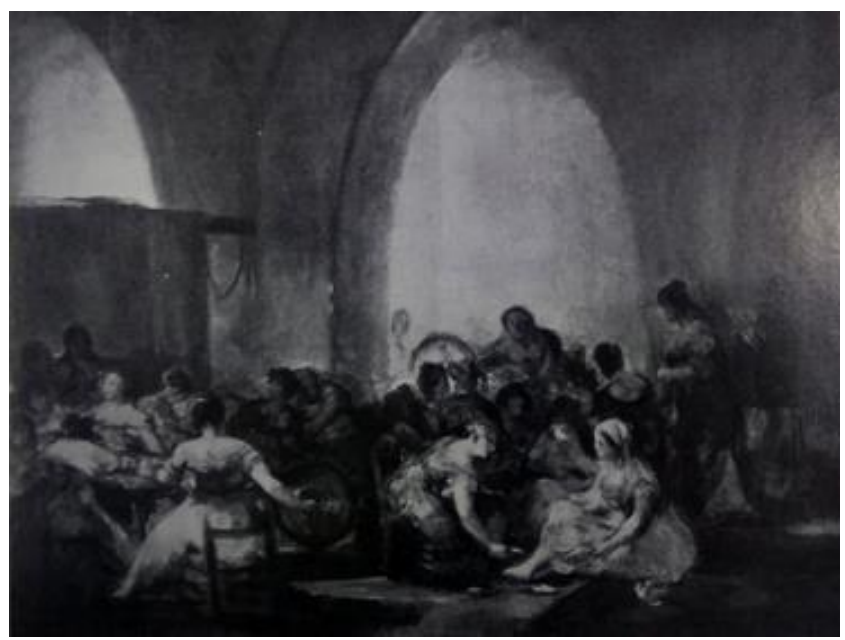

561. Las Hilanderas, óleo sobre tela, 95×107cm 


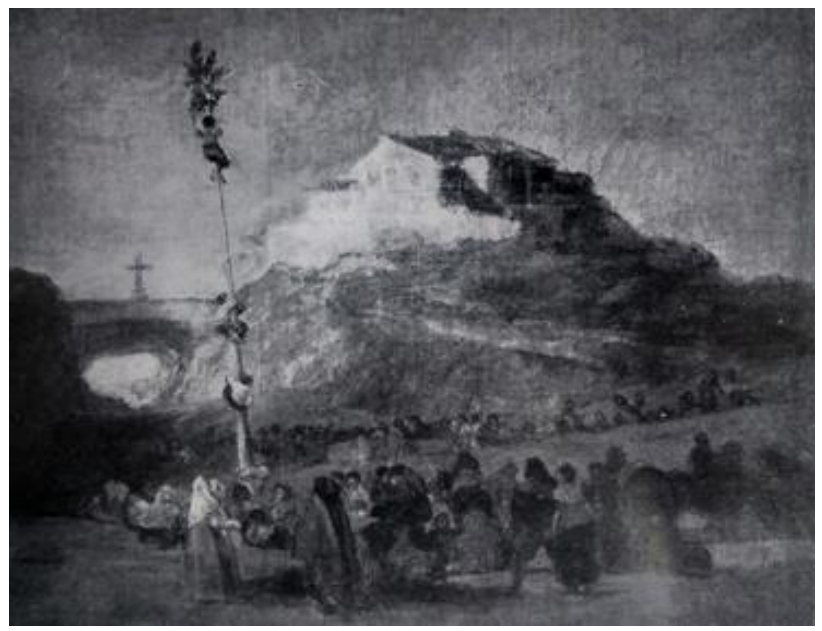

563. La cucaña, óleo sobre tela, $80 \times 103 \mathrm{~cm}$

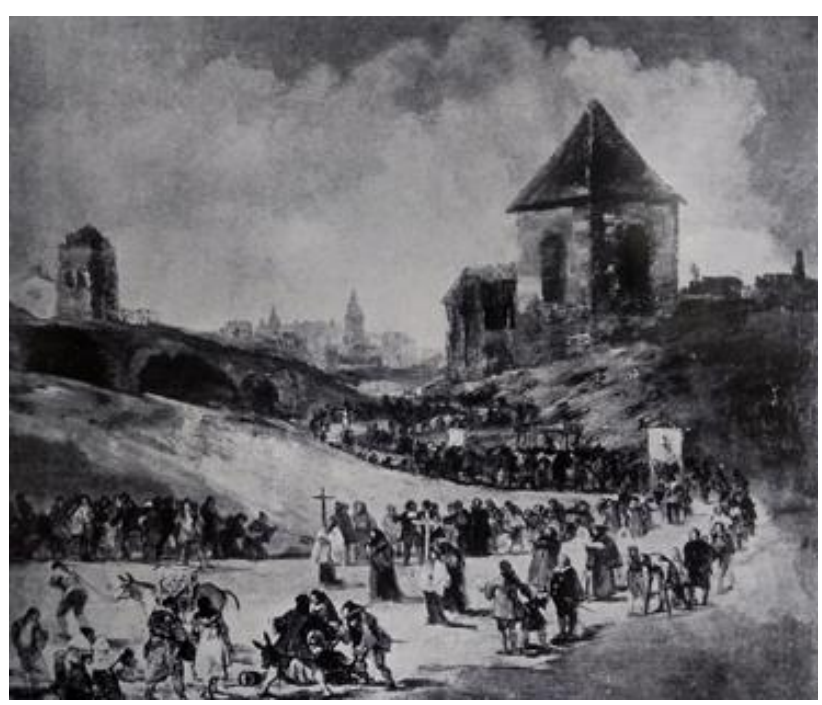

564. Procesión, óleo sobre tela, $102 \times 125 \mathrm{~cm}$

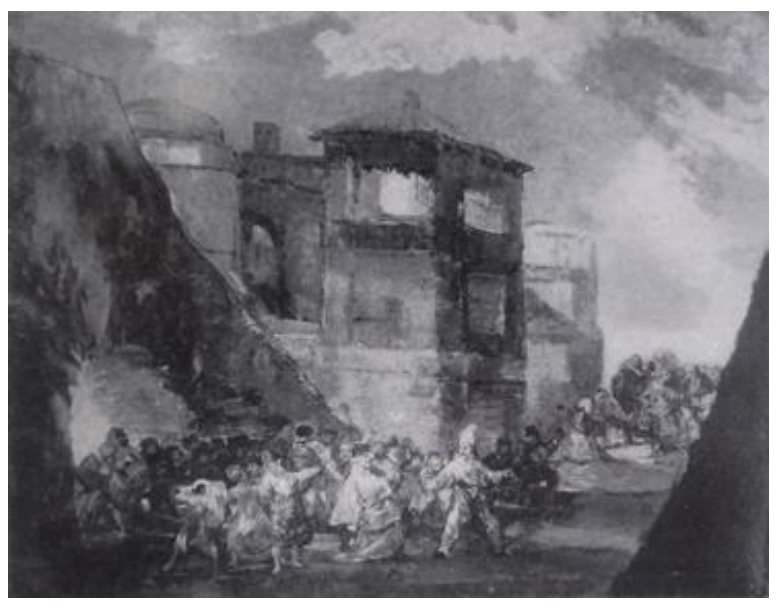

565. Carnaval, óleo sobre tela, $84 \times 104 \mathrm{~cm}$ 


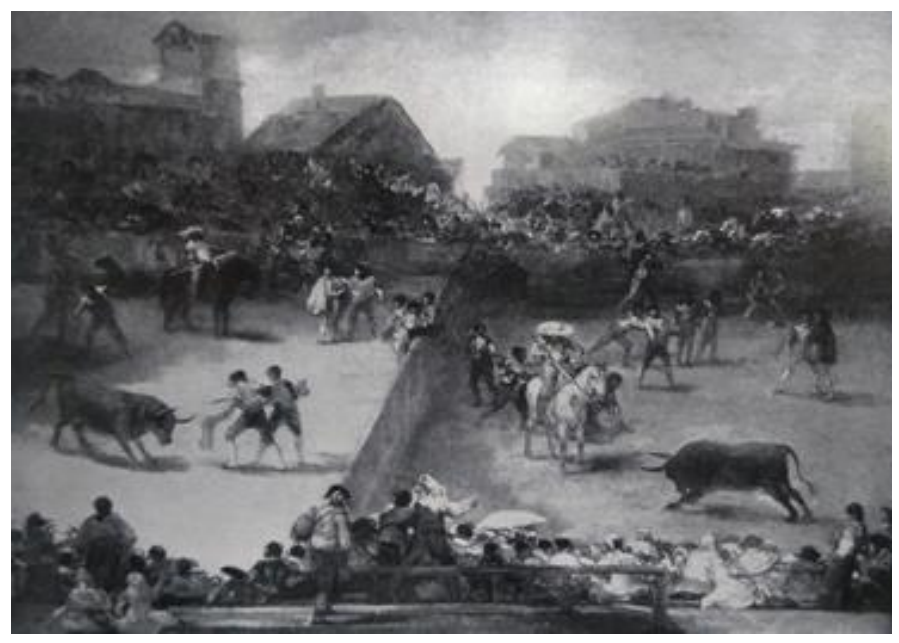

566. Corrida de toros en plaza partida, óleo sobre tela, $98 \times 126 \mathrm{~cm}$

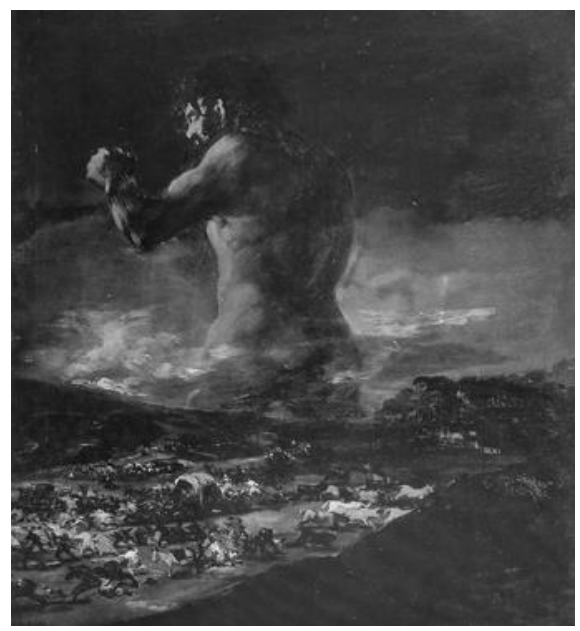

580. El coloso (Un gigante), óleo sobre tela, 116x105cm

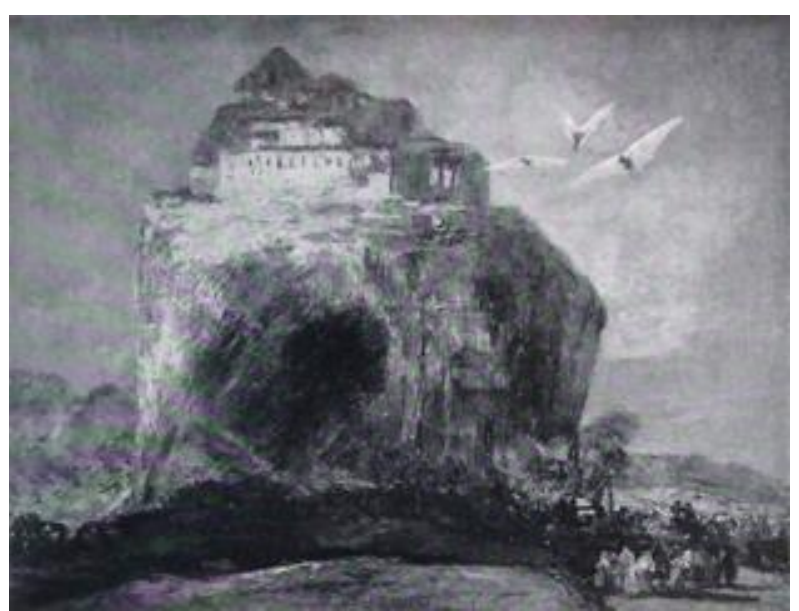

645. Ataque a una fortaleza sobre una roca, óleo sobre tela, $83 \times 104 \mathrm{~cm}$ 


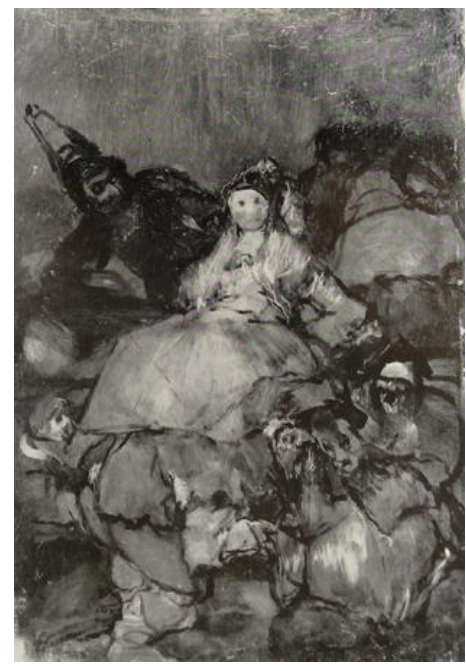

698. Escena de Carnaval, óleo sobre tabla, $31 \times 20 \mathrm{~cm}$

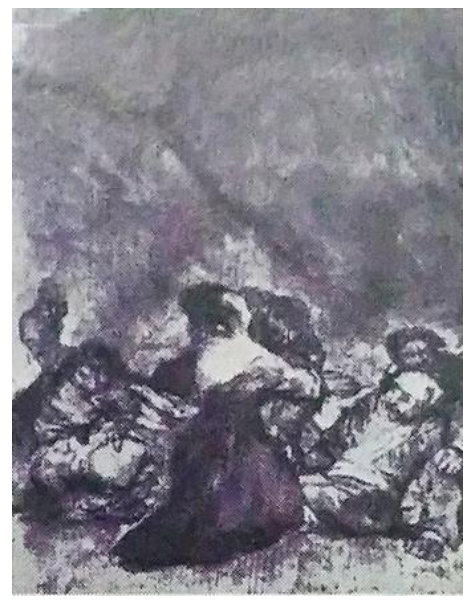

699. Escena de bandidaje, óleo sobre tabla, $31 \times 20 \mathrm{~cm}$

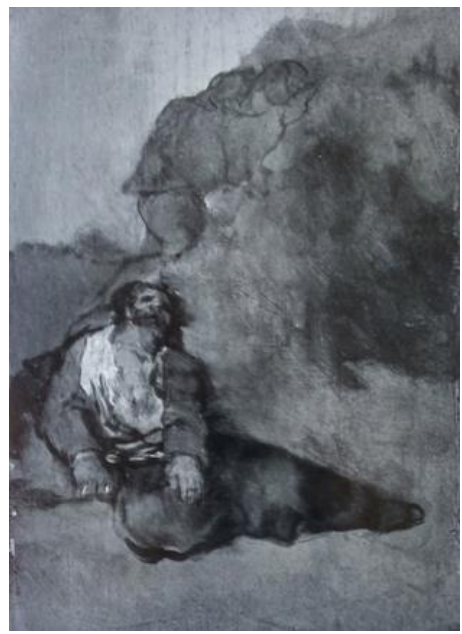

700. EI herido, óleo sobre tabla, $31 \times 20 \mathrm{~cm}$ 


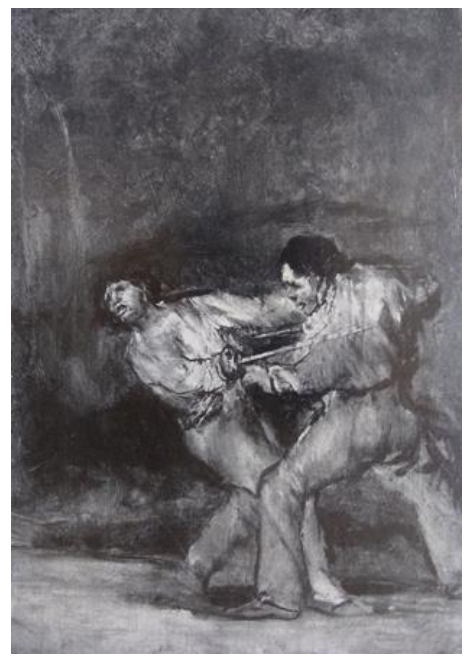

701. Un duelo, óleo sobre tabla, $31 \times 20 \mathrm{~cm}$

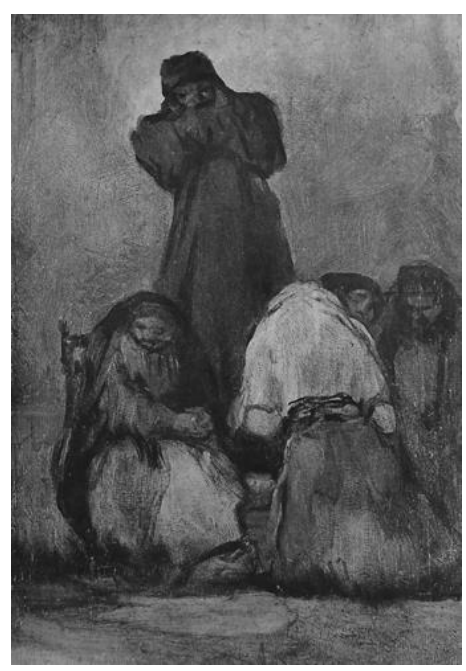

702. Grupo de ancianos, óleo sobre tabla, $31 \times 20 \mathrm{~cm}$

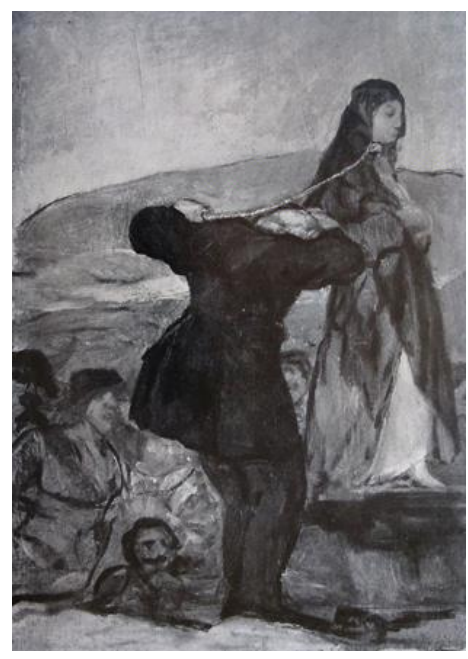

703. Mujer en el patíbulo, óleo sobre tabla, $31 \times 20 \mathrm{~cm}$ 


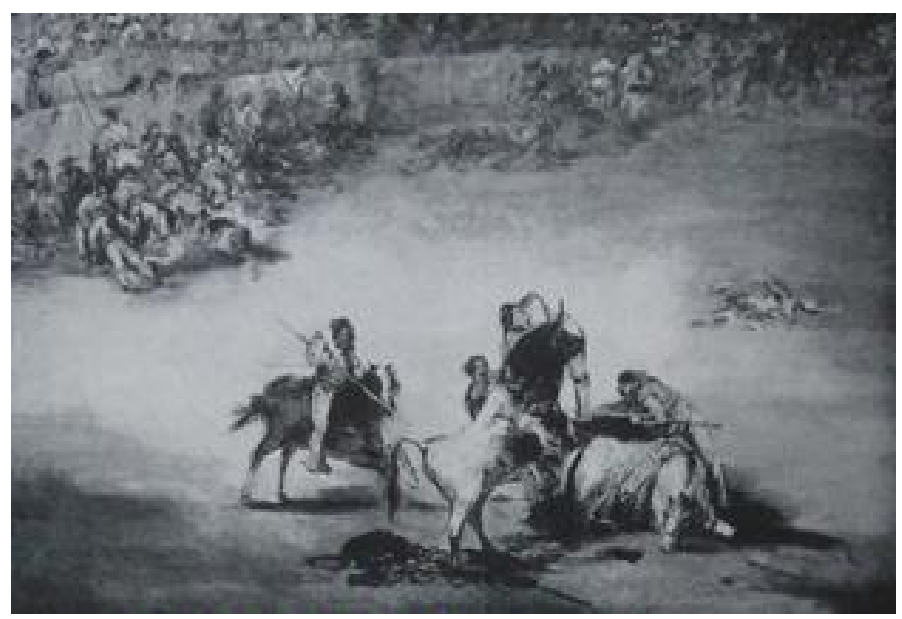

728. Cogida de un picador, óleo sobre tela, $64 \times 93 \mathrm{~cm}$

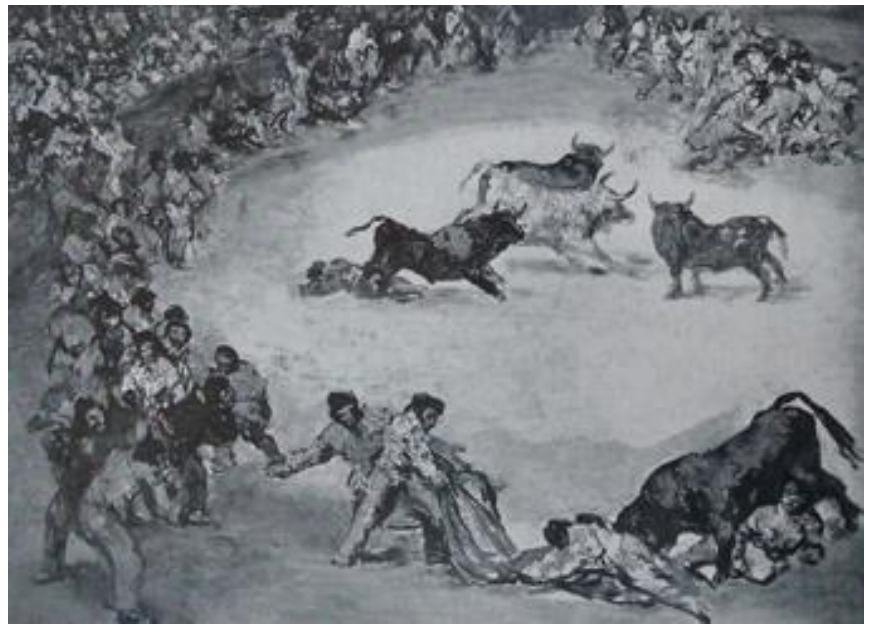

729. Diversión en España, óleo sobre tela, 46x58cm

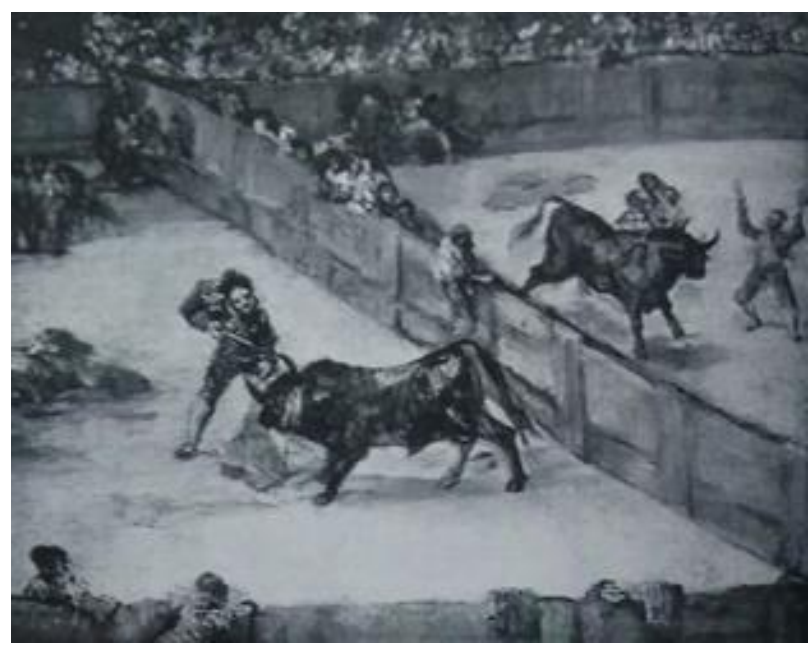

730. Plaza partida, óleo sobre tela, $45 \times 57 \mathrm{~cm}$ 


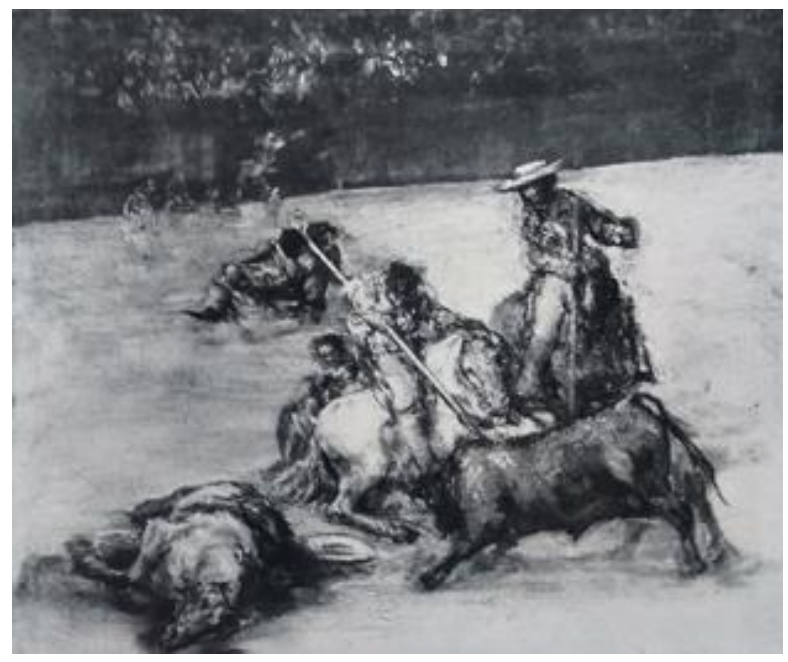

731. Corrida de toros, óleo sobre tela, $34 \mathrm{x} 44 \mathrm{~cm}$

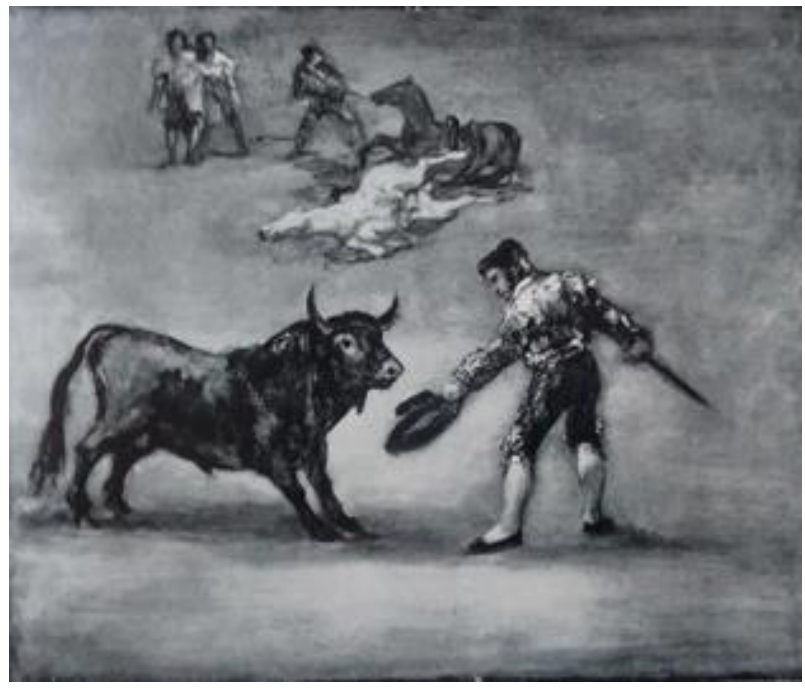

732. Pedro Romero utilizando su sombrero como muleta, óleo sobre tela, $37 \mathrm{x} 45 \mathrm{~cm}$ 


\section{Bibliografía}

ARCHIMBAUD, Michel. Francis Bacon. In conversation with Michel Archimbaud. Phaidon, New York, 1993.

BATESON, Gregory. Pasos hacia una ecología de la mente. Luhmen, Buenos Aires, 1998.

CACCIARI, Massimo. El dios que baila. Paidós, Buenos Aires, 2000.

DELEUZE, Giles. Francis Bacon. Lógica de la sensación. Editions de la defférence, 1984.

DELEUZE, Giles. Nietzsche y la filosofia, Anagrama, Barcelona, 1971.

DELEUZE, Giles. Pintura. El concepto de diagrama. Cactus, Buenos Aires, 2007.

DELEUZE, Giles y GUATARI, Félix. Mil mesetas. Pretextos, Valencia, 2004.

DELL'ACQUA, Gian Alberto y otros. La obra pictórica completa de Goya. NoguerRizzoli, Barcelona, 1976.

DORAN, Michael (compilador). Sobre Cézanne. Conversaciones y testimonios. Gustavo Gili, Barcelona, 1980.

FAURE, Elie. Historia del arte. $4^{\circ}$ volumen. Poseidón, Buenos Aires, 1994.

GLENDINNING, Nigel. Arte, ideología y originalidad en la obra de Goya. Ediciones Universidad de Salamanca, Salamanca, 2008.

GUDIOL, José. Goya 1746-1828. Polígrafa, Barcelona, 1980.

HELMAN, Edith. Trasmundo de Goya. Alianza Editorial, Madrid, 1983.

LYOTARD, Jean-Francois. Discurso, figura. Gustavo Gili, Barcelona, 1979.

MENA, Manuela. El coloso y su atribución a Goya. Artículo de investigación, página de Museo del Prado, Madrid, 2011. https://www.museodelprado.es/recurso/el-coloso-y-suatribucion-a-gova/661a409d-72c2-48dd-9247-34a241f81f43

ROSSET, Clément. El mundo y sus remedios. El cuenco de plata, Buenos Aires, 2012.

SONTAG, Susan. Contra la interpretación y otros ensayos. Seix Barral, Barcelona, 1984.

SYLVESTER, David. La brutalidad de los hechos. Entrevistas con Francis Bacon. Ediciones Polígrafa, Barcelona, 2007.

VALLENTIN, Antonina. Goya. Losada, Anaya \& Mario Muchnik, Madrid, 1994.

WAGENBACH, Klaus. La juventud de Kafka. Monte Ávila, Caracas, 1989.

WÖLFFLIN, Heinrich. Conceptos fundamentales de la historia del arte. Espasa-Calpe, Madrid, 1924. 